Article

\title{
Screening for Small Molecule Modulators of Trypanosoma brucei Hsp70 Chaperone Activity Based upon Alcyonarian Coral-Derived Natural Products
}

\author{
Sarah K. Andreassend ${ }^{1,2,+}$, Stephen J. Bentley ${ }^{3, \dagger}$, Gregory L. Blatch ${ }^{4,5}$, Aileen Boshoff ${ }^{3}$ \\ and Robert A. Keyzers $1,2, *$ (D) \\ 1 School of Chemical and Physical Sciences, Victoria University of Wellington, Wellington 6012, New Zealand; \\ sarah.andreassend@vuw.ac.nz \\ 2 Centre for Biodiscovery, Victoria University of Wellington, Wellington 6012, New Zealand \\ 3 Biotechnology Innovation Centre, Rhodes University, Grahamstown 6140, South Africa; \\ stephenjohnbentley@gmail.com (S.J.B.); aileenboshoff18@gmail.com (A.B.) \\ 4 Biomedical Biotechnology Research Unit, Department of Biochemistry and Microbiology, \\ Grahamstown 6140, South Africa; g.blatch@ru.ac.za \\ 5 Office of the PVC Research, The University of Notre Dame Australia, Fremantle, \\ Western Australia 6959, Australia \\ * Correspondence: robert.keyzers@vuw.ac.nz; Tel.: +64-4-463-5117 \\ + These authors contributed equally to this work.
}

Received: 13 December 2019; Accepted: 16 January 2020; Published: 27 January 2020 updates

\begin{abstract}
The Trypanosoma brucei Hsp70/J-protein machinery plays an essential role in survival, differentiation, and pathogenesis of the protozoan parasite, and is an emerging target against African Trypanosomiasis. This study evaluated a set of small molecules, inspired by the malonganenones and nuttingins, as modulators of the chaperone activity of the cytosolic heat inducible T. brucei Hsp70 and constitutive TbHsp70.4 proteins. The compounds were assessed for cytotoxicity on both the bloodstream form of T. $b$. brucei parasites and a mammalian cell line. The compounds were then investigated for their modulatory effect on the aggregation suppression and ATPase activities of the TbHsp70 proteins. A structure-activity relationship for the malonganenone-class of alkaloids is proposed based upon these results.
\end{abstract}

Keywords: anti-parasitic; heat shock protein; malonganenone; SAR; African Trypanosomiasis

\section{Introduction}

The etiological agent of African Trypanosomiasis, Trypanosoma brucei (T. brucei), is an extracellular blood- and tissue-borne unicellular parasitic protozoan. It gives rise to infection in both humans and animals, predominantly across sub-Saharan Africa, and is transmitted to its mammalian host during a blood meal of the infected tsetse fly vector (Glossina spp.), which ensures the cyclical transmission of the parasite between numerous hosts [1]. There is a dire need for the development of more effective and safer drugs to treat the disease, because of the toxicity and long duration for the current treatments, coupled to the increase of drug resistance in trypanosomes and the lack of a vaccine [2,3]. Molecular chaperones have been shown to play an essential role in stress-induced stage differentiation and are vital for disease progression and transmission [4,5], making this protein family an attractive anti-parasitic chemotherapeutic target.

The highly ubiquitous 70-kDa heat shock protein (Hsp70) family of molecular chaperones, known as HSPA in humans, is one of the most evolutionarily conserved protein families. It is involved in a plethora of essential cellular functions that include promoting the correct protein folding of newly 
synthesized polypeptides, mediating protein translocation, and facilitating proteolytic degradation of non-native and aggregated proteins [6,7]. The domain architecture of eukaryotic cytosolic Hsp70s is typically comprised of an N-terminal nucleotide binding domain connected via a linker region to a C-terminal domain with a substrate binding domain, and a $10-\mathrm{kDa} \alpha$-helical domain with a conserved EEVD motif [8,9]. The function and specificity of Hsp70s are regulated by the 40-kDa heat shock protein (Hsp40) family, also referred to as J-proteins, due to the presence of their signature domain, the conserved $\sim 70$ amino acid region known as the J-domain [10], which interacts with the nucleotide binding domain of Hsp70. J-proteins function as a co-chaperone of Hsp70 by delivering specific substrates and stimulating the low intrinsic ATPase activity of Hsp70 [10]. J-proteins are classified into four types, with types I and II binding protein and preventing aggregation of unfolded proteins, thereby displaying a holding-function [11].

The Trypanosoma brucei Hsp70 (TbHsp70) and J-protein families have undergone greater evolutionary expansion relative to other eukaryotic systems, and contain diverse family members [12]. RNAi-mediated knockdown of T. brucei genes conducted by Alsford and colleagues [13] demonstrated that the Hsp70/J-protein machinery plays a prominent role in trypanosome biology, as the loss of certain members of these protein families was found to be lethal at one or more stages in its life cycle. It has been proposed that TbHsp70 plays an essential role in cytoprotection during cellular stress [12], and in vivo studies on the Type I cytosolic J-protein, Tbj2, have shown that it is stress inducible and essential [14]. Furthermore, evidence from in vitro assays [15] suggested that Tbj2 has chaperone (e.g., able to suppress protein aggregation of model substrates) and co-chaperone properties (e.g., able to stimulate the ATPase activity of a trypanosomal Hsp70).

Several promising studies have been conducted on assessing the potential of naturally occurring marine- or plant-based extractables as modulators of the Hsp70 chaperone system in Plasmodium falciparum (P. falciparum) [16-20]. Cockburn and colleagues [18] investigated a set of small molecules derived from two classes of compounds, 1,4-naphthoquinones and marine prenylated alkaloids, for modulation of the activity of two biologically important plasmodial Hsp70s. One of the compounds, malonganenone A, showed desirable properties as a plasmodial Hsp70 modulator, as the compound inhibited the steady-state and J-protein stimulated ATPase activity of plasmodial Hsp70s, and not that of human Hsp70 [18]. It was also shown to disrupt the interaction between the exported PfHsp70-x and J-protein, marking malonganenone A for further study particularly with the synthesis of analogues that have more potent antimalarial activities and higher selectivity as PfHsp70 inhibitors [18].

The malonganenones are a family of tetraprenylated alkaloid marine natural products isolated from gorgonian sea fans, collected in Africa and China [21-24]. To date, a total of 17 malonganenones (A-Q) have been isolated, as well as six closely related nuttingins (A-F) (Figure 1). The malonganenones and nuttingins are cytotoxic against several cancer cell lines $\left(\mathrm{IC}_{50} 0.35-84.9 \mu \mathrm{M}\right)$ [21,23] while malonganenones $\mathrm{D}-\mathrm{H}$ and nuttingins $\mathrm{A}-\mathrm{F}$ cause apoptosis of transformed mammalian cells $(1.25 \mu \mathrm{g} / \mathrm{mL})$ [22]. Additionally, malonganenones $\mathrm{L}$ and $\mathrm{Q}$ are inhibitory against phosphodiesterase-4D (IC 50.5 and $20.3 \mu \mathrm{M})$ [24] and malonganenone D reduces c-Met kinase activity 2-fold $(10 \mu \mathrm{M})$ [23]. Importantly, malonganenones $\mathrm{A}$ and $\mathrm{C}$ are anti-plasmodial against $P$. falciparum ( $\mathrm{IC}_{50} 0.81$ and $5.20 \mu \mathrm{M})[17]$.

The malonganenones vary mainly in the composition of the nitrogenous head group, with small changes at the end of the prenyl side chain. Bioactivity mainly varies relative to the identity of the head group, suggesting that they play the primary role of pharmacophore. Therefore, a simpler prenyl chain, as in malonganenone J, could be substituted for the other natural product side chains, and still be expected to present useful bioactivity. Although the side chain may be less important for bioactivity, it still plays a significant role. A simplified analogue of malonganenone B, which substituted the side chain with a methyl group, was completely inactive in the same assay against PfHsp70-1, whereas the original compound's activity was dose-dependent [17]. This result suggests that an extended side chain could be important for adding lipophilicity. Therefore, in this study, a structure-activity relationship (SAR) of the side chain length was probed by varying the length 
from one to three prenyl units. Analogues of the malonganenone and nuttingins were synthesized by alkylation of $N$-heterocyclic compounds, while analogues of malonganenone $C$ were synthesized by simple derivatization of terpenoid amines. It should be noted that malonganenone $\mathrm{J}$ is the only member of the family to have succumbed to total synthesis to date [25].<smiles>[R]n1cnc2c1c(=O)ncn2C</smiles><smiles>[R]n1cnc(N(C)C(=O)NC)c1C(=O)NC</smiles><smiles>[R]NC=O</smiles><smiles>[R]n1cnc2c1c(=O)n(C)c(=O)n2C</smiles><smiles>[R]n1cnc2c1C(=O)N(C)CN2C</smiles><smiles></smiles>

\footnotetext{
Malonganenone $A R=a$ Malonganenone $B R=a$ Malonganenone $C R=a$ Nuttingin $A R=b \quad$ Nuttingin $C R=b \quad$ Nuttingin $F \quad R=c$ Malonganenone $D \quad R=b$ Malonganenone $F \quad R=b \quad$ Malonganenone $H \quad R=c \quad$ Nuttingin $B \quad R=a \quad$ Nuttingin $D \quad R=c$ Malonganenone $E R=c \quad$ Malonganenone $G R=c \quad$ Malonganenone $K R=b \quad$ Nuttingin $E R=a$ Malonganenone I $R=d$ Malonganenone $O R=f$

Malonganenone $J$ R $=e$ Malonganenone $P R=g$

Malonganenone $L R=f \quad$ Malonganenone $Q R=i$

Malonganenone $M \quad R=g$

Malonganenone N R $=f$
}
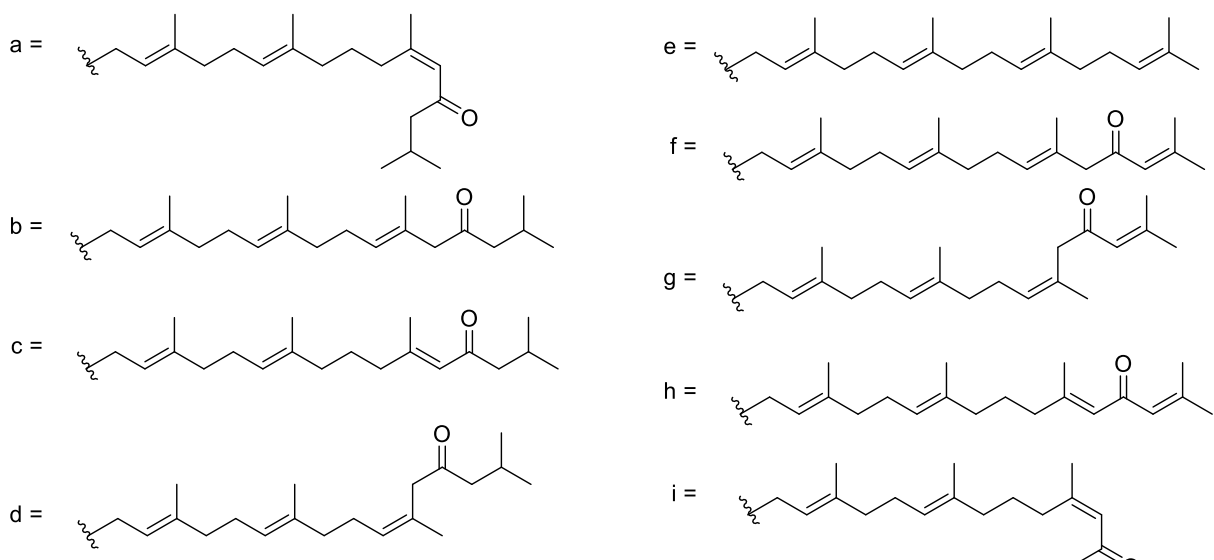<smiles>CC(C)=CC(=O)C/C(C)=C/CC/C(C)=C/CC/C(C)=C/CC[18F]</smiles><smiles>[CH]CC/C=C(\C)CC/C=C(\C)CC/C=C(/C)CC(=O)C=C(C)C</smiles>

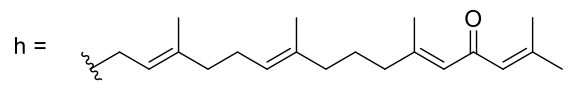

$i=$

Figure 1. Structures of all currently known malonganenones (A-Q) and nuttingins (A-F).

Overall, this study aimed to evaluate potential inhibitors, inspired by the malonganenones and nuttingins, of the chaperone activity of T. brucei Hsp70 proteins. The compounds were assessed for cytotoxicity on both the bloodstream form of T. $b$. brucei parasites and a mammalian cell line. The compounds were then investigated for their modulatory effect on the aggregation suppression and ATPase activities of cytosolic TbHsp70 (homologue of the cytosolic inducible human Hsp70, HSPA1A) and TbHsp70.4 (homologue of the constitutive human Hsp70, HSPA8). The human chaperone HSPA8 and its co-chaperone DNAJB2 (Hsj1a), a Type II J-protein, were chosen as model representatives for investigation of the modulatory effect of the small molecules on a human Hsp70/J-protein partnership. HSPA8 has been shown to be involved in essential housekeeping functions [26,27], as knockout of the gene in mice was shown to be lethal [28], and RNAi-mediated knockdown resulted in massive cell death in various cell types [29]. DNAJB2 has been shown to be preferentially expressed in neuronal cells [30], where it plays a prominent role in protein degradation [31], and it has been shown to stimulate the in vitro basal ATPase activity of HSPA8 [32], HSPA1A [16,18,33], PfHsp70-1 [16,18], and PfHsp70-x [18]. The intention was to identify inhibitors that were specific to modulating the activities of the trypanosomal Hsp70s, TbHsp70 and/or TbHsp70.4. Overall, this study aimed to identify a potential new avenue to African trypanosomiasis chemotherapy. 


\section{Results and Discussion}

\subsection{Synthesis of Malonganenone and Nuttingin Analogues}

Coverage of chemical space was maximized for the first generation of malonganenone and nuttingin analogues by using non-selective alkylation conditions and terpenoid bromides, with geometric mixtures at the $\mathrm{C}-2$ alkene, to give maximal compound diversity. These conditions tended to efficiently yield multiple regio- and geometric isomers per reaction. The regioisomers were easily separated by chromatography, but the geometric isomers proved to be more difficult. The (2E)and (2Z)-isomers of the farnesyl derivatives were often isolated as mixtures and were tested as such. The geometric isomers of the geranylgeranyl derivatives were markedly easier to separate by chromatography.

The purines, adenine (1), 6-(dimethylamino) purine (2), and 6-chloropurine (3) were alkylated with prenyl bromides (Scheme 1). Alkylation of $\mathbf{1}$ yielded $N-3-(\mathbf{4}, \mathbf{6})$ and $N-9(7,8)$ monoalkylated products. Alkylation with geranyl bromide produced a minor amount of a dialkylated species (5), which was not isolated from the other reactions. Alkylation of 2 also yielded $N-3-(\mathbf{1 0}, \mathbf{1 2})$ and $N-9(\mathbf{9}, \mathbf{1 1}$, 13, 14) monoalkylated regioisomers. The ${ }^{1} \mathrm{H}$ NMR spectra of $\mathbf{9 - 1 4}$ had broad $\mathrm{N}$-methyl resonances, which were only equivalent for the $N-9$ isomers. This was rationalized by the formation of a stable imine resonance form for the $N-3$ regioisomer, which has also been observed previously for a similar N-3 alkylated 6-(dimethylamino)purine [34]. Alkylation of 3 yielded N-9- $(\mathbf{1 5}, \mathbf{1 7}, \mathbf{1 9})$, and N-7 (16, 18, 20, 21) monoalkylated regioisomers.

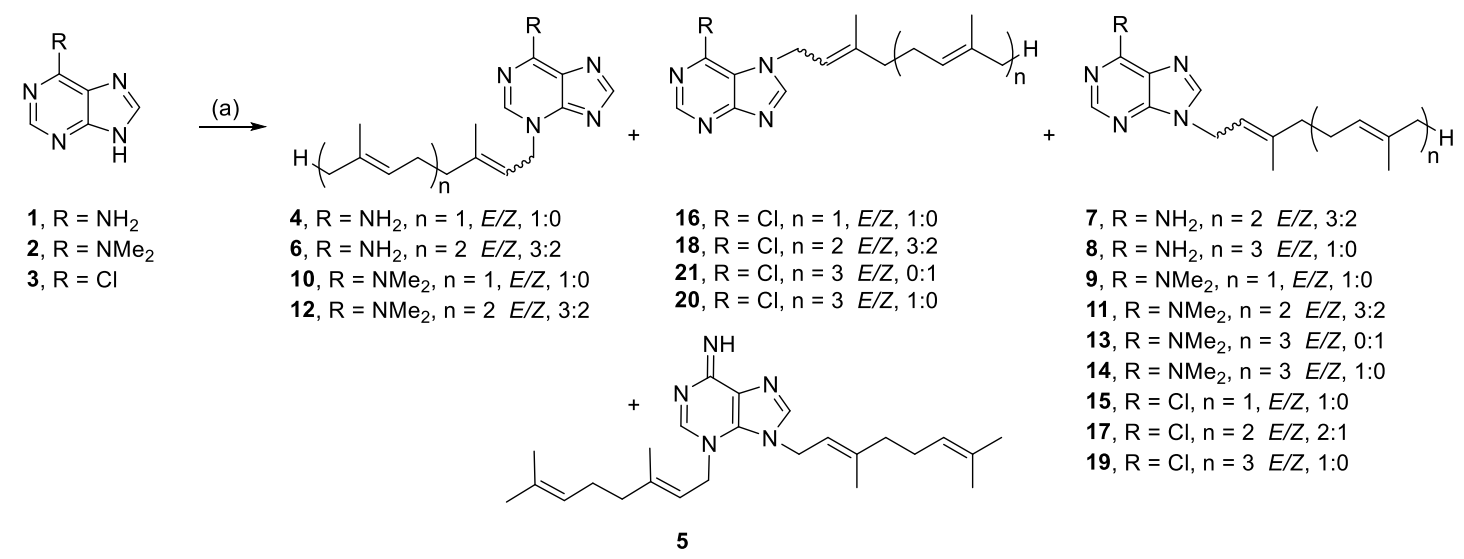

Scheme 1. Alkylation of purines. Reagents and conditions: (a) Geranyl-, farnesyl-, or geranylgeranyl bromide, $\mathrm{K}_{2} \mathrm{CO}_{3}$, $\mathrm{RT}$ or $50^{\circ} \mathrm{C}, \mathrm{DMF}, 21-44 \mathrm{~h}$.

Head groups based on purinones were also alkylated since the head group of nine malonganenones comprise a hypoxanthine core, with a carbonyl at C-6. Xanthine (22), 3-methylxanthine (23), and theophylline (24) are related by increasing methylation; theophylline is the head group of nuttingin A and B. The other two purinones selected were 2-mercapto-3-methylhypoxanthine (25) and 1,3-dimethyluric acid (26). Alkylation of the methyl series of purinones, and 25, all yielded $\mathrm{N}-7$ monoalkylated regioisomers (29-41), except for 22, which only yielded N-3,N-7 dialkylated species (27, 28) (Scheme 2). 
<smiles></smiles>

(a)

22, $\mathrm{X}=\mathrm{O}, \mathrm{R}=\mathrm{R}^{\prime}=\mathrm{H}$

23, $X=O, R=H, R^{\prime}=M e$

24, $X=O, R=R^{\prime}=M e$

25, $X=S, R=H, R^{\prime}=M e$<smiles></smiles>

27, $\mathrm{X}=\mathrm{O}, \mathrm{R}=\mathrm{H}, \mathrm{R}^{\prime}=$ geranyl, $\mathrm{n}=1, E / Z 1: 0$

28, $X=O, R=H, R^{\prime}=$ farnesyl, $n=2, E / Z 3: 2$

29, $X=O, R=H, R^{\prime}=M e, n=1, E / Z 1: 0$

30, $\mathrm{X}=\mathrm{O}, \mathrm{R}=\mathrm{H}, \mathrm{R}^{\prime}=\mathrm{Me}, \mathrm{n}=2, E / Z \mathrm{Z} 0: 1$

31, $\mathrm{X}=\mathrm{O}, \mathrm{R}=\mathrm{H}, \mathrm{R}^{\prime}=\mathrm{Me}, \mathrm{n}=2, E / Z 2: 1$

32, $X=O, R=H, R^{\prime}=M e, n=3, E / Z 0: 1$

33, $\mathrm{X}=\mathrm{O}, \mathrm{R}=\mathrm{H}, \mathrm{R}^{\prime}=\mathrm{Me}, \mathrm{n}=3, E / Z$ 1:0

34, $\mathrm{X}=\mathrm{O}, \mathrm{R}=\mathrm{R}^{\prime}=\mathrm{Me}, \mathrm{n}=1, E / Z 1: 0$

35, $X=O, R=R^{\prime}=M e, n=2, E / Z 1: 0$

36, $X=O, R=R^{\prime}=M e, n=3, E / Z 0: 1$

37, $X=O, R=R^{\prime}=M e, n=3, E / Z 1: 0$

38, $X=S, R=H, R^{\prime}=M e, n=1, E / Z 1: 0$

39, $\mathrm{X}=\mathrm{S}, \mathrm{R}=\mathrm{H}, \mathrm{R}^{\prime}=\mathrm{Me}, \mathrm{n}=2, E / Z 2: 1$

40, $\mathrm{X}=\mathrm{S}, \mathrm{R}=\mathrm{H}, \mathrm{R}^{\prime}=\mathrm{Me}, \mathrm{n}=3, E / Z$ 0:1

41, $X=S, R=H, R^{\prime}=M e, n=3, E / Z 1: 0$

Scheme 2. Alkylation of purinones. Reagents and conditions: (a) Geranyl-, farnesyl-, or geranylgeranyl bromide, $\mathrm{K}_{2} \mathrm{CO}_{3}$, RT or $50-80{ }^{\circ} \mathrm{C}, \mathrm{DMF}, 3-48 \mathrm{~h}$.

Alkylation of 26 yielded C-5 monoalkylated regioisomers $(42,43)$ and only a minor amount of $N-9$ monoalkylated regioisomer (44) from the farnesyl bromide reaction (Scheme 3). We suggest that these species result from enolate reactivity, providing a simple method for forming quaternary carbon-carbon bonds (Scheme 4).<smiles>Cn1c(=O)c2[nH]c(=O)[nH]c2n(C)c1=O</smiles>

(a)

26<smiles>C/C(=C\CC12NC(=O)N=C1N(C)C(=O)N(C)C2=O)CC/C=C(\C)Cc1ccccc1</smiles>

42, $\mathrm{n}=1, E / Z 1: 0$

$43, \mathrm{n}=2, E / Z 2: 1$

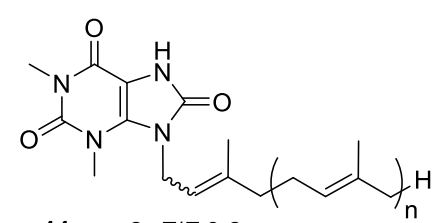

44, $\mathrm{n}=2, E / Z 3: 2$

Scheme 3. Alkylation of 1,3-dimethyluric acid. Reagents and conditions: (a) Geranyl-, farnesyl-, or geranylgeranyl bromide, $\mathrm{K}_{2} \mathrm{CO}_{3}, \mathrm{RT}$, DMF, 19-24 h.

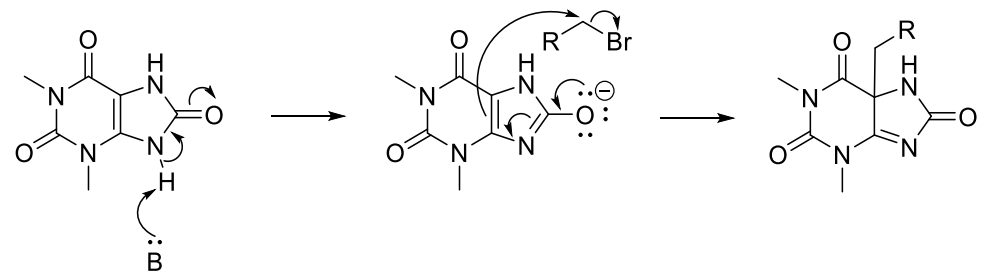

Scheme 4. Mechanism for the C-5 alkylation of 1,3-dimethyluric acid (26).

Alkylation of 45 yielded $N-5$ monoalkylated analogues $(46,49)$, as well as $N-1, N-5-(47,50)$ and $N-2, N-7$ (48) dialkylated analogues, presumably from enhanced nucleophilicity of the pyrimidine ring (Scheme 5). 
<smiles>Oc1ncnc2[nH]ncc12</smiles>

45<smiles>CCC(C)=CCCCCC(C)=CCn1cnc2nncc-2c1O</smiles>

46, $\mathrm{n}=1, E / Z 1: 0$ $49, \mathrm{n}=2, E / Z 3: 2$

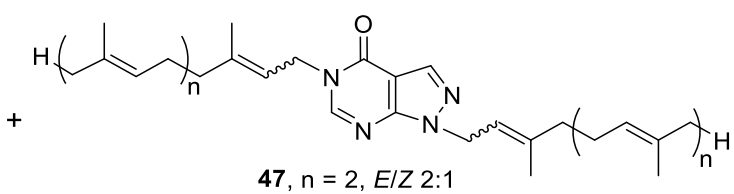

$\mathbf{5 0}, \mathrm{n}=3, E / Z 1: 0$

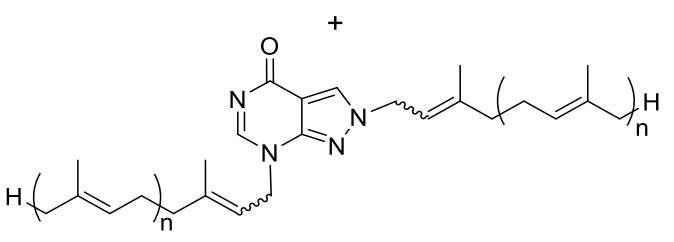

48, $n=2, E / Z 3: 2$

Scheme 5. Alkylation of allopurinol. Reagents and conditions: (a) Geranyl-, farnesyl-, or geranylgeranyl bromide, $\mathrm{K}_{2} \mathrm{CO}_{3}$, $\mathrm{RT}$ or $70^{\circ} \mathrm{C}, \mathrm{DMF}, 24-27 \mathrm{~h}$.

Other readily available $N$-heterocyclic compounds were also alkylated, including the pyrimidines, uracil (51), thymine (52), and cytosine (53). Alkylation of 51, and 52 yielded only $N-1$ monoalkylated derivatives (54-59) whereas 53 only produced $N-1, N-3$ dialkylated products $(61,63)$ (Scheme 6). In addition to the dialkylated cytosines, formylated imine derivatives $(\mathbf{6 0}, \mathbf{6 2}, 64)$ were also isolated, likely formed via the reaction solvent, DMF. Although formylation with DMF usually requires pre-activation, such as in the Vilsmeier-Haack reaction [35], milder conditions have also been successful at yielding formylated derivatives. For example, moderate heating of DMF and imidazole formylated a variety of amino acids and primary amines [36]. The proposed mechanism suggests that imidazole acts as an intermediate acyl transfer reagent (Scheme 7), therefore it is feasible that cytosine could also fulfil this role. The formyl imidazole produced is itself further reactive when other amine nucleophiles are present. The absence of stronger nucleophiles in these alkylation reactions resulted in the isolation of formyl cytosine.<smiles></smiles>

$51, X=O, R=R^{\prime}=H$ 52, $X=O, R=H, R^{\prime}=M e$ 53, $X=N H, R=R^{\prime}=H$<smiles></smiles>

54, $\mathrm{X}=\mathrm{O}, \mathrm{R}=\mathrm{R}^{\prime}=\mathrm{H}, \mathrm{n}=1, E / Z 1: 0$

55, $X=O, R=R^{\prime}=H, n=2, E / Z 2: 1$

56, $X=O, R=R^{\prime}=H, n=3, E / Z 0: 1$

57, $\mathrm{X}=\mathrm{O}, \mathrm{R}=\mathrm{H}, \mathrm{R}^{\prime}=\mathrm{Me}, \mathrm{n}=1, E / Z 1: 0$

58, $X=O, R=H, R^{\prime}=M e, n=2, E / Z 3: 2$

59, $X=O, R=H, R^{\prime}=M e, n=3, E / Z 1: 0$

60, $X=\mathrm{NCHO}, \mathrm{R}=$ geranyl, $\mathrm{R}^{\prime}=\mathrm{H}, \mathrm{n}=1, E / Z$ 1:0

61, $X=N H, R=$ geranyl, $R^{\prime}=H, n=1, E / Z 1: 0$

62, $X=$ NCHO, $R=$ farnesyl, $R^{\prime}=H, n=2, E / Z 3: 2$

63, $X=N H, R=$ farnesyl, $R^{\prime}=H, n=2, E / Z 3: 2$

64, $X=N C H O, R=$ geranylgeranyl, $R^{\prime}=H, n=3, E / Z 1: 0$

Scheme 6. Alkylation of pyrimidines. Reagents and conditions: (a) Geranyl-, farnesyl-, or geranylgeranyl bromide, $\mathrm{K}_{2} \mathrm{CO}_{3}$, $\mathrm{RT}$ or $50-70{ }^{\circ} \mathrm{C}$, DMF, $21-27 \mathrm{~h}$. 


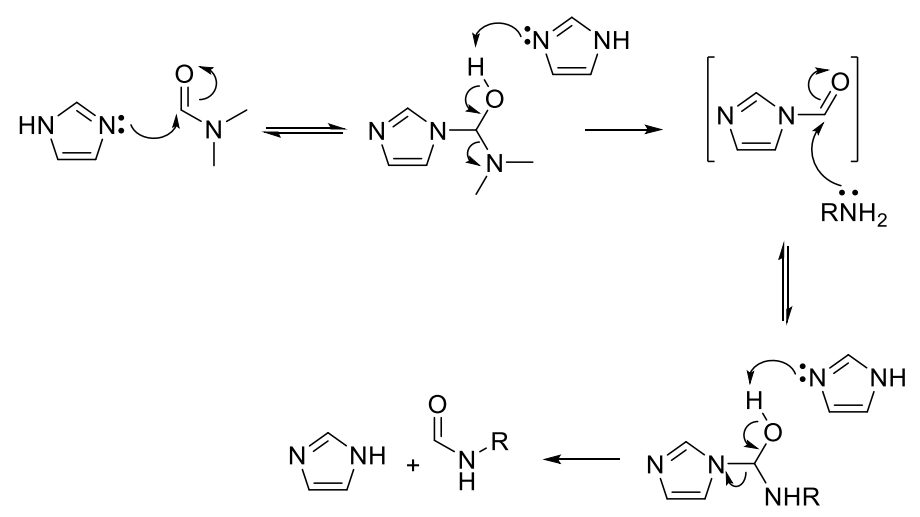

Scheme 7. Mechanism of formylation by DMF mediated by imidazole [36].

Alkylation of potassium phthalimide (65) (Scheme 8) and imidazole (66) (Scheme 9) furnished the last of the $N$-heterocyclic analogues. Both reactions proceeded straightforwardly to yield $\mathrm{N}-1$ monoalkylated analogues (67-72).<smiles>CN1C(=O)c2ccccc2C1=O</smiles>

65<smiles>[131I-]</smiles><smiles>CC(C)=CCCC(C)=CCN1C(=O)c2ccccc2C1=O</smiles>

67, $\mathrm{n}=1, E / Z 1: 0$

68, $\mathrm{n}=2, E / Z 5: 4$

$69, \mathrm{n}=3, E / Z$ 1:0

Scheme 8. Alkylation of potassium phthalimide. Reagents and conditions: (a) Geranyl-, farnesyl-, or geranylgeranyl bromide, $\mathrm{K}_{2} \mathrm{CO}_{3}$, RT, DMF, 19-24 h.

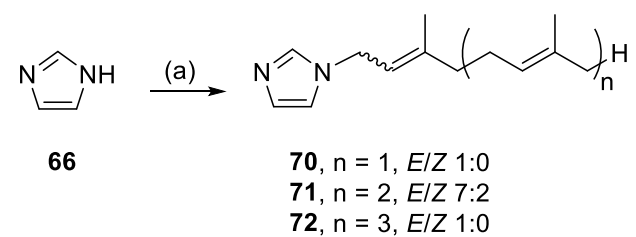

Scheme 9. Alkylation of imidazole. Reagents and conditions: (a) Geranyl-, farnesyl-, or geranylgeranyl bromide, $\mathrm{K}_{2} \mathrm{CO}_{3}$, $\mathrm{RT}$, DMF, $46-48 \mathrm{~h}$.

Malonganenones $\mathrm{C}, \mathrm{H}$, and $\mathrm{K}$, have a simple formamide head group and analogues were synthesized by formylation [37,38] or acetylation [39,40] of prenyl amines [41], followed by methylation [42] (Scheme 10). The ${ }^{1} \mathrm{H}$ NMR spectra of the formamide- (73-77) and N-methyl formamide (78-80) series suggested a mixture of two rotamers, with doubling of most resonances near the head group. These observations are consistent with previous data reported for geranyl formamide [43] and of more relevance, malonganenone B [37]. Conversely, the acetamide analogues (81-85) were not rotameric but became so upon $N$-methylation (86-88), analogous to DMF. 


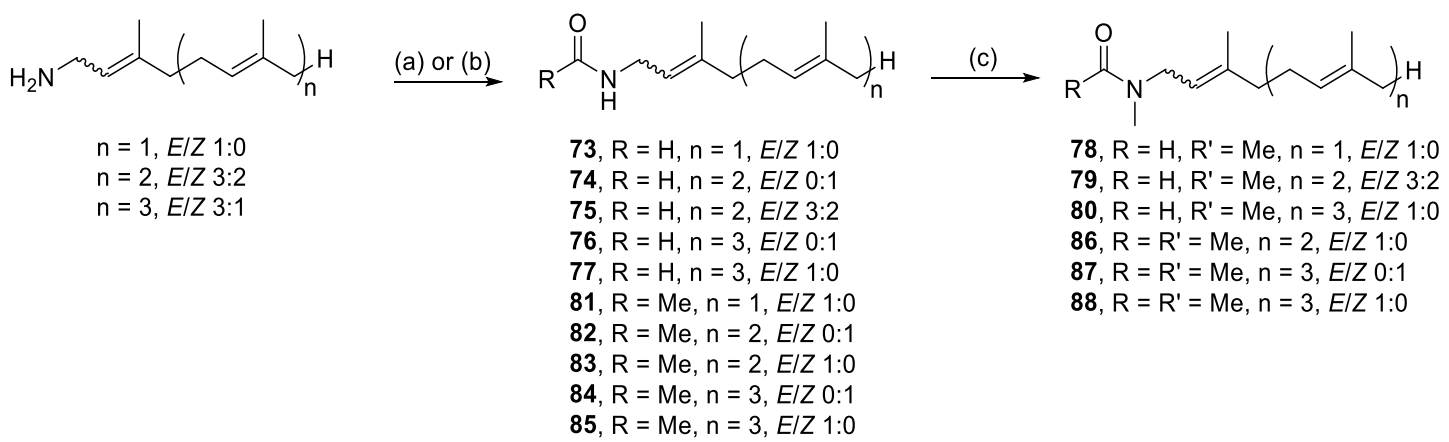

Scheme 10. Synthesis of malonganenone $C, H$, and $K$ analogues. Reagents and conditions: (a) Formic acid, acetic anhydride mixture, RT, 3-5 h; (b) Acetyl chloride, triethylamine, $0{ }^{\circ} \mathrm{C}$ to $\mathrm{RT}, 5 \mathrm{~h}$; (c) $\mathrm{KOH}$, MeI, RT, DMSO, 2.5 h.

\subsection{Evaluation of the Potential Small Molecule Inhibitors for Cytotoxicity on Mammalian Cells and Parasites}

A resazurin-based cytotoxicity assay was conducted to assess the potential anti-trypanosomal activity of the 74 compounds (Figure S1). Seven were identified to be non-toxic as the parasite survival was $\geq 100 \%$ (Figure S1).

The compounds were further assessed for toxicity using HeLa (human cervix adenocarcinoma) cells. Emetine is a natural alkaloid that has been shown to induce apoptosis in mammalian cell lines [44] and was incorporated into the study as a positive control, displaying high toxicity at $10 \mu \mathrm{M}$ towards HeLa cells (6.03\% cell viability). Compounds 5, 61, and 62 were toxic to HeLa cells at $20 \mu \mathrm{M}$ (Figure S2). Comparison of the toxicity of the compounds at $20 \mu \mathrm{M}$ toward both trypanosomes and HeLa cells indicates that the toxicity of most compounds is selective towards the parasite (Figure S2).

Most of the synthetic compounds were shown to display high anti-trypanosomal activity; 48 compounds were selected for further assessment as they reduced parasite growth $\geq 80 \%$ at $20 \mu \mathrm{M}$ (Figure S1). Dose-response curves of the 48 selected compounds were generated, and the $\mathrm{IC}_{50}$ (50\% inhibitory concentration) values for each compound was determined (Table 1, Table S1). For comparative purposes, pentamidine, an existing drug used to treat the early stages of Human African trypanosomiasis caused by T. b. gambiense $[45,46]$ was used as the positive control.

Table 1. $\mathrm{IC}_{50}$ values of selected compounds toward T. $b$. brucei parasites cultured in vitro. Drug standard pentamidine $\mathrm{IC}_{50} 5.3 \mathrm{nM}$.

\begin{tabular}{cccccc}
\hline Compound & IC $_{\mathbf{5 0}} / \boldsymbol{\mu M}$ & Compound & $\mathrm{IC}_{\mathbf{5 0}} / \boldsymbol{\mu M}$ & Compound & IC $_{\mathbf{5 0}} / \boldsymbol{\mu M}$ \\
\hline $\mathbf{6}$ & 12.7 & $\mathbf{2 8}$ & 1.2 & $\mathbf{5 9}$ & 15.8 \\
$\mathbf{7}$ & 47.7 & $\mathbf{2 9}$ & 18.9 & $\mathbf{6 0}$ & 4.9 \\
$\mathbf{8}$ & 13.4 & $\mathbf{3 0}$ & 4.6 & $\mathbf{6 3}$ & 2.1 \\
$\mathbf{9}$ & 28.4 & $\mathbf{3 1}$ & 1.9 & $\mathbf{6 8}$ & 32.2 \\
$\mathbf{1 1}$ & 9.5 & $\mathbf{3 2}$ & 5.9 & $\mathbf{6 9}$ & 9.2 \\
$\mathbf{1 2}$ & 14.0 & $\mathbf{3 3}$ & 10.2 & $\mathbf{7 1}$ & 26.8 \\
$\mathbf{1 3}$ & 8.7 & $\mathbf{3 6}$ & 5.2 & $\mathbf{7 2}$ & 3.4 \\
$\mathbf{1 4}$ & 9.2 & $\mathbf{3 7}$ & 21.6 & $\mathbf{7 4}$ & 27.3 \\
$\mathbf{1 5}$ & 12.2 & $\mathbf{4 2}$ & 10.9 & $\mathbf{7 6}$ & 11.0 \\
$\mathbf{1 6}$ & 11.0 & $\mathbf{4 4}$ & 16.6 & $\mathbf{7 7}$ & 41.8 \\
$\mathbf{1 7}$ & 12.9 & $\mathbf{4 7}$ & 1.2 & $\mathbf{8 0}$ & 41.2 \\
$\mathbf{1 0}$ & 9.3 & $\mathbf{4 8}$ & 5.5 & $\mathbf{8 2}$ & 4.5 \\
$\mathbf{1 9}$ & 6.8 & $\mathbf{4 9}$ & 16.7 & $\mathbf{8 3}$ & 21.5 \\
$\mathbf{2 0}$ & 11.0 & $\mathbf{5 0}$ & 2.1 & $\mathbf{8 4}$ & 2.2 \\
$\mathbf{2 1}$ & 19.1 & $\mathbf{5 5}$ & 16.5 & $\mathbf{8 5}$ & 3.1 \\
$\mathbf{2 7}$ & 2.0 & $\mathbf{5 6}$ & 6.2 & $\mathbf{8 8}$ & 38.4 \\
\hline
\end{tabular}


Although none of the tested compounds are comparable to the drug standard pentamidine in potency, tentative SAR can be proposed from the results to aid in designing a second generation of analogues. SAR analysis of the side chain suggests that length correlates positively with activity as most of the shortest side chain derivatives are inactive and activity increases upon lengthening the side chain from farnesyl to geranylgeranyl (i.e., 7 vs. 8,55 vs. 56,68 vs. 69,71 vs. 72 ). The activity is further influenced by the head group. Activating head groups have shorter optimal chain lengths and further lengthening has minimal effect (i.e., 11 vs. 14, 18 vs. 20, 21) whereas the deactivating head group series are completely inactive (i.e., 38-41), or activity is only rescued at the longest side chain length (i.e., 59, 37). No general trends can be derived from the identity of the head group, but small changes such as methylation seem to have a large effect on activity. For example, 3-methylxanthine (23) and theophylline (24) differ by the presence of an N-1 methyl and while all side chain lengths of the N-7 alkylated 3-methylxanthines (29-33) are active, only the $N-7$ geranylgeranyl theophyllines (36, 37) display activity. Converse to $N$-methyl deactivation, the acetamides are all more active than the formamides by 5 - to 13 -fold ( 74 vs. 82,76 vs. 84,77 vs. 85 ).

The SAR pertinent to alkene geometry generally suggests that the (2Z)-isomers or (2Z/E)-mixtures are more active than the (2E)-isomers, where the latter is inactive (i.e., $74 \mathrm{vs} .75)$ or activity is reduced by 1.5 - to 5 -fold (i.e., 36 vs. 37,82 vs. 83,84 vs. 85 ).

Of the 48 compounds screened, 22 compounds were shown to display high toxicity towards parasites with $\mathrm{IC}_{50}$ values all below $10 \mu \mathrm{M}$ (Table 1, Table S1). However, the positive control pentamidine was shown to display the highest toxicity towards the parasite $\left(\mathrm{IC}_{50} 5.3 \mathrm{nM}\right)$. Despite this, pentamidine is limited to treating the haemolymphatic stage of T. b. gambiense infections [47], and pentamidine resistance has been reported [48]. From these 22 compounds, the top five active compounds $(\mathbf{2 8}, \mathbf{4 7}, \mathbf{3 1}$, 27, and 63), and two further compounds (60 and 48) with abundantly available mass, were selected for further assessment. Even though the mechanism of inhibition of the parasites by the selected compounds is currently unknown, their modulatory effect on the molecular chaperone activity of TbHsp70 proteins was evaluated.

\subsection{Modulation of the Aggregation Suppression Activity of TbHsp70 and TbHsp70.4}

The malate dehydrogenase $(\mathrm{MDH})$ aggregation suppression assay was used to evaluate the modulatory effect of the seven selected compounds, that were highly toxic towards the parasites with $\mathrm{IC}_{50}$ values all below $7 \mu \mathrm{M}(27,47,48,31,28,60$, and 63$)$, on the chaperone activities of TbHsp70 and TbHsp70.4. Human HSPA8 was not suitable for MDH aggregation suppression experiments, as the protein is prone to aggregation at $48^{\circ} \mathrm{C}$ (Figure S3). The target compounds (in the absence of the Hsp70) were shown to have no effect on the aggregation of MDH (Figure S4), and thus were ruled out as chemical chaperones. DMSO $(1 \% v / v)$ had no significant effect on the chaperone activity of both T. brucei Hsp70s (not shown). Increasing concentrations of the compounds resulted in a general increase in \% MDH aggregation due to inhibition of the aggregation suppression activity of TbHsp70 and TbHsp70.4 (Figure 2A,B). Peptide substrate motifs recognized by Hsp70s have been described as having a central hydrophobic region of four to five residues, flanked by basic residues [49]. It is possible that the hydrophobic hydrocarbon side chains of the compounds are binding to the hydrophobic pocket of the substrate binding domains of the T. brucei Hsp70s, preventing MDH from binding. 


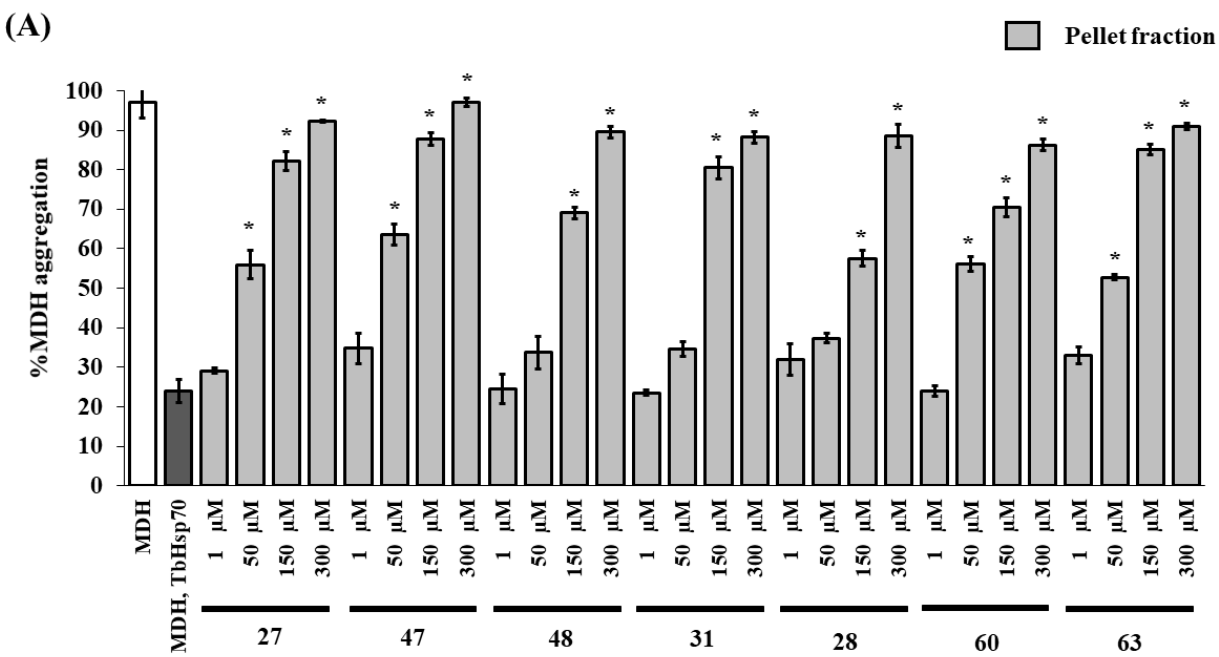

(B)

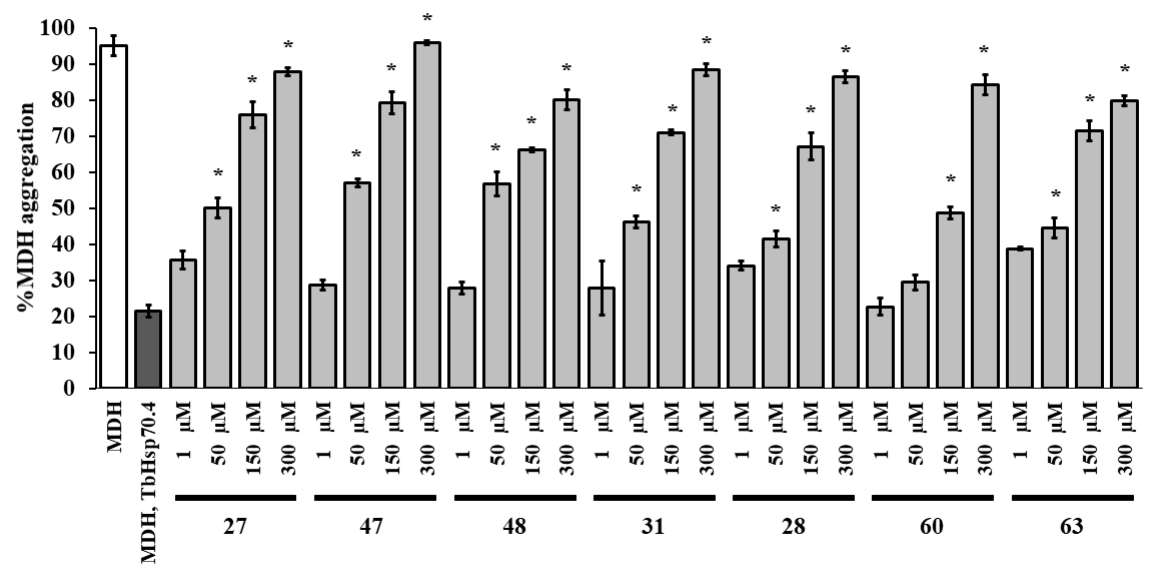

Figure 2. The compounds modulate the chaperone activity of TbHsp70 and TbHsp70.4. The chaperone function of TbHsp70 $(1 \mu \mathrm{M})$ and TbHsp70.4 $(1 \mu \mathrm{M})$ was conducted by monitoring the heat-induced aggregation of $\mathrm{MDH}$ in vitro at $48{ }^{\circ} \mathrm{C}$ and quantitating the pellet (insoluble) and supernatant (soluble) fractions after heat exposure. The chaperone capability of TbHsp70 (A) and TbHsp70.4 (B) was assessed by assessing the heat-induced aggregation of MDH in the presence and absence of a range of the selected compounds. Concentrations on the $x$-axis indicate compound concentration. $\mathrm{MDH}$ aggregation was expressed as a percentage of the pellet fraction (insoluble) of the experimental reaction in relation to the pellet fraction (insoluble) of MDH alone. Standard deviations were obtained from two replicate assays on three independent batches of recombinant protein. Significant differences relative to the "no compound" reaction (MDH, TbHsp70s; dark grey bars) are indicated by * $(p<0.05)$ above the reaction.

\subsection{The Basal ATPase Activities of TbHsp70, TbHsp70.4 and HsHSPA8 Can Be Differentially Modulated}

An initial screen of the modulatory effects of the selected compounds $(27,47,48,31,28,60$, and 63$)$ on the basal ATPase activity of the TbHsp70s was conducted at single concentrations ( $300 \mu \mathrm{M})$ (Figure S6). DMSO $(1 \% v / v)$ was also shown to have no significant effect on the ATPase activity of both T. brucei Hsp70s and HsHSPA8 (Figure S6). The compounds inhibited the basal ATPase activities of TbHsp70 and TbHsp70.4 to different extents. In comparison to TbHsp70.4, 31, 28, and 60 inhibited the basal ATPase activity of TbHsp70 to a lesser extent, with 60 being the least effective with 39\% inhibition (Figure S6). These molecules may have a selective mode of inhibition through interaction with specific 
residues of the targeted domain in TbHsp70.4. Compounds which reduced the basal ATPase activities of the TbHsp70s by $\geq 70 \%$ at $300 \mu \mathrm{M}$ (Figure S6) were further tested over a range of concentrations (Figure 3). The selected compounds inhibited the basal ATPase activities of TbHsp70.4 and TbHsp70 in dose-dependent manners (Figure 3). Compound 47 inhibited the ATPase activities to the greatest extent for both TbHsp70s, with the lowest concentration of $1 \mu \mathrm{M}$ inhibiting the basal ATPase activity of TbHsp70.4 by $66 \%$ and TbHsp70 by $44 \%$, respectively. Due to limited availability, only compounds 27, 28, 31, 47, and 63 were further assessed for inhibition of the basal ATPase activity of HsHSPA8 over a range of concentrations. The degree of inhibition of the basal HsHSPA8 ATPase activity by the same compounds was reduced in comparison to the TbHsp70s (Figure 3). The contrast in inhibition between the trypanosomal and human Hsp70 proteins may be due to a greater binding affinity of the compounds to the T. brucei Hsp70s than to human HSPA8.

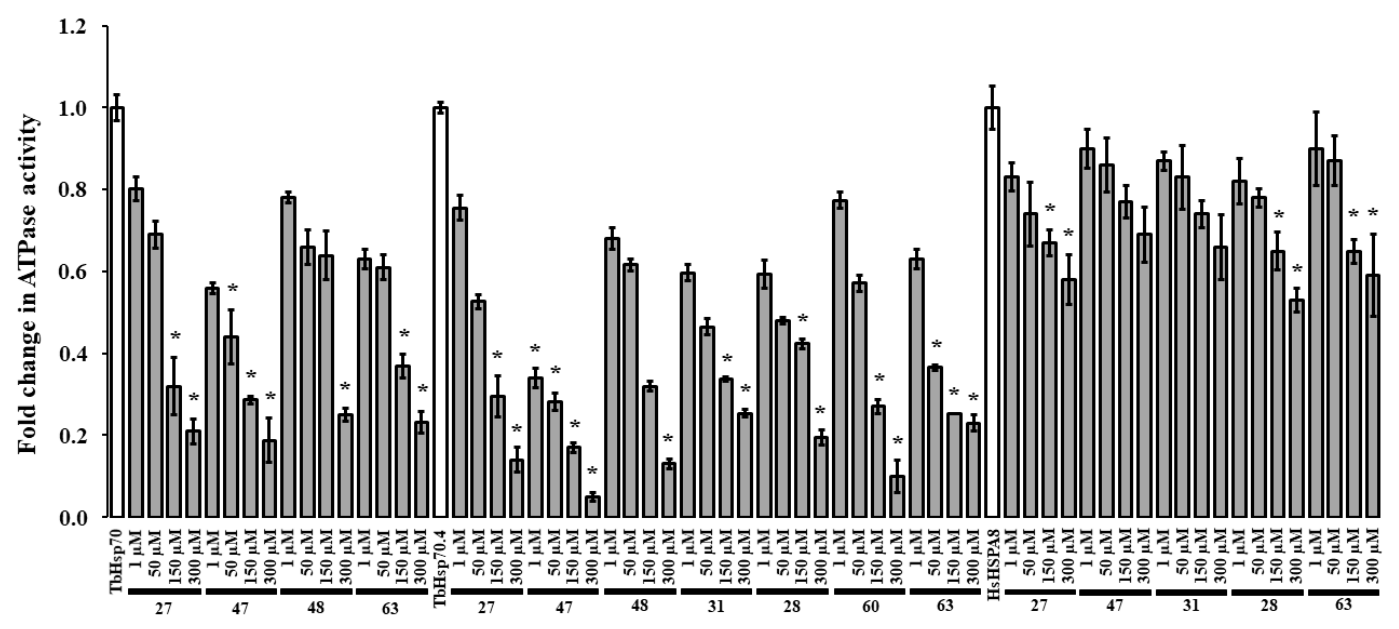

Figure 3. Compounds differentially modulate the basal ATPase activities of TbHsp70, TbHsp70.4 and HsHSPA8. Recombinant Hsp70s $(0.8 \mu \mathrm{M})$ alone and in the presence of varying concentrations of the selected compounds, were incubated with $1 \mathrm{mM}$ ATP for $1 \mathrm{~h}$, and the released Pi was monitored at $595 \mathrm{~nm}$ using a direct colorimetric assay. Results are represented as fold change in the untreated ATPase activity of the Hsp70s (white bar) in relation to the ATPase activity of the Hsp70s in the presence of compounds at varying concentrations (grey bars). Standard deviations were obtained from two replicate assays on three independent batches of protein. Significant differences relative to the "no compound" reaction (Hsp70; white bar) are indicated by * $(p<0.05)$ above the reaction using a Student's t-test.

\subsection{Modulation of the J-Protein-Stimulated ATPase Activities of TbHsp70, TbHsp70.4 and HsHSPA8}

Due to the promising results obtained, the remaining available compounds $(27,28,31,47$, and 63$)$ were investigated for modulation of J-stimulated ATPase activity of the T. brucei Hsp70s, and possible disruption of the Hsp70/J-protein partnerships. A preliminary screen of the modulatory effects of the five compounds at $300 \mu \mathrm{M}$ was performed on the Tbj2-stimulated ATPase activities of TbHsp70 and TbHsp704 and the HsDnaJB2-stimulated ATPase activity of HsHSPA8 (Figure S7). DMSO (1\% $v / v$ ) was also shown to have no significant effect on the J-stimulated ATPase activity of both T. brucei Hsp70s and HsHSPA8 (Figure S7). Tbj2 stimulated the ATPase activities of TbHsp70 3.23-fold and TbHsp70.4 2.98-fold, whilst HsDNAJB2 stimulated the ATPase activity of HsHSPA8 $~ 5$-fold (data not shown). All the tested compounds were shown to inhibit the J-stimulated ATPase activities of TbHsp70 and TbHsp70.4 by $~ 60 \%$ and inhibit the J-stimulated ATPase activity of HsHSPA 8 by $\sim 40 \%$ (Figure S7) The addition of increasing concentrations of the compounds $(27,28,31,47$, and 63$)$ reduced the J-stimulated ATPase activities of TbHsp70 and TbHsp70.4, with the greatest reduction observed for TbHsp70 (Figure 4). The compounds tested were also shown to suppress the DNAJB2-stimulated ATPase activity of HsHSPA8 (Figure 4). The small molecules were shown to have a decreased effect on 
the J-stimulated ATPase activity of HsHSPA8 in comparison to the TbHsp70s (Figure 4), though the results indicate that $\mathrm{Tbj} 2$ is stimulating the compound-induced inhibition of the basal ATPase activity.

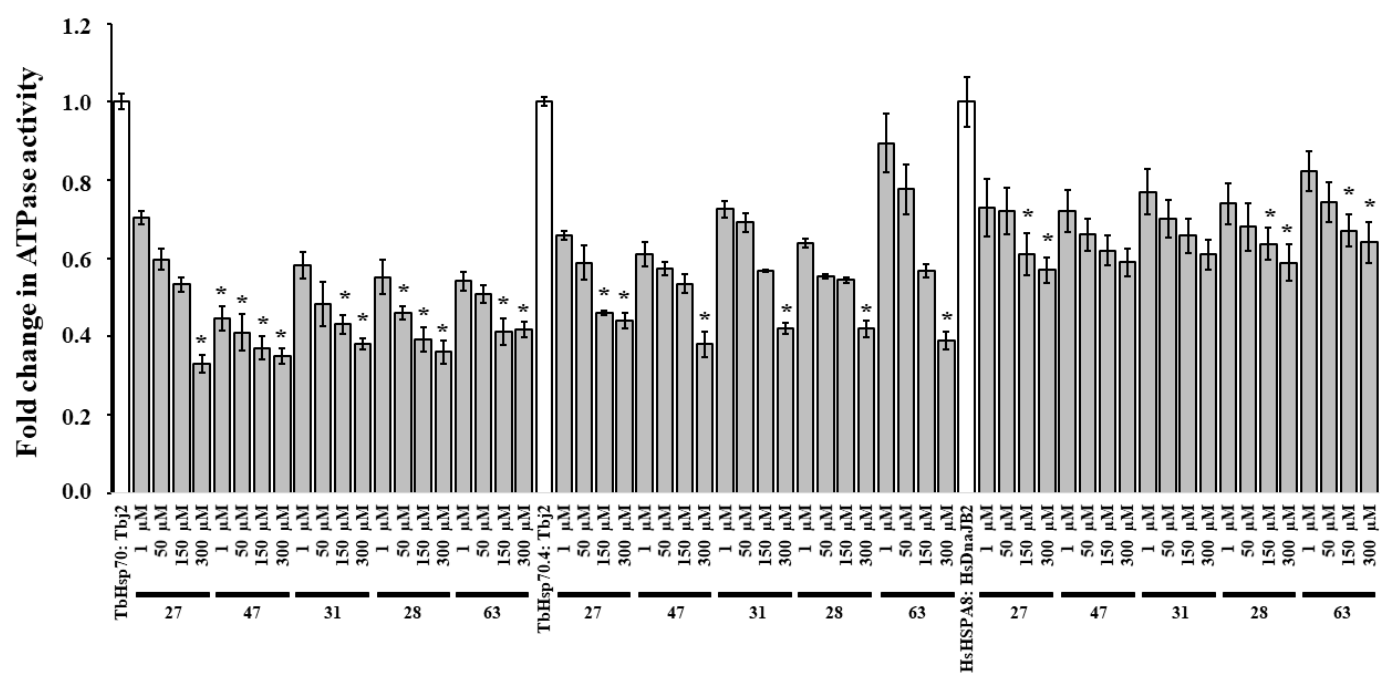

Figure 4. Compounds modulate the J-stimulated ATPase activity of TbHsp70s and HsHSPA8. Recombinant J-proteins $(0.4 \mu \mathrm{M})$ and Hsp70 proteins $(0.8 \mu \mathrm{M})$ alone and in the presence of the compounds at varying concentrations were incubated with $1 \mathrm{mM}$ ATP for $1 \mathrm{~h}$, and the released Pi was monitored at $595 \mathrm{~nm}$ using a direct colorimetric assay. Results are represented as fold change in the untreated J-stimulated Hsp70 ATPase activity (white bar) in relation to J-stimulated ATPase activity of the Hsp70s in the presence of compounds at varying concentrations (grey bars). Standard deviations were obtained from two replicate assays on three independent batches of proteins. Significant differences relative to the "no compound" reaction (Hsp70: J-protein; white bar) are indicated by * $(p<0.05)$ above the reaction.

An additional experiment was carried out to assess the effect of varying the order of addition of the compounds $(27,28,31,47$, and 63$)$ at single concentrations $(150 \mu \mathrm{M})$ and Tbj2 in the assay. This was conducted to elucidate if the small molecules were disrupting the Hsp70/J-protein partnership. However, no significant difference was observed in the inhibition of the J-stimulated ATPase activity for both T. brucei Hsp70s by varying the order of addition of the reaction components ( $p<0.05$; Figure 5). This suggests that the small molecules are not disrupting the binding of Tbj2 to the TbHsp70s but are binding to a site, independent of the Tbj2 binding site.

(A)

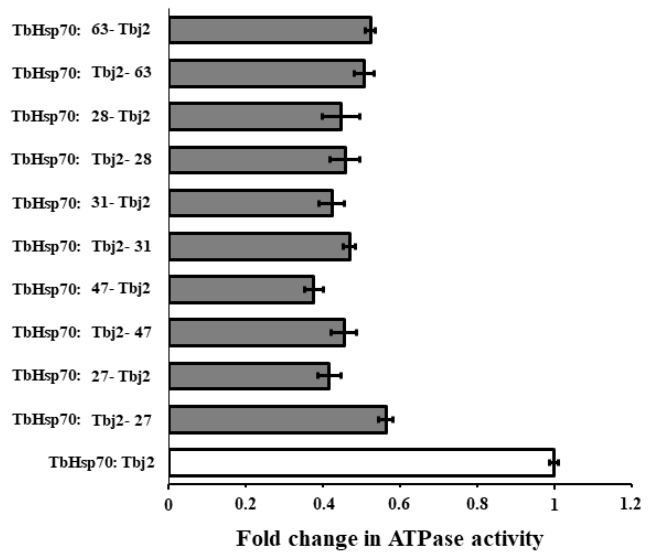

(B)

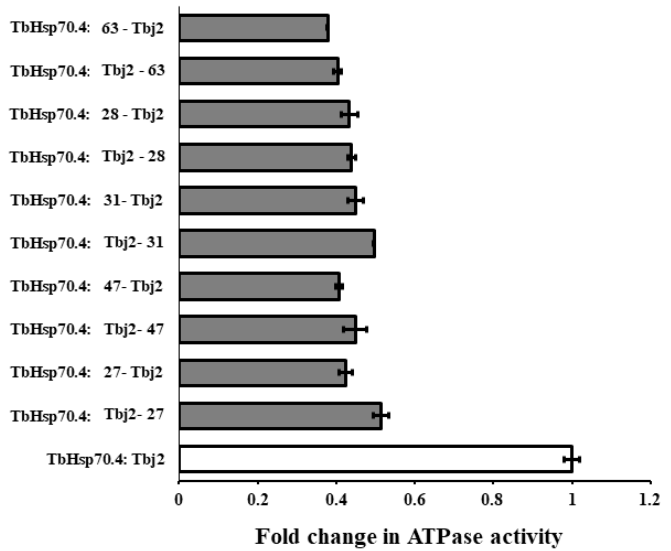

Figure 5. The compounds do not disrupt the interaction of Tbj2 with the T. brucei Hsp70s. Investigation into whether varying the order of addition of the reaction components impacts inhibition 
of Tbj2-stimulated ATPase activity of the T. brucei Hsp70s, TbHsp70 (A) and TbHsp70.4 (B), and elucidation of whether the small molecules disrupt Hsp70/J-protein interaction. Bars denoted with Hsp70: small molecule-J-protein indicate reactions in which the Hsp70 was pre-incubated with the small molecule prior to addition of the J-protein and vice versa. Results are represented as fold change in the untreated J-stimulated Hsp70 ATPase activity (white bars) in relation to J-stimulated ATPase activity of the Hsp70s in the presence of small molecules at varying concentrations (grey bars). Standard deviations were obtained from two replicate assays on three independent batches of proteins. However, no significant difference was observed in the inhibition of the J-stimulated ATPase activity for both T. brucei Hsp70s by varying the order of addition of the reaction components $(p<0.05)$.

\section{Materials and Methods}

\subsection{General Synthetic Procedures}

All reactions were carried out under an inert atmosphere $\left(\operatorname{Ar}\right.$ or $\left.\mathrm{N}_{2}\right)$, with oven or vacuum-dried glassware, using standard syringe techniques and dry solvents. Dry DCM, $\mathrm{Et}_{2} \mathrm{O}$, and THF were obtained from a Puresolv. system (Innovative Technology). Triethylamine was distilled from $\mathrm{CaH}_{2}$. Methyl iodide was run through a plug of activated alumina prior to use. 2-Mercapto-3-methylhypoxanthine [50], the relevant terpenoid bromides [51-53], and terpenoid amines [41] were synthesized according to literature. The $\mathrm{C}-2$ alkene $E / Z$ ratio of the terpenoid bromides was determined from integrated peak areas detected by ${ }^{1} \mathrm{H}$ NMR spectroscopy. Geranyl bromide was entirely the (2E)-isomer as set by the $(2 E)$-configuration of the geraniol starting material. Farnesyl bromide was synthesized from an isomeric mixture of farnesol, with an $E / Z$ ratio of 3:2. Geranylgeranyl bromide was synthesized from racemic geranyllinalool, with the resulting $E / Z$ ratio of 3:1. All other solvents and reagents were used as received from commercial suppliers. All compounds were purified by silica gel flash chromatography, using silica gel 60 (40-63 micron), unless otherwise stated. Thin-layer chromatography was performed on Macherey-Nagel, POLYGRAM ${ }^{\circledR}$ Sil G/UV254 plates, and were visualized with a UV lamp, iodine-, ceric ammonium molybdate-, vanillin-, or sulfuric acid stain. $1 \mathrm{D}\left({ }^{1} \mathrm{H},{ }^{13} \mathrm{C}, \mathrm{NOESY}\right)$ and $2 \mathrm{D}$ (COSY, HSQC, HMBC) NMR spectra were recorded using Varian Inova or DirectDrive instruments operating at 300 (Inova), 500 (Inova), or 600 (DirectDrive) MHz for proton and 125 or $150 \mathrm{MHz}$ for carbon. IR spectra were obtained using an ALPHA FT-IR spectrometer (Bruker). MS data and tandem MS data were obtained using an Agilent 6530 Q-TOF LC/MS high-resolution mass spectrometer equipped with an Agilent 1260 HPLC system for sample introduction.

\subsection{General Alkylation Procedure for Synthesis of 4-21, 27-50, 54-64, 67-72}

3.2.1. (E)-3-(3,7-Dimethylocta-2,6-dien-1-yl)-3H-purin-6-amine (4) and 3,9-bis((E)-3,7-dimethylocta-2,6-dien-1-yl)-3,9-dihydro-6H-purin-6-imine (5)

Adenine (1.00 mmol, $134.7 \mathrm{mg})$ and $\mathrm{K}_{2} \mathrm{CO}_{3}(1.31 \mathrm{mmol}, 181.3 \mathrm{mg})$ were stirred in DMF $(2 \mathrm{~mL})$ at RT for $10 \mathrm{~min}$ before dropwise addition of geranyl bromide (1.2 mmol, $250.6 \mathrm{mg})$. The reaction was stirred for $21 \mathrm{~h}$, then poured onto $\mathrm{H}_{2} \mathrm{O}(6 \mathrm{~mL})$ and extracted with $\mathrm{EA}(3 \times 2 \mathrm{~mL})$. The combined extracts were washed with $\mathrm{H}_{2} \mathrm{O}(3 \times 2 \mathrm{~mL})$, then brine $(1 \times 2 \mathrm{~mL})$ and dried over anhydrous $\mathrm{MgSO}_{4}$. The dried residue was purified by silica gel flash chromatography (5\% MeOH/EA) to yield 4 and 5 .

Compound 4: $51.9 \mathrm{mg}(19 \%)$, pale-yellow crystals; $\mathrm{R}_{f}=0.80(5 \% \mathrm{MeOH} / \mathrm{EA}) ;{ }^{1} \mathrm{H} \mathrm{NMR}(500 \mathrm{MHz}$, $\left.\mathrm{CDCl}_{3}\right): \delta 8.06(\mathrm{~s}, 1 \mathrm{H}, \mathrm{H}-8), 8.02(\mathrm{~s}, 1 \mathrm{H}, \mathrm{H}-2), 5.49(\mathrm{t}, J=7.3 \mathrm{~Hz}, 1 \mathrm{H}, \mathrm{CH}=), 5.07-5.03(\mathrm{~m}, 1 \mathrm{H}, \mathrm{CH}=)$, $5.01\left(\mathrm{~d}, \mathrm{~J}=7.3 \mathrm{~Hz}, 2 \mathrm{H}, \mathrm{NCH}_{2}\right), 2.12\left(\right.$ br s, 4H, $\left.2 \times \mathrm{CH}_{2}\right), 1.83\left(\mathrm{~s}, 3 \mathrm{H}, \mathrm{CH}_{3}\right), 1.66\left(\mathrm{~s}, 3 \mathrm{H}, \mathrm{CH}_{3}\right), 1.57(\mathrm{~s}$, $\left.3 \mathrm{H}, \mathrm{CH}_{3}\right) ;{ }^{13} \mathrm{C}\left\{{ }^{1} \mathrm{H}\right\}$ NMR $\left(150 \mathrm{MHz} \mathrm{CDCl}_{3}\right): \delta 154.3(\mathrm{C}, \mathrm{C}-6), 153.9(\mathrm{CH}, \mathrm{C}-8), 150.9(\mathrm{C}, \mathrm{C}-4), 145.0$ $(\mathrm{C}=), 141.7(\mathrm{CH}, \mathrm{C}-2), 132.5(\mathrm{C}=), 123.4(\mathrm{CH}=), 120.8(\mathrm{C}, \mathrm{C}-5), 116.2(\mathrm{CH}=), 47.4\left(\mathrm{NCH}_{2}\right), 39.6\left(\mathrm{CH}_{2}\right)$, $26.2\left(\mathrm{CH}_{2}\right), 25.8\left(\mathrm{CH}_{3}\right), 17.9\left(\mathrm{CH}_{3}\right), 16.8\left(\mathrm{CH}_{3}\right)$; IR (film from $\left.\mathrm{CH}_{2} \mathrm{Cl}_{2}\right): v_{\max }$ 3231, 3067, 2966, 2912, 
$2853 \mathrm{~cm}^{-1}$; HRESIMS m/z: $[\mathrm{M}+\mathrm{H}]^{+}$Calcd. for $\mathrm{C}_{15} \mathrm{H}_{22} \mathrm{~N}_{5}$ 272.1870; Found 272.1875 ( $\Delta=1.8 \mathrm{ppm}$ ); HRESIMS/MS (40 eV) $\mathrm{m} / \mathrm{z}(\%): 136.0612$ (100), 81.0700 (17).

Compound 5: $7.8 \mathrm{mg}(3 \%)$, pale-yellow oil; $\mathrm{R}_{f}=0.04(10 \% \mathrm{MeOH} / \mathrm{EA}) ;{ }^{1} \mathrm{H} \mathrm{NMR}(600 \mathrm{MHz}$, $\left.\mathrm{CDCl}_{3}\right): \delta 7.68(\mathrm{~s}, 1 \mathrm{H}, \mathrm{H}-8), 7.26(\mathrm{~s}, 1 \mathrm{H}, \mathrm{H}-2), 5.47(\mathrm{t}, J=7.3 \mathrm{~Hz}, 1 \mathrm{H}, \mathrm{CH}=), 5.35(\mathrm{t}, J=7.6 \mathrm{~Hz}, 1 \mathrm{H}, \mathrm{CH}=)$, $5.15\left(\mathrm{~d}, J=7.3 \mathrm{~Hz}, 2 \mathrm{H}, \mathrm{NCH}_{2}\right), 5.08-5.00(\mathrm{~m}, 2 \mathrm{H}, 2 \times \mathrm{CH}=), 4.60\left(\mathrm{~d}, J=7.1 \mathrm{~Hz}, 2 \mathrm{H}, \mathrm{NCH}_{2}\right), 2.15-2.03$ $\left(\mathrm{m}, 8 \mathrm{H}, 4 \times \mathrm{CH}_{2}\right), 1.78\left(\mathrm{~s}, 3 \mathrm{H}, \mathrm{CH}_{3}\right), 1.77\left(\mathrm{~s}, 3 \mathrm{H}, \mathrm{CH}_{3}\right), 1.67\left(\mathrm{~s}, 3 \mathrm{H}, \mathrm{CH}_{3}\right), 1.65\left(\mathrm{~s}, 3 \mathrm{H}, \mathrm{CH}_{3}\right), 1.58(\mathrm{~s}, 3 \mathrm{H}$, $\left.\mathrm{CH}_{3}\right), 1.57\left(\mathrm{~s}, 3 \mathrm{H}, \mathrm{CH}_{3}\right) ;{ }^{13} \mathrm{C}\left\{{ }^{1} \mathrm{H}\right\}$ NMR $\left(150 \mathrm{MHz}, \mathrm{CDCl}_{3}\right): \delta 155.2(\mathrm{C}, \mathrm{C}-6), 144.9(\mathrm{CH}, \mathrm{C}-8), 144.6(\mathrm{C}$, C-4), $143.5(\mathrm{C}=), 143.0(\mathrm{C}=), 140.5(\mathrm{CH}, \mathrm{C}-2), 132.43(\mathrm{C}=), 132.38(\mathrm{C}=), 123.7(\mathrm{CH}=), 123.4(\mathrm{CH}=), 117.0$ $(\mathrm{CH}=), 116.4(\mathrm{CH}=), 112.6(\mathrm{C}, \mathrm{C}-5), 45.7\left(\mathrm{NCH}_{2}\right), 46.1\left(\mathrm{NCH}_{2}\right), 39.63\left(\mathrm{CH}_{2}\right), 39.60\left(\mathrm{CH}_{2}\right), 26.23\left(\mathrm{CH}_{2}\right)$, $26.22\left(\mathrm{CH}_{2}\right), 25.9\left(\mathrm{CH}_{3}\right), 25.8\left(\mathrm{CH}_{3}\right), 17.88\left(\mathrm{CH}_{3}\right), 17.85\left(\mathrm{CH}_{3}\right), 16.79\left(\mathrm{CH}_{3}\right), 16.76\left(\mathrm{CH}_{3}\right)$; IR (film from $\left.\mathrm{CH}_{2} \mathrm{Cl}_{2}\right): v_{\max } 2966,2916,2855,1629 \mathrm{~cm}^{-1}$; HRESIMS $\mathrm{m} / \mathrm{z}$ : [M + H] ${ }^{+}$Calcd. for $\mathrm{C}_{25} \mathrm{H}_{38} \mathrm{~N}_{5}$ 408.3122; Found 408.3129 ( $\Delta=1.7 \mathrm{ppm}$ ); HRESIMS/MS (20 eV) m/z (\%): 272.1851 (41), 136.0608 (100), 81.0698 (20).

3.2.2. 3-((6E)-3,7,11-Trimethyldodeca-2,6,10-trien-1-yl)-3H-purin-6-amine (6) and 9-((6E)-3,7,11-trimethyldodeca-2,6,10-trien-1-yl)-9H-purin-6-amine (7)

Adenine $(0.51 \mathrm{mmol}, 68.3 \mathrm{mg}), \mathrm{K}_{2} \mathrm{CO}_{3}(0.52 \mathrm{mmol}, 71.9 \mathrm{mg})$ and farnesyl bromide $(0.55 \mathrm{mmol}$, $157.0 \mathrm{mg})$ in DMF ( $2 \mathrm{~mL}$ ) at $50{ }^{\circ} \mathrm{C}$ for $27 \mathrm{~h}$ yielded 6 and 7 , with modified work up- $\mathrm{H}_{2} \mathrm{O}(6 \mathrm{~mL})$ was added to the reaction filtrate and stored in the fridge until precipitate formed. The isolated solid was purified by chromatography.

Compound 6: $22.4 \mathrm{mg}$ (13\%), pale-yellow crystals; $\mathrm{R}_{f}=0.17(5 \% \mathrm{MeOH} / \mathrm{EA}) ; 3: 2 \mathrm{E} / \mathrm{Z}$, data for major isomer: ${ }^{1} \mathrm{H} \mathrm{NMR}\left(600 \mathrm{MHz}, \mathrm{CDCl}_{3}\right): \delta 8.05(\mathrm{~s}, 1 \mathrm{H}, \mathrm{H}-8), 8.00(\mathrm{~s}, 1 \mathrm{H}, \mathrm{H}-2), 5.51-5.45(\mathrm{~m}, 1 \mathrm{H}, \mathrm{CH}=)$, 5.10-5.03 (m, 2H, $2 \times \mathrm{CH}=), 5.01\left(\mathrm{~d}, J=7.3 \mathrm{~Hz}, 2 \mathrm{H}, \mathrm{NCH}_{2}\right), 2.15-2.09\left(\mathrm{~m}, 4 \mathrm{H}, 2 \times \mathrm{CH}_{2}\right), 2.05-1.98(\mathrm{~m}, 2 \mathrm{H}$, $\left.\mathrm{CH}_{2}\right), 1.98-1.92\left(\mathrm{~m}, 2 \mathrm{H}, \mathrm{CH}_{2}\right), 1.83\left(\mathrm{~s}, 3 \mathrm{H}, \mathrm{CH}_{3}\right), 1.65\left(\mathrm{~s}, 3 \mathrm{H}, \mathrm{CH}_{3}\right), 1.57\left(\mathrm{~s}, 6 \mathrm{H}, 2 \times \mathrm{CH}_{3}\right) ;{ }^{13} \mathrm{C}\left\{{ }^{1} \mathrm{H}\right\} \mathrm{NMR}$ (150 MHz, $\left.\mathrm{CDCl}_{3}\right): \delta 154.5$ (C, C-6), 154.1 (CH, C-8), 150.9 (C, C-4), 144.9 (C=), $141.6(\mathrm{CH}, \mathrm{C}-2), 136.1$ $(\mathrm{C}=), 131.5(\mathrm{C}=), 124.3(\mathrm{CH}=), 123.3(\mathrm{CH}=), 121.1(\mathrm{C}, \mathrm{C}-5), 116.2(\mathrm{CH}=), 47.4\left(\mathrm{NCH}_{2}\right), 39.8\left(\mathrm{CH}_{2}\right), 39.6$ $\left(\mathrm{CH}_{2}\right), 26.8\left(\mathrm{CH}_{2}\right), 26.2\left(\mathrm{CH}_{2}\right), 25.8\left(\mathrm{CH}_{3}\right), 17.8\left(\mathrm{CH}_{3}\right), 16.9\left(\mathrm{CH}_{3}\right), 16.2\left(\mathrm{CH}_{3}\right)$; IR (film from $\left.\mathrm{CH}_{2} \mathrm{Cl}_{2}\right)$ : $v_{\max } 3231,3065,2965,2915,2855,1704 \mathrm{~cm}^{-1}$; HRESIMS $m / z:[\mathrm{M}+\mathrm{H}]^{+}$Calcd. for $\mathrm{C}_{20} \mathrm{H}_{30} \mathrm{~N}_{5} 340.2496$; Found 340.2505 ( $\Delta=2.6 \mathrm{ppm})$; HRESIMS/MS (40 eV) $\mathrm{m} / \mathrm{z}(\%)$ : 136.0610 (100), 119.0345 (13).

Compound 7: $3.6 \mathrm{mg}(2 \%)$, white powder; $\mathrm{R}_{f}=0.30(\mathrm{EA}) ; 3: 2 \mathrm{E} / \mathrm{Z}$, NMR data for major isomer: ${ }^{1} \mathrm{H} \mathrm{NMR}\left(500 \mathrm{MHz}, \mathrm{CDCl}_{3}\right): \delta 8.38(\mathrm{~s}, 1 \mathrm{H}, \mathrm{H}-2), 7.78(\mathrm{~s}, 1 \mathrm{H}, \mathrm{H}-8), 5.59\left(\mathrm{br} \mathrm{s}, 2 \mathrm{H}, \mathrm{NH}_{2}\right), 5.45(\mathrm{t}, J=7.1 \mathrm{~Hz}$, $1 \mathrm{H}, \mathrm{CH}=), 5.13-5.03(\mathrm{~m}, 2 \mathrm{H}, 2 \times \mathrm{CH}=), 4.78\left(\mathrm{~d}, J=7.1 \mathrm{~Hz}, 2 \mathrm{H}, \mathrm{NCH}_{2}\right), 2.19-2.08\left(\mathrm{~m}, 4 \mathrm{H}, 2 \times \mathrm{CH}_{2}\right)$, 2.08-1.92 (m, 4H, $\left.2 \times \mathrm{CH}_{2}\right), 1.81\left(\mathrm{~s}, 3 \mathrm{H}, \mathrm{CH}_{3}\right), 1.67\left(\mathrm{~s}, 6 \mathrm{H}, 2 \times \mathrm{CH}_{3}\right), 1.59\left(\mathrm{~s}, 3 \mathrm{H}, \mathrm{CH}_{3}\right) ;{ }^{13} \mathrm{C}\left\{{ }^{1} \mathrm{H}\right\} \mathrm{NMR}$ $\left(150 \mathrm{MHz}, \mathrm{CDCl}_{3}\right): \delta 155.4$ (C, C-6), $153.0(\mathrm{CH}, \mathrm{C}-2), 150.1$ (C, C-4), $143.0(\mathrm{C}=), 140.2(\mathrm{CH}, \mathrm{C}-8), 135.9$ $(\mathrm{C}=), 131.6(\mathrm{C}=), 124.3(\mathrm{CH}=), 123.5(\mathrm{CH}=), 119.7(\mathrm{C}, \mathrm{C}-5), 117.5(\mathrm{CH}=), 41.4\left(\mathrm{NCH}_{2}\right), 39.8\left(\mathrm{CH}_{2}\right), 39.6$ $\left(\mathrm{CH}_{2}\right), 26.8\left(\mathrm{CH}_{2}\right), 26.3\left(\mathrm{CH}_{2}\right), 25.9\left(\mathrm{CH}_{2}\right), 17.9\left(\mathrm{CH}_{3}\right), 16.7\left(\mathrm{CH}_{3}\right), 16.2\left(\mathrm{CH}_{3}\right)$; IR (film from $\left.\mathrm{CH}_{2} \mathrm{Cl}_{2}\right)$ : $v_{\max } 3307,3140,2965,2924,2865,1601 \mathrm{~cm}^{-1}$; HRESIMS m/z: $[\mathrm{M}+\mathrm{H}]^{+}$Calcd. for $\mathrm{C}_{20} \mathrm{H}_{30} \mathrm{~N}_{5} 340.2496$; Found 340.2501 ( $\Delta=1.5$ ppm); HRESIMS/MS (40 eV) m/z (\%): 136.0613 (100), 119.0346 (12).

\subsubsection{9-((2E,6E,10E)-3,7,11,15-Tetramethylhexadeca-2,6,10,14-tetraen-1-yl)-9H-purin-6-amine (8)}

Adenine (0.69 mmol, $93.8 \mathrm{mg}), \mathrm{K}_{2} \mathrm{CO}_{3}(0.78 \mathrm{mmol}, 108.0 \mathrm{mg})$ and geranylgeranyl bromide $(0.73 \mathrm{mmol}, 259 \mathrm{mg})$ in DMF $(1 \mathrm{~mL})$ for $27 \mathrm{~h}$ yielded $8,9.9 \mathrm{mg}(4 \%)$, pale-yellow crystals. $\mathrm{R}_{f}=0.32$ (EA); ${ }^{1} \mathrm{H}$ NMR (500 MHz, $\mathrm{CDCl}_{3}$ ): $\delta 8.37$ (s, 1H, H-2), $7.77(\mathrm{~s}, 1 \mathrm{H}, \mathrm{H}-8), 5.77$ (br s, 2H, NH 2$), 5.44(\mathrm{t}$, $J=7.2 \mathrm{~Hz}, 1 \mathrm{H}, \mathrm{CH}=), 5.11-5.05(\mathrm{~m}, 3 \mathrm{H}, 3 \times \mathrm{CH}=), 4.77\left(\mathrm{~d}, J=7.2 \mathrm{~Hz}, 2 \mathrm{H}, \mathrm{NCH}_{2}\right), 2.16-2.08(\mathrm{~m}, 4 \mathrm{H}, 2 \times$ $\left.\mathrm{CH}_{2}\right), 2.08-2.01\left(\mathrm{~m}, 4 \mathrm{H}, 2 \times \mathrm{CH}_{2}\right), 2.01-1.92\left(\mathrm{~m}, 4 \mathrm{H}, 2 \times \mathrm{CH}_{2}\right), 1.81\left(\mathrm{~s}, 3 \mathrm{H}, \mathrm{CH}_{3}\right), 1.67\left(\mathrm{~s}, 3 \mathrm{H}, \mathrm{CH}_{3}\right), 1.59$ (s, 9H, $\left.3 \times \mathrm{CH}_{3}\right) ;{ }^{13} \mathrm{C}\left\{{ }^{1} \mathrm{H}\right\}$ NMR $\left(150 \mathrm{MHz}, \mathrm{CDCl}_{3}\right): \delta 155.5(\mathrm{C}, \mathrm{C}-6), 153.0(\mathrm{CH}, \mathrm{C}-2), 150.1(\mathrm{C}, \mathrm{C}-4)$, $143.0(\mathrm{C}=), 140.1(\mathrm{CH}, \mathrm{C}-8), 135.9(\mathrm{C}=), 135.2(\mathrm{C}=), 131.4(\mathrm{C}=), 124.5(\mathrm{CH}=), 124.2(\mathrm{CH}=), 123.5(\mathrm{CH}=)$, $119.7(\mathrm{C}, \mathrm{C}-5), 117.5(\mathrm{CH}=), 41.3\left(\mathrm{NCH}_{2}\right), 39.9\left(\mathrm{CH}_{2}\right), 39.8\left(\mathrm{CH}_{2}\right), 39.6\left(\mathrm{CH}_{2}\right), 26.9\left(\mathrm{CH}_{2}\right), 26.7\left(\mathrm{CH}_{2}\right)$, $26.3\left(\mathrm{CH}_{2}\right), 25.8\left(\mathrm{CH}_{3}\right), 17.8\left(\mathrm{CH}_{3}\right), 16.7\left(\mathrm{CH}_{3}\right), 16.2\left(\mathrm{CH}_{3}\right), 16.1\left(\mathrm{CH}_{3}\right)$; IR (film from $\left.\mathrm{CH}_{2} \mathrm{Cl}_{2}\right)$ : $v_{\max }$ 3468, 3324, 3153, 3051, $29692918 \mathrm{~cm}^{-1}$; HRESIMS $m / z$ : $[\mathrm{M}+\mathrm{H}]^{+}$Calcd. for $\mathrm{C}_{25} \mathrm{H}_{38} \mathrm{~N}_{5}$ 408.3122; Found 408.3129 ( $\Delta=1.7 \mathrm{ppm}$ ); HRESIMS/MS (40 eV) $\mathrm{m} / \mathrm{z}(\%): 136.0614$ (100). 
3.2.4. (E)-9-(3,7-Dimethylocta-2,6-dien-1-yl)-N,N-dimethyl-9H-purin-6-amine (9) and (E)-3-(3,7-dimethylocta-2,6-dien-1-yl)-N,N-dimethyl-3H-purin-6-amine (10)

6-(Dimethylamino)purine (0.17 mmol, $28.3 \mathrm{mg}), \mathrm{Na}_{2} \mathrm{CO}_{3} / \mathrm{K}_{2} \mathrm{CO}_{3}(1: 1,108 \mathrm{mg})$ and geranyl bromide $(0.42 \mathrm{mmol}, 90.8 \mathrm{mg})$ in DMF ( $3 \mathrm{~mL})$ for $48 \mathrm{~h}$ yielded 9 and 10, with modified work up-concentration under reduced pressure.

Compound 9: $9.2 \mathrm{mg}(18 \%)$, white powder; $\mathrm{R}_{f}=0.12$ (1:2 EA/PE); ${ }^{1} \mathrm{H} \mathrm{NMR}\left(600 \mathrm{MHz}, \mathrm{CDCl}_{3}\right): \delta$ 8.35 (s, 1H, H-2), 7.69 (s, 1H, H-8), $5.43(\mathrm{t}, J=7.1 \mathrm{~Hz}, 1 \mathrm{H}, \mathrm{CH}=), 5.05(\mathrm{t}, J=6.1 \mathrm{~Hz}, 1 \mathrm{H}, \mathrm{CH}=), 4.75(\mathrm{~d}$, $\left.J=7.1 \mathrm{~Hz}, 2 \mathrm{H}, \mathrm{NCH}_{2}\right), 3.53\left(\right.$ br s, $\left.6 \mathrm{H}, 2 \times \mathrm{NCH}_{3}\right), 2.15-2.04\left(\mathrm{~m}, 4 \mathrm{H}, 2 \times \mathrm{CH}_{2}\right) 1.79\left(\mathrm{~s}, 3 \mathrm{H}, \mathrm{CH}_{3}\right), 1.67(\mathrm{~s}$, $\left.3 \mathrm{H}, \mathrm{CH}_{3}\right), 1.58\left(\mathrm{~s}, 3 \mathrm{H}, \mathrm{CH}_{3}\right) ;{ }^{13} \mathrm{C}\left\{{ }^{1} \mathrm{H}\right\} \mathrm{NMR}\left(150 \mathrm{MHz}, \mathrm{CDCl}_{3}\right): \delta 155.1(\mathrm{C}, \mathrm{C}-6), 152.5(\mathrm{CH}, \mathrm{C}-2), 150.5$ (C, C-4), $142.5(\mathrm{C}=), 137.9(\mathrm{CH}, \mathrm{C}-8), 132.2(\mathrm{C}=), 123.7(\mathrm{CH}=), 120.3(\mathrm{C}, \mathrm{C}-5), 117.9(\mathrm{CH}=), 41.1\left(\mathrm{NCH}_{2}\right)$, 39.6 $\left(\mathrm{CH}_{2}\right), 38.7\left(2 \times \mathrm{NCH}_{3}\right), 26.3\left(\mathrm{CH}_{2}\right), 25.8\left(\mathrm{CH}_{3}\right), 17.9\left(\mathrm{CH}_{3}\right), 16.6\left(\mathrm{CH}_{3}\right)$; IR (film from $\left.\mathrm{CH}_{2} \mathrm{Cl}_{2}\right)$ : $v_{\max } 2963,2919,1637 \mathrm{~cm}^{-1}$; HRESIMS m/z: $[\mathrm{M}+\mathrm{H}]^{+}$Calcd. for $\mathrm{C}_{17} \mathrm{H}_{26} \mathrm{~N}_{5} 300.2183$; Found 300.2184 $(\Delta=0.3 \mathrm{ppm})$. HRESIMS/MS (40 eV) m/z (\%): 164.0914 (100), 149.0683 (11), 121.0503 (16).

Compound 10: $6.3 \mathrm{mg}(12 \%)$, white powder; $\mathrm{R}_{f}=0.21(5 \% \mathrm{MeOH} / \mathrm{EA}) ;{ }^{1} \mathrm{H} \mathrm{NMR}(600 \mathrm{MHz}$, $\left.\mathrm{CDCl}_{3}\right): \delta 8.00(\mathrm{~s}, 1 \mathrm{H}, \mathrm{H}-8), 7.95(\mathrm{~s}, 1 \mathrm{H}, \mathrm{H}-2), 5.48(\mathrm{t}, \mathrm{J}=6.9 \mathrm{~Hz}, 1 \mathrm{H}, \mathrm{CH}=), 5.07-5.02(\mathrm{~m}, 1 \mathrm{H}, \mathrm{CH}=), 4.95$ $\left(\mathrm{d}, J=7.1 \mathrm{~Hz}, 2 \mathrm{H}, \mathrm{NCH}_{2}\right), 3.92$ (br s, 3H, $\left.\mathrm{NCH}_{3}\right), 3.34$ (br s, 3H, $\left.\mathrm{NCH}_{3}\right), 2.17-2.08\left(\mathrm{~m}, 4 \mathrm{H}, 2 \times \mathrm{CH}_{2}\right)$, $\left.1.81\left(\mathrm{~s}, 3 \mathrm{H}, \mathrm{CH}_{3}\right), 1.68\left(\mathrm{~s}, 3 \mathrm{H}, \mathrm{CH}_{3}\right), 1.58\left(\mathrm{~s}, 3 \mathrm{H}, \mathrm{CH}_{3}\right) ;{ }^{13} \mathrm{C}^{1}{ }^{1} \mathrm{H}\right\} \mathrm{NMR}\left(150 \mathrm{MHz}, \mathrm{CDCl}_{3}\right): \delta 153.4(\mathrm{C}$, C-6), 152.6 (C, C-8), 150.7 (C, C-4), $144.4(\mathrm{C}=), 140.3$ (CH, C-2), $132.4(\mathrm{C}=), 123.6(\mathrm{CH}=), 121.6(\mathrm{C}, \mathrm{C}-5)$, 116.6 $(\mathrm{CH}=), 46.9\left(\mathrm{NCH}_{2}\right), 39.9\left(\mathrm{NCH}_{3}\right), 39.6\left(\mathrm{CH}_{2}\right), 38.1\left(\mathrm{NCH}_{3}\right), 26.3\left(\mathrm{CH}_{2}\right), 25.8\left(\mathrm{CH}_{3}\right), 17.9\left(\mathrm{CH}_{3}\right)$, $16.7\left(\mathrm{CH}_{3}\right)$; IR (film from $\left.\mathrm{CH}_{2} \mathrm{Cl}_{2}\right): v_{\max } 3077,2964,2922,1607 \mathrm{~cm}^{-1}$; HRESIMS m/z: $[\mathrm{M}+\mathrm{H}]^{+}$Calcd. for $\mathrm{C}_{17} \mathrm{H}_{26} \mathrm{~N}_{5}$ 300.2183; Found 300.2184 ( $\Delta=0.3$ ppm); HRESIMS/MS (20 eV) m/z (\%): 164.0914 (100).

3.2.5. N,N-Dimethyl-9-((6E)-3,7,11-trimethyldodeca-2,6,10-trien-1-yl)-9H-purin-6-amine (11) and $N, N$-dimethyl-3-((6E)-3,7,11-trimethyldodeca-2,6,10-trien-1-yl)-3H-purin-6-amine (12)

6-(Dimethylamino)purine $(0.088 \mathrm{mmol}, 14.4 \mathrm{mg}), \mathrm{K}_{2} \mathrm{CO}_{3}(0.16 \mathrm{mmol}, 22.3 \mathrm{mg})$ and farnesyl bromide $(0.11 \mathrm{mmol}, 31.6 \mathrm{mg})$ in DMF $(1 \mathrm{~mL})$ at $50{ }^{\circ} \mathrm{C}$ for $21 \mathrm{~h}$ yielded 11 and 12.

Compound 11: $5.6 \mathrm{mg}(17 \%)$, white powder; $\mathrm{R}_{f}=0.29(1: 1 \mathrm{EA} / \mathrm{PE}) ; 3: 2 \mathrm{E} / \mathrm{Z}, \mathrm{NMR}$ data for major isomer: ${ }^{1} \mathrm{H}$ NMR (500 MHz, $\left.\mathrm{CDCl}_{3}\right): \delta 8.36(\mathrm{~s}, 1 \mathrm{H}, \mathrm{H}-2), 7.70(\mathrm{~s}, 1 \mathrm{H}, \mathrm{H}-8), 5.44(\mathrm{t}, \mathrm{J}=7.1 \mathrm{~Hz}, 1 \mathrm{H}, \mathrm{CH}=)$, 5.11-5.03 (m, 2H, $2 \times \mathrm{CH}=), 4.75\left(\mathrm{~d}, J=7.1 \mathrm{~Hz}, 2 \mathrm{H}, \mathrm{NCH}_{2}\right), 3.53\left(\mathrm{br} \mathrm{s}, 6 \mathrm{H}, 2 \times \mathrm{NCH}_{3}\right), 2.16-2.06(\mathrm{~m}, 4 \mathrm{H}$, $\left.2 \times \mathrm{CH}_{2}\right), 2.06-1.99\left(\mathrm{~m}, 2 \mathrm{H}, \mathrm{CH}_{2}\right), 1.99-1.92\left(\mathrm{~m}, 2 \mathrm{H}, \mathrm{CH}_{2}\right), 1.81\left(\mathrm{~s}, 3 \mathrm{H}, \mathrm{CH}_{3}\right), 1.68\left(\mathrm{~s}, 3 \mathrm{H}, \mathrm{CH}_{3}\right), 1.58(\mathrm{~s}$, $\left.6 \mathrm{H}, 2 \times \mathrm{CH}_{3}\right) ;{ }^{13} \mathrm{C}\left\{{ }^{1} \mathrm{H}\right\} \mathrm{NMR}\left(150 \mathrm{MHz}, \mathrm{CDCl}_{3}\right): \delta 155.1(\mathrm{C}, \mathrm{C}-6), 152.5(\mathrm{CH}, \mathrm{C}-2), 150.5(\mathrm{C}, \mathrm{C}-4), 142.5$ $(\mathrm{C}=), 137.9(\mathrm{CH}, \mathrm{C}-8), 135.9(\mathrm{C}=), 131.5(\mathrm{C}=), 124.4(\mathrm{CH}=), 120.3(\mathrm{C}, \mathrm{C}-5), 117.9(\mathrm{CH}=), 41.2\left(\mathrm{NCH}_{2}\right)$, $39.8\left(\mathrm{CH}_{2}\right), 39.6\left(\mathrm{CH}_{2}\right), 38.7\left(2 \times \mathrm{NCH}_{3}\right), 26.8\left(\mathrm{CH}_{2}\right), 26.3\left(\mathrm{CH}_{2}\right), 25.9\left(\mathrm{CH}_{3}\right), 17.8\left(\mathrm{CH}_{3}\right), 16.7\left(\mathrm{CH}_{3}\right), 16.2$ $\left(\mathrm{CH}_{3}\right)$; IR (film from $\left.\mathrm{CH}_{2} \mathrm{Cl}_{2}\right): v_{\max } 3051,2961,2917,2856,1589 \mathrm{~cm}^{-1}$; HRESIMS m/z: $[\mathrm{M}+\mathrm{H}]^{+} \mathrm{Calcd}$. for $\mathrm{C}_{22} \mathrm{H}_{34} \mathrm{~N}_{5}$ 368.2809; Found 368.2817 ( $\Delta=2.2$ ppm); HRESIMS/MS (20 eV) m/z (\%): 164.0894 (100).

Compound 12: $9.5 \mathrm{mg}(29 \%)$, white powder; $\mathrm{R}_{f}=0.25$ (10\% MeOH/EA); 3:2 E/Z, NMR data for major isomer: ${ }^{1} \mathrm{H}$ NMR $\left(600 \mathrm{MHz} \mathrm{CDCl}_{3}\right): \delta 8.01(\mathrm{~s}, 1 \mathrm{H}, \mathrm{H}-8), 7.95(\mathrm{~s}, 1 \mathrm{H}, \mathrm{H}-2), 5.48(\mathrm{t}, J=7.3 \mathrm{~Hz}, 1 \mathrm{H}$, $\mathrm{CH}=)$, 5.09-5.03 (m, 2H, $2 \times \mathrm{CH}=), 4.96\left(\mathrm{~d}, J=7.3 \mathrm{~Hz}, 2 \mathrm{H}, \mathrm{NCH}_{2}\right), 3.92\left(\mathrm{br} \mathrm{s}, 3 \mathrm{H}, \mathrm{NCH}_{3}\right), 3.33(\mathrm{br} \mathrm{s}, 3 \mathrm{H}$, $\left.\mathrm{NCH}_{3}\right), 2.17-2.08\left(\mathrm{~m}, 4 \mathrm{H}, 2 \times \mathrm{CH}_{2}\right), 2.05-1.99\left(\mathrm{~m}, 2 \mathrm{H}, \mathrm{CH}_{2}\right), 1.99-1.94\left(\mathrm{~m}, 2 \mathrm{H}, \mathrm{CH}_{2}\right), 1.82\left(\mathrm{~s}, 3 \mathrm{H}, \mathrm{CH}_{3}\right)$, $1.66\left(\mathrm{~s}, 3 \mathrm{H}, \mathrm{CH}_{3}\right), 1.58\left(\mathrm{~s}, 6 \mathrm{H}, 2 \times \mathrm{CH}_{3}\right) ;{ }^{13} \mathrm{C}\left\{{ }^{1} \mathrm{H}\right\} \mathrm{NMR}\left(150 \mathrm{MHz}, \mathrm{CDCl}_{3}\right): \delta 153.4(\mathrm{C}, \mathrm{C}-6), 152.4(\mathrm{CH}$, C-8), 150.5 (C, C-4), 144.5 (C=), $140.4(\mathrm{CH}, \mathrm{C}-2), 136.1$ (C=), $131.5(\mathrm{C}=), 124.4(\mathrm{CH}=), 123.3(\mathrm{CH}=), 121.6$ (C, C-5), $116.5(\mathrm{CH}=), 46.9\left(\mathrm{NCH}_{2}\right), 39.9\left(\mathrm{NCH}_{3}\right), 39.8\left(\mathrm{CH}_{2}\right), 39.6\left(\mathrm{CH}_{2}\right), 38.1\left(\mathrm{NCH}_{3}\right), 26.8\left(\mathrm{CH}_{2}\right), 26.2$ $\left(\mathrm{CH}_{2}\right), 25.8\left(\mathrm{CH}_{3}\right), 17.8\left(\mathrm{CH}_{3}\right), 16.8\left(\mathrm{CH}_{3}\right), 16.2\left(\mathrm{CH}_{3}\right)$; IR (film from $\left.\mathrm{CH}_{2} \mathrm{Cl}_{2}\right): v_{\max } 2963,2924,2856$, $1608 \mathrm{~cm}^{-1}$; HRESIMS m/z: $[\mathrm{M}+\mathrm{H}]^{+}$Calcd. for $\mathrm{C}_{22} \mathrm{H}_{34} \mathrm{~N}_{5} 368.2809$; Found $368.2818(\Delta=2.4 \mathrm{ppm})$; HRESIMS/MS (40 eV) m/z (\%): 164.0932 (100), 81.0704 (14). 
3.2.6. $N, N$-Dimethyl-9-((2Z,6E,10E)-3,7,11,15-tetramethylhexadeca-2,6,10,14-tetraen-1-yl)-9Hpurin-6-amine (13) and $N, N$-dimethyl-9-((2E,6E,10E)-3,7,11,15-tetramethylhexadeca2,6,10,14-tetraen-1-yl)-9H-purin-6-amine (14)

6-(Dimethylamino)purine (0.14 mmol, $23.4 \mathrm{mg}), \mathrm{K}_{2} \mathrm{CO}_{3}(0.16 \mathrm{mmol}, 22.7 \mathrm{mg})$ and geranylgeranyl bromide $(0.15 \mathrm{mmol}, 51.5 \mathrm{mg})$ in DMF $(1 \mathrm{~mL})$ for $44 \mathrm{~h}$ yielded 13 and 14.

Compound 13: $4.5 \mathrm{mg}(28 \%)$, white solid; $\mathrm{R}_{f}=0.21$ (1:2 EA/PE); ${ }^{1} \mathrm{H} \mathrm{NMR}\left(500 \mathrm{MHz}, \mathrm{CDCl}_{3}\right): \delta$ 8.35 (s, 1H, H-2), 7.70 (s, 1H, H-8), 5.43 (t, J = 7.1 Hz, 1H, CH=), 5.15-5.04 (m, 3H, $3 \times \mathrm{CH}=), 4.75$ (d, $\left.J=7.1 \mathrm{~Hz}, 2 \mathrm{H}, \mathrm{NCH}_{2}\right), 3.53\left(\mathrm{br} \mathrm{s}, 6 \mathrm{H}, 2 \times \mathrm{NCH}_{3}\right), 2.27-2.20\left(\mathrm{~m}, 2 \mathrm{H}, \mathrm{CH}_{2}\right), 2.18-2.10\left(\mathrm{~m}, 2 \mathrm{H}, \mathrm{CH}_{2}\right)$, 2.10-2.01 (m, 4H, $\left.2 \times \mathrm{CH}_{2}\right), 2.01-1.91\left(\mathrm{~m}, 4 \mathrm{H}, 2 \times \mathrm{CH}_{2}\right), 1.79\left(\mathrm{~s}, 3 \mathrm{H}, \mathrm{CH}_{3}\right), 1.67\left(\mathrm{~s}, 3 \mathrm{H}, \mathrm{CH}_{3}\right), 1.61(\mathrm{~s}, 3 \mathrm{H}$, $\left.\mathrm{CH}_{3}\right), 1.59\left(\mathrm{~s}, 6 \mathrm{H}, 2 \times \mathrm{CH}_{3}\right) ;{ }^{13} \mathrm{C}\left\{{ }^{1} \mathrm{H}\right\} \mathrm{NMR}\left(150 \mathrm{MHz}, \mathrm{CDCl}_{3}\right): \delta 155.1(\mathrm{C}, \mathrm{C}-6), 152.5(\mathrm{CH}, \mathrm{C}-2), 150.5$ (C, C-4), $142.4(\mathrm{C}=), 137.9(\mathrm{CH}, \mathrm{C}-8), 136.3(\mathrm{C}=), 135.2(\mathrm{C}=), 131.4(\mathrm{C}=), 124.5(\mathrm{CH}=), 124.2(\mathrm{CH}=), 123.3$ $(\mathrm{CH}=), 120.7(\mathrm{C}, \mathrm{C}-5), 118.7(\mathrm{CH}=), 41.0\left(\mathrm{NCH}_{2}\right), 39.9\left(\mathrm{CH}_{2}\right), 39.8\left(\mathrm{CH}_{2}\right), 38.6\left(2 \times \mathrm{NCH}_{3}\right), 32.3\left(\mathrm{CH}_{2}\right)$, $26.9\left(\mathrm{CH}_{2}\right), 26.7\left(\mathrm{CH}_{2}\right), 26.5\left(\mathrm{CH}_{2}\right), 25.9\left(\mathrm{CH}_{3}\right), 23.6\left(\mathrm{CH}_{3}\right), 17.8\left(\mathrm{CH}_{3}\right), 16.20\left(\mathrm{CH}_{3}\right), 16.16\left(\mathrm{CH}_{3}\right) ; \mathrm{IR}$ (film from $\mathrm{CH}_{2} \mathrm{Cl}_{2}$ ): $v_{\max } 3043,2921,2854,1590 \mathrm{~cm}^{-1}$; HRESIMS m/z: $[\mathrm{M}+\mathrm{H}]^{+}$Calcd. for $\mathrm{C}_{27} \mathrm{H}_{42} \mathrm{~N}_{5}$ 436.3435; Found 436.3430 ( $\Delta=-1.1 \mathrm{ppm})$; HRESIMS/MS (40 eV) $\mathrm{m} / \mathrm{z}(\%)$ : 164.0912 (100).

Compound 14: $6.7 \mathrm{mg}(14 \%)$, white solid; $\mathrm{R}_{f}=0.18$ (1:2 EA/PE); ${ }^{1} \mathrm{H} \mathrm{NMR}\left(500 \mathrm{MHz}, \mathrm{CDCl}_{3}\right): \delta$ 8.36 (s, 1H, H-2), 7.70 (s, 1H, H-8), 5.43 (t, J = 7.0 Hz, 1H, CH=), 5.12-5.04 (m, 3H, $3 \times \mathrm{CH}=), 4.75$ (d, $\left.J=7.1 \mathrm{~Hz}, 2 \mathrm{H}, \mathrm{NCH}_{2}\right), 3.56\left(\mathrm{br} \mathrm{s}, 6 \mathrm{H}, 2 \times \mathrm{NCH}_{3}\right), 2.15-2.08\left(\mathrm{~m}, 4 \mathrm{H}, 2 \times \mathrm{CH}_{2}\right), 2.08-2.01(\mathrm{~m}, 4 \mathrm{H}, 2 \times$ $\left.\mathrm{CH}_{2}\right), 1.99-1.93\left(\mathrm{~m}, 4 \mathrm{H}, 2 \times \mathrm{CH}_{2}\right), 1.80\left(\mathrm{~s}, 3 \mathrm{H}, \mathrm{CH}_{3}\right), 1.67\left(\mathrm{~s}, 3 \mathrm{H}, \mathrm{CH}_{3}\right), 1.59\left(\mathrm{~s}, 3 \mathrm{H}, \mathrm{CH}_{3}\right), 1.58(\mathrm{~s}, 6 \mathrm{H}, 2 \times$ $\left.\mathrm{CH}_{3}\right) ;{ }^{13} \mathrm{C}\left\{{ }^{1} \mathrm{H}\right\}$ NMR $\left(150 \mathrm{MHz} \mathrm{CDCl}_{3}\right): \delta 155.1(\mathrm{C}, \mathrm{C}-6), 152.5(\mathrm{CH}, \mathrm{C}-2), 150.5(\mathrm{C}, \mathrm{C}-4), 142.5(\mathrm{C}=)$, $137.9(\mathrm{CH}, \mathrm{C}-8), 135.9(\mathrm{C}=), 135.2(\mathrm{C}=), 131.4(\mathrm{C}=), 124.5(\mathrm{CH}=), 124.2(\mathrm{CH}=), 123.5(\mathrm{CH}=), 120.3(\mathrm{C}$, C-5), $117.9(\mathrm{CH}=), 41.1\left(\mathrm{NCH}_{2}\right), 39.9\left(\mathrm{CH}_{2}\right), 39.8\left(\mathrm{CH}_{2}\right), 39.6\left(\mathrm{CH}_{2}\right), 38.6\left(2 \times \mathrm{NCH}_{3}\right), 26.9\left(\mathrm{CH}_{2}\right), 26.7$ $\left(\mathrm{CH}_{2}\right), 26.3\left(\mathrm{CH}_{2}\right), 25.8\left(\mathrm{CH}_{3}\right), 17.8\left(\mathrm{CH}_{3}\right), 16.7\left(\mathrm{CH}_{3}\right), 16.2\left(\mathrm{CH}_{3}\right), 16.1\left(\mathrm{CH}_{3}\right)$; IR (film from $\left.\mathrm{CH}_{2} \mathrm{Cl}_{2}\right)$ : $v_{\max } 3104,2962,2917,2855,1590 \mathrm{~cm}^{-1}$; HRESIMS m/z: $[\mathrm{M}+\mathrm{H}]^{+}$Calcd. for $\mathrm{C}_{27} \mathrm{H}_{42} \mathrm{~N}_{5} 436.3435$; Found 436.3466 ( $\Delta=7.1 \mathrm{ppm})$; HRESIMS/MS (40 eV) m/z (\%): 164.0873 (100).

3.2.7. (E)-6-Chloro-9-(3,7-dimethylocta-2,6-dien-1-yl)-9H-purine (15) and

(E)-6-chloro-7-(3,7-dimethylocta-2,6-dien-1-yl)-7H-purine (16)

Following the general alkylation procedure, also previously published using $80{ }^{\circ} \mathrm{C}[54]$, 6-chloropurine $(0.30 \mathrm{mmol}, 45.9 \mathrm{mg}), \mathrm{K}_{2} \mathrm{CO}_{3}(0.62 \mathrm{mmol}, 85.6 \mathrm{mg})$ and geranyl bromide $(0.33 \mathrm{mmol}$, $71.8 \mathrm{mg})$ in DMF (1 mL) for $21 \mathrm{~h}$ yielded 15 and 16.

Compound 15: $39.4 \mathrm{mg}(46 \%)$, colourless oil; $\mathrm{R}_{f}=0.48$ (2:3 EA/PE); IR data and select ${ }^{1} \mathrm{H}$ NMR data previously reported in $\mathrm{CD}_{3} \mathrm{OD}[54] ;{ }^{1} \mathrm{H} \mathrm{NMR}\left(300 \mathrm{MHz}, \mathrm{CDCl}_{3}\right): \delta 8.72(\mathrm{~s}, 1 \mathrm{H}, \mathrm{H}-2), 8.07(\mathrm{~s}, 1 \mathrm{H}$, $\mathrm{H}-8), 5.42(\mathrm{t}, J=7.2 \mathrm{~Hz}, 1 \mathrm{H}, \mathrm{CH}=), 5.05-4.97(\mathrm{~m}, 1 \mathrm{H}, \mathrm{CH}=), 4.84\left(\mathrm{~d}, J=7.3 \mathrm{~Hz}, 2 \mathrm{H}, \mathrm{NCH}_{2}\right), 2.09$ (s, 4H, 2 $\left.\times \mathrm{CH}_{2}\right), 1.81\left(\mathrm{~s}, 3 \mathrm{H}, \mathrm{CH}_{3}\right), 1.64\left(\mathrm{~s}, 3 \mathrm{H}, \mathrm{CH}_{3}\right), 1.55\left(\mathrm{~s}, 3 \mathrm{H}, \mathrm{CH}_{3}\right) ;{ }^{13} \mathrm{C}\left\{{ }^{1} \mathrm{H}\right\} \mathrm{NMR}\left(150 \mathrm{MHz}, \mathrm{CDCl}_{3}\right): \delta 151.9$ (CH, C-2), 151.8 (C, C-6), 150.9 (C, C-4), 144.8 (CH, C-8), 144.1 (C=), 132.4 (C, C-5), 131.8 (C=), 123.4 $(\mathrm{CH}=), 116.7(\mathrm{CH}=), 41.9\left(\mathrm{NCH}_{2}\right), 39.5\left(\mathrm{CH}_{2}\right), 26.1\left(\mathrm{CH}_{2}\right), 25.8\left(\mathrm{CH}_{3}\right), 17.8\left(\mathrm{CH}_{3}\right), 16.7\left(\mathrm{CH}_{3}\right) ; \mathrm{HRESIMS}$ $m / z:[\mathrm{M}+\mathrm{H}]^{+}$Calcd. for $\mathrm{C}_{15} \mathrm{H}_{20} \mathrm{ClN}_{4} 291.1371 ;$ Found $291.1371(\Delta=0.0 \mathrm{ppm}) ; \mathrm{HRESIMS} / \mathrm{MS}(40 \mathrm{eV})$ $m / z$ (\%): 157.0074 (22), 155.0105 (57), 119.0346 (100).

Compound 16: $17.2 \mathrm{mg}(20 \%)$, colourless oil; $\mathrm{R}_{f}=0.16$ (2:3 EA/PE); IR data and select ${ }^{1} \mathrm{H}$ NMR data previously reported in $\mathrm{CD}_{3} \mathrm{OD}[54] ;{ }^{1} \mathrm{H} \mathrm{NMR}\left(300 \mathrm{MHz}, \mathrm{CDCl}_{3}\right): \delta 8.85(\mathrm{~s}, 1 \mathrm{H}, \mathrm{H}-2), 8.23(\mathrm{~s}, 1 \mathrm{H}$, $\mathrm{H}-8), 5.43(\mathrm{t}, J=6.8 \mathrm{~Hz}, 1 \mathrm{H}, \mathrm{CH}=), 5.07\left(\mathrm{~d}, J=7.0 \mathrm{~Hz}, 2 \mathrm{H}, \mathrm{NCH}_{2}\right), 5.05-5.00(\mathrm{~m}, 1 \mathrm{H}, \mathrm{CH}=), 2.13(\mathrm{~s}, 4 \mathrm{H}, 2$ $\left.\times \mathrm{CH}_{2}\right), 1.80\left(\mathrm{~s}, 3 \mathrm{H}, \mathrm{CH}_{3}\right), 1.66\left(\mathrm{~s}, 3 \mathrm{H}, \mathrm{CH}_{3}\right), 1.58\left(\mathrm{~s}, 3 \mathrm{H}, \mathrm{CH}_{3}\right) ;{ }^{13} \mathrm{C}\left\{{ }^{1} \mathrm{H}\right\} \mathrm{NMR}\left(150 \mathrm{MHz}, \mathrm{CDCl}_{3}\right): \delta 162.2$ (C, C-6), 152.5 (CH, C-2), 148.4 (CH, C-8), 144.2 (C=), 143.3 (C, C-4), 132.6 (C=), $123.3(\mathrm{CH}=), 122.7$ (C, C-5), $117.1(\mathrm{CH}=), 45.4\left(\mathrm{NCH}_{2}\right), 39.5\left(\mathrm{CH}_{2}\right), 26.1\left(\mathrm{CH}_{2}\right), 25.8\left(\mathrm{CH}_{3}\right), 17.9\left(\mathrm{CH}_{3}\right), 16.8\left(\mathrm{CH}_{3}\right)$; HRESIMS $m / z:[\mathrm{M}+\mathrm{H}]^{+}$Calcd. for $\mathrm{C}_{15} \mathrm{H}_{20} \mathrm{ClN}_{4} 291.1371$; Found 291.1365 ( $\left.\Delta=-2.1 \mathrm{ppm}\right) ; \mathrm{HRESIMS} / \mathrm{MS}(40 \mathrm{eV})$ $m / z$ (\%): 157.0062 (100), 155.0081 (40). 
3.2.8. 6-Chloro-9-((6E)-3,7,11-trimethyldodeca-2,6,10-trien-1-yl)-9H-purine (17) and 6-chloro-7-((2E,6E)-3,7,11-trimethyldodeca-2,6,10-trien-1-yl)-9H-purine (18)

6-Chloropurine $(0.31 \mathrm{mmol}, 48.5 \mathrm{mg}), \mathrm{K}_{2} \mathrm{CO}_{3}(0.6 \mathrm{mmol}, 83 \mathrm{mg})$ and farnesyl bromide $(0.33 \mathrm{mmol}$, $94.0 \mathrm{mg})$ in DMF (2 mL) at $50{ }^{\circ} \mathrm{C}$ for $24 \mathrm{~h}$ yielded 17 and 18.

Compound 17: $47.4 \mathrm{mg}(43 \%)$, colourless oil; $\mathrm{R}_{f}=0.24$ (1:2 EA/PE); 2:1 E/Z, NMR data for major isomer: ${ }^{1} \mathrm{H}$ NMR (600 MHz, $\left.\mathrm{CDCl}_{3}\right): \delta 8.72(\mathrm{~s}, 1 \mathrm{H}, \mathrm{H}-2), 8.08(\mathrm{~s}, 1 \mathrm{H}, \mathrm{H}-8), 5.42(\mathrm{t}, \mathrm{J}=7.2 \mathrm{~Hz}, 1 \mathrm{H}, \mathrm{CH}=)$, 5.06-5.00 (m, 2H, $2 \times \mathrm{CH}=), 4.85\left(\mathrm{~d}, J=7.3 \mathrm{~Hz}, 2 \mathrm{H}, \mathrm{NCH}_{2}\right), 2.13-2.07\left(\mathrm{~m}, 4 \mathrm{H}, 2 \times \mathrm{CH}_{2}\right), 2.02-1.96(\mathrm{~m}$, $\left.\left.2 \mathrm{H}, \mathrm{CH}_{2}\right), 1.95-1.90\left(\mathrm{~m}, 2 \mathrm{H}, \mathrm{CH}_{2}\right), 1.82\left(\mathrm{~s}, 3 \mathrm{H}, \mathrm{CH}_{3}\right), 1.63\left(\mathrm{~s}, 3 \mathrm{H}, \mathrm{CH}_{3}\right), 1.55\left(\mathrm{~s}, 6 \mathrm{H}, 2 \times \mathrm{CH}_{3}\right) ;{ }^{13} \mathrm{C}^{1} \mathrm{H}^{1}\right\}$ NMR (150 MHz, CDCl $): \delta 152.0$ (C, C-2), 151.8 (C, C-6), 151.0 (C, C-4), 144.9 (C, C-8), 144.1 (C=), 136.0 $(\mathrm{C}=), 132.3(\mathrm{C}, \mathrm{C}-5), 131.5(\mathrm{C}=), 124.3(\mathrm{CH}=), 123.3(\mathrm{CH}=), 116.6(\mathrm{CH}=), 41.9\left(\mathrm{NCH}_{2}\right), 39.8\left(\mathrm{CH}_{2}\right), 39.5$ $\left(\mathrm{CH}_{2}\right), 26.8\left(\mathrm{CH}_{2}\right), 26.2\left(\mathrm{CH}_{2}\right), 25.8\left(\mathrm{CH}_{3}\right), 17.8\left(\mathrm{CH}_{3}\right), 16.8\left(\mathrm{CH}_{3}\right), 16.2\left(\mathrm{CH}_{3}\right)$; IR (film from $\left.\mathrm{CH}_{2} \mathrm{Cl}_{2}\right)$ : $v_{\max } 3115,2969,2930,1335,939,637 \mathrm{~cm}^{-1} ; \mathrm{HRESIMS} \mathrm{m} / z:[\mathrm{M}+\mathrm{H}]^{+}$Calcd. for $\mathrm{C}_{20} \mathrm{H}_{28} \mathrm{ClN}_{4}$ 359.1997; Found 359.1993 ( $\Delta=-1.1 \mathrm{ppm})$; HRESIMS/MS (40 eV) m/z (\%): 157.0073 (40), 155.0103 (100), 119.0343 (47), 81.0697 (47).

Compound 18: $21.3 \mathrm{mg}(19 \%)$, colourless oil; $\mathrm{R}_{f}=0.20$ (1:1 EA/PE); $E / Z$ 3:2, NMR data for major isomer: ${ }^{1} \mathrm{H} \mathrm{NMR}\left(600 \mathrm{MHz}, \mathrm{CDCl}_{3}\right): \delta 8.86(\mathrm{~s}, 1 \mathrm{H}, \mathrm{H}-2), 8.23(\mathrm{~s}, 1 \mathrm{H}, \mathrm{H}-8), 5.44(\mathrm{t}, J=7.0 \mathrm{~Hz}, 1 \mathrm{H}, \mathrm{CH}=)$, $5.08\left(\mathrm{~d}, J=7.1 \mathrm{~Hz}, 2 \mathrm{H}, \mathrm{NCH}_{2}\right), 5.07-5.04(\mathrm{~m}, 2 \mathrm{H}, 2 \times \mathrm{CH}=), 2.18-2.09\left(\mathrm{~m}, 4 \mathrm{H}, 2 \times \mathrm{CH}_{2}\right), 2.05-1.99$ (m, 2H, $\left.\mathrm{CH}_{2}\right), 1.98-1.93\left(\mathrm{~m}, 2 \mathrm{H}, \mathrm{CH}_{2}\right), 1.82\left(\mathrm{~s}, 3 \mathrm{H}, \mathrm{CH}_{3}\right), 1.65\left(\mathrm{~s}, 3 \mathrm{H}, \mathrm{CH}_{3}\right), 1.58\left(\mathrm{~s}, 6 \mathrm{H}, 2 \times \mathrm{CH}_{3}\right)$; ${ }^{13} \mathrm{C}\left\{{ }^{1} \mathrm{H}\right\}$ NMR $\left(150 \mathrm{MHz}, \mathrm{CDCl}_{3}\right): \delta 162.0(\mathrm{C}, \mathrm{C}-6), 152.4(\mathrm{CH}, \mathrm{C}-2), 148.5(\mathrm{CH}, \mathrm{C}-8), 144.2(\mathrm{C}=), 143.3(\mathrm{C}$, C-4), $136.2(\mathrm{C}=), 131.5(\mathrm{C}=), 124.2(\mathrm{CH}=), 123.2(\mathrm{CH}=), 122.6(\mathrm{C}, \mathrm{C}-5), 117.0(\mathrm{CH}=), 45.4\left(\mathrm{NCH}_{2}\right), 39.8$ $\left(\mathrm{CH}_{2}\right), 39.5\left(\mathrm{CH}_{2}\right), 26.8\left(\mathrm{CH}_{2}\right), 26.2\left(\mathrm{CH}_{2}\right), 25.8\left(\mathrm{CH}_{3}\right), 17.8\left(\mathrm{CH}_{3}\right), 16.9\left(\mathrm{CH}_{3}\right), 16.2\left(\mathrm{CH}_{3}\right)$; IR (film from $\left.\mathrm{CH}_{2} \mathrm{Cl}_{2}\right): v_{\max } 3053,2981,1264,732 \mathrm{~cm}^{-1}$; HRESIMS m/z: $[\mathrm{M}+\mathrm{H}]^{+}$Calcd. for $\mathrm{C}_{20} \mathrm{H}_{28} \mathrm{ClN}_{4}$ 359.1997; Found 359.2002 ( $\Delta=1.4 \mathrm{ppm})$; HRESIMS/MS (40 eV) $m / z(\%): 157.0001$ (27), 155.0031 (66), 119.0287 (31), 95.0806 (23), 93.0651 (13), 81.0660 (100), 79.0539 (15).

3.2.9. 6-Chloro-9-((2E,6E,10E)-3,7,11,15-tetramethylhexadeca-2,6,10,14-tetraen-1-yl)-9H-purine (19), 6-chloro-7-((2E,6E,10E)-3,7,11,15-tetramethylhexadeca-2,6,10,14-tetraen-1-yl)-7H-purine (20), and 6-chloro-7-((2Z,6E,10E)-3,7,11,15-tetramethylhexadeca-2,6,10,14-tetraen-1-yl)-7H-purine (21)

Following the general alkylation procedure, also previously published [55], 6-chloropurine $(0.30 \mathrm{mmol}, 45.6 \mathrm{mg}), \mathrm{K}_{2} \mathrm{CO}_{3}(0.35 \mathrm{mmol}, 48.2 \mathrm{mg})$ and geranylgeranyl bromide $(0.32 \mathrm{mmol}, 111 \mathrm{mg}) \mathrm{in}$ DMF (1 mL) for $27 \mathrm{~h}$ yielded 19, 20, and 21.

Compound 19: $19.4 \mathrm{mg}(19 \%)$, colourless oil; $\mathrm{R}_{f}=0.51(2: 3 \mathrm{EA} / \mathrm{PE}) ;{ }^{1} \mathrm{H}$ and ${ }^{13} \mathrm{C} \mathrm{NMR}$ data previously reported [55]; IR (film from $\mathrm{CH}_{2} \mathrm{Cl}_{2}$ ): $v_{\max }$ 3070, 2966, 2922, 2855, 1592, 1560, $1335 \mathrm{~cm}^{-1}$; HRESIMS m/z: $[\mathrm{M}+\mathrm{H}]^{+}$Calcd. for $\mathrm{C}_{25} \mathrm{H}_{36} \mathrm{ClN}_{4}$ 427.2623; Found $427.2614(\Delta=-2.1 \mathrm{ppm}) ; \mathrm{HRESIMS} / \mathrm{MS}(40 \mathrm{eV}) \mathrm{m} / \mathrm{z}$ (\%): 157.0068 (39), 155.0098 (100), 119.0334 (21).

Compound 20: $15.2 \mathrm{mg}(15 \%)$, colourless oil; $\mathrm{R}_{f}=0.21$ (2:3 EA/PE); ${ }^{1} \mathrm{H}$ and ${ }^{13} \mathrm{C}$ NMR data previously reported [55]; IR (film from $\mathrm{CH}_{2} \mathrm{Cl}_{2}$ ): $v_{\max } 3053,2971,2931,733 \mathrm{~cm}^{-1}$; HRESIMS m/z: $[\mathrm{M}+\mathrm{H}]^{+}$Calcd. for $\mathrm{C}_{25} \mathrm{H}_{36} \mathrm{ClN}_{4}$ 427.2623; Found $427.2642(\Delta=4.4 \mathrm{ppm})$.

Compound 21: $16.8 \mathrm{mg}(49 \%)$, colourless oil; $\mathrm{R}_{f}=0.3$ (2:3 EA/PE); ${ }^{1} \mathrm{H} \mathrm{NMR}\left(500 \mathrm{MHz}, \mathrm{CDCl}_{3}\right): \delta$ 8.87 (s, 1H, H-2), 8.23 (s, 1H, H-8), 5.45 (t, J = 7.1 Hz, 1H, CH=), 5.15-5.08 (m, 3H, 3 × CH=), 5.07 (d, $\left.J=7.1 \mathrm{~Hz}, 2 \mathrm{H}, \mathrm{NCH}_{2}\right), 2.28-2.21\left(\mathrm{~m}, 2 \mathrm{H}, \mathrm{CH}_{2}\right), 2.21-2.13\left(\mathrm{~m}, 2 \mathrm{H}, \mathrm{CH}_{2}\right), 2.10-2.02\left(\mathrm{~m}, 4 \mathrm{H}, 2 \times \mathrm{CH}_{2}\right)$, 2.02-1.93 (m, 4H, $\left.2 \times \mathrm{CH}_{2}\right), 1.84\left(\mathrm{~s}, 3 \mathrm{H}, \mathrm{CH}_{3}\right), 1.67\left(\mathrm{~s}, 3 \mathrm{H}, \mathrm{CH}_{3}\right), 1.62\left(\mathrm{~s}, 3 \mathrm{H}, \mathrm{CH}_{3}\right), 1.59\left(\mathrm{~s}, 6 \mathrm{H}, 2 \times \mathrm{CH}_{3}\right)$; ${ }^{13} \mathrm{C}\left\{{ }^{1} \mathrm{H}\right\} \mathrm{NMR}\left(150 \mathrm{MHz}, \mathrm{CDCl}_{3}\right): \delta 162.1(\mathrm{C}, \mathrm{C}-6), 152.5(\mathrm{CH}, \mathrm{C}-2), 148.4(\mathrm{CH}, \mathrm{C}-8), 144.1(\mathrm{C}=), 143.2$ (C, C-4), $136.9(\mathrm{C}=), 135.4(\mathrm{C}=), 131.3(\mathrm{C}=), 124.4(\mathrm{CH}=), 124.1(\mathrm{CH}=), 122.9(\mathrm{CH}=), 122.5(\mathrm{C}, \mathrm{C}-5)$, $117.9(\mathrm{CH}=), 45.2\left(\mathrm{NCH}_{2}\right), 39.9\left(\mathrm{CH}_{2}\right), 39.8\left(\mathrm{CH}_{2}\right), 32.5\left(\mathrm{CH}_{2}\right), 26.9\left(\mathrm{CH}_{2}\right), 26.7\left(\mathrm{CH}_{2}\right), 26.3\left(\mathrm{CH}_{2}\right), 25.8$ $\left(\mathrm{CH}_{3}\right), 23.6\left(\mathrm{CH}_{3}\right), 17.8\left(\mathrm{CH}_{3}\right), 16.18\left(\mathrm{CH}_{3}\right), 16.16\left(\mathrm{CH}_{3}\right)$; IR (film from $\left.\mathrm{CH}_{2} \mathrm{Cl}_{2}\right)$ : $v_{\max }$ 3055, 2973, 2932, $733 \mathrm{~cm}^{-1}$; HRESIMS m/z: [M + H] ${ }^{+}$Calcd. for $\mathrm{C}_{25} \mathrm{H}_{36} \mathrm{ClN}_{4} 427.2623$; Found $427.2634(\Delta=2.6 \mathrm{ppm})$; HRESIMS/MS (40 eV) m/z (\%): 157.0086 (32), 155.0118 (100), 121.10185 (10), 119.03516 (16), 109.1013 (11), 107.0858 (15). 


\subsubsection{3,7-Bis((E)-3,7-dimethylocta-2,6-dien-1-yl)-3,7-dihydro-1H-purine-2,6-dione (27)}

Xanthine (2.1 mmol, $311.5 \mathrm{mg}), \mathrm{K}_{2} \mathrm{CO}_{3}(2.0 \mathrm{mmol}, 272.2 \mathrm{mg})$ and geranyl bromide (2.4 mmol, $521 \mathrm{mg}$ ) in DMF (3 mL) for $48 \mathrm{~h}$ yielded 27, with modified work up-concentrating under reduced pressure, $44.6 \mathrm{mg}(9 \%)$, colourless oil. $\mathrm{R}_{f}=0.15(1: 2 \mathrm{EA} / \mathrm{PE}) ;{ }^{1} \mathrm{H}$ NMR $\left(600 \mathrm{MHz}, \mathrm{CDCl}_{3}\right): \delta 8.10(\mathrm{br}$ $\mathrm{s}, 1 \mathrm{H}, \mathrm{NH}), 7.55(\mathrm{~s}, J=2.8 \mathrm{~Hz}, 1 \mathrm{H}, \mathrm{H}-8), 5.43(\mathrm{t}, J=6.7 \mathrm{~Hz}, 1 \mathrm{H}, \mathrm{CH}=), 5.34(\mathrm{t}, J=6.4 \mathrm{~Hz}, 1 \mathrm{H}, \mathrm{CH}=)$, $5.07-5.01(\mathrm{~m}, 2 \mathrm{H}, 2 \times \mathrm{CH}=), 4.89\left(\mathrm{~d}, J=7.3 \mathrm{~Hz}, 2 \mathrm{H}, \mathrm{NCH}_{2}\right), 4.66\left(\mathrm{~d}, J=6.9 \mathrm{~Hz}, 2 \mathrm{H}, \mathrm{NCH}_{2}\right), 2.15-2.09(\mathrm{~m}$, $\left.4 \mathrm{H}, 2 \times \mathrm{CH}_{2}\right), 2.09-2.03\left(\mathrm{~m}, 2 \mathrm{H}, \mathrm{CH}_{2}\right), 2.02-1.96\left(\mathrm{~m}, 2 \mathrm{H}, \mathrm{CH}_{2}\right), 1.84\left(\mathrm{~s}, 3 \mathrm{H}, \mathrm{CH}_{3}\right), 1.77\left(\mathrm{~s}, 3 \mathrm{H}, \mathrm{CH}_{3}\right), 1.68$ $\left(\mathrm{s}, 3 \mathrm{H}, \mathrm{CH}_{3}\right), 1.63\left(\mathrm{~s}, 3 \mathrm{H}, \mathrm{CH}_{3}\right), 1.59\left(\mathrm{~s}, 3 \mathrm{H}, \mathrm{CH}_{3}\right), 1.56\left(\mathrm{~s}, 3 \mathrm{H}, \mathrm{CH}_{3}\right) ;{ }^{13} \mathrm{C}\left\{{ }^{1} \mathrm{H}\right\} \mathrm{NMR}\left(150 \mathrm{MHz}, \mathrm{CDCl}_{3}\right): \delta$ 154.7 (C, C-6), 150.62 (C, C-2 or C-4), 150.58 (C, C-2 or C-4), 143.8 (C=), 140.8 (CH=), 140.7 (CH, C-8), $132.4(\mathrm{C}=), 131.8(\mathrm{C}=), 124.0(\mathrm{CH}=), 123.6(\mathrm{CH}=), 118.0(\mathrm{CH}=), 117.2(\mathrm{CH}=), 107.5(\mathrm{C}, \mathrm{C}-5), 44.7\left(\mathrm{NCH}_{2}\right)$, $40.9\left(\mathrm{NCH}_{2}\right), 39.7\left(\mathrm{CH}_{2}\right), 39.6\left(\mathrm{CH}_{2}\right), 26.5\left(\mathrm{CH}_{2}\right), 26.3\left(\mathrm{CH}_{2}\right), 25.84\left(\mathrm{CH}_{3}\right), 25.80\left(\mathrm{CH}_{3}\right), 17.9\left(\mathrm{CH}_{3}\right), 17.8$ $\left(\mathrm{CH}_{3}\right), 16.7\left(\mathrm{CH}_{3}\right), 16.6\left(\mathrm{CH}_{3}\right)$; IR (film from $\left.\mathrm{CH}_{2} \mathrm{Cl}_{2}\right): v_{\max } 3423,3176,3115,3052,2967,2926,1679$ $\mathrm{cm}^{-1}$; HRESIMS m/z: $[\mathrm{M}+\mathrm{H}]^{+}$Calcd. for $\mathrm{C}_{25} \mathrm{H}_{37} \mathrm{~N}_{4} \mathrm{O}_{2}$ 425.2911; Found 425.2910 ( $\Delta=-0.2 \mathrm{ppm}$ ); HRESIMS/MS (10 eV) m/z (\%): 289.1638 (70), 153.0395 (100).

\subsubsection{3,7-Bis((6E)-3,7,11-trimethyldodeca-2,6,10-trien-1-yl)-3,7-dihydro-1H-purine-2,6-dione (28)}

Xanthine (2.0 mmol, $306.3 \mathrm{mg}), \mathrm{K}_{2} \mathrm{CO}_{3}(3.0 \mathrm{mmol}, 420.3 \mathrm{mg})$ and farnesyl bromide (2.4 mmol, $683.4 \mathrm{mg}$ ) in DMF (3 mL) for $25 \mathrm{~h}$ yielded $28,19.3 \mathrm{mg}(3 \%)$, colourless oil. $\mathrm{R}_{f}=0.25$ (1:2 EA/PE); 3:2 E/Z, NMR data for major isomer: ${ }^{1} \mathrm{H}$ NMR $\left(600 \mathrm{MHz} \mathrm{CDCl}_{3}\right): \delta 8.57(\mathrm{br} \mathrm{s}, 1 \mathrm{H}, \mathrm{NH}), 7.54(\mathrm{~s}, 1 \mathrm{H}, \mathrm{H}-8), 5.43$ $(\mathrm{t}, J=6.6 \mathrm{~Hz}, 1 \mathrm{H}, \mathrm{CH}=), 5.34(\mathrm{t}, J=6.8 \mathrm{~Hz}, 1 \mathrm{H}, \mathrm{CH}=), 5.12-5.02(\mathrm{~m}, 4 \mathrm{H}, 4 \times \mathrm{CH}=), 4.89(\mathrm{~d}, J=7.2 \mathrm{~Hz}$, $\left.2 \mathrm{H}, \mathrm{NCH}_{2}\right), 4.66\left(\mathrm{~d}, J=6.9 \mathrm{~Hz}, 2 \mathrm{H}, \mathrm{NCH}_{2}\right), 2.16-1.89\left(\mathrm{~m}, 16 \mathrm{H}, 8 \times \mathrm{CH}_{2}\right), 1.85\left(\mathrm{~s}, 3 \mathrm{H}, \mathrm{CH}_{3}\right), 1.78(\mathrm{~s}, 3 \mathrm{H}$, $\left.\left.\mathrm{CH}_{3}\right), 1.66\left(\mathrm{~s}, 6 \mathrm{H}, 2 \times \mathrm{CH}_{3}\right), 1.58\left(\mathrm{~s}, 9 \mathrm{H}, 3 \times \mathrm{CH}_{3}\right), 1.55\left(\mathrm{~s}, 3 \mathrm{H}, \mathrm{CH}_{3}\right) ;{ }^{12} \mathrm{C}^{1}{ }^{1} \mathrm{H}\right\} \mathrm{NMR}\left(150 \mathrm{MHz}, \mathrm{CDCl}_{3}\right)$ : $\delta 154.9$ (C, C-6), 150.7 (C, C-2 or C-4), 150.6 (C, C-2 or C-4), 143.8 (C=), $141.1(\mathrm{C}=), 140.8$ (CH, C-8), $136.0(\mathrm{C}=), 135.4(\mathrm{C}=), 131.5(\mathrm{C}=), 131.4(\mathrm{C}=), 124.4(\mathrm{CH}=), 124.3(\mathrm{CH}=), 123.9(\mathrm{CH}=), 123.4(\mathrm{CH}=)$, $118.0(\mathrm{CH}=), 117.2(\mathrm{CH}=), 107.5(\mathrm{C}, \mathrm{C}-5), 44.7\left(\mathrm{NCH}_{2}\right), 40.8\left(\mathrm{NCH}_{2}\right), 39.79\left(\mathrm{CH}_{2}\right), 39.78\left(\mathrm{CH}_{2}\right), 39.7$ $\left(\mathrm{CH}_{2}\right), 39.6\left(\mathrm{CH}_{2}\right), 26.81\left(\mathrm{CH}_{2}\right), 26.78\left(\mathrm{CH}_{2}\right), 26.4\left(\mathrm{CH}_{2}\right), 26.3\left(\mathrm{CH}_{2}\right), 25.84\left(\mathrm{CH}_{3}\right), 25.83\left(\mathrm{CH}_{3}\right), 17.82$ $\left(\mathrm{CH}_{3}\right), 17.81\left(\mathrm{CH}_{3}\right), 16.74\left(\mathrm{CH}_{3}\right), 16.67\left(\mathrm{CH}_{3}\right), 16.2\left(\mathrm{CH}_{3}\right), 16.1\left(\mathrm{CH}_{3}\right)$; IR (film from $\left.\mathrm{CH}_{2} \mathrm{Cl}_{2}\right): v_{\max } 3166$, 3065, 2964, 2927, 2856, $1686 \mathrm{~cm}^{-1}$; HRESIMS $\mathrm{m} / z$ : $[\mathrm{M}+\mathrm{H}]^{+}$Calcd. for $\mathrm{C}_{35} \mathrm{H}_{53} \mathrm{~N}_{4} \mathrm{O}_{2}$ 561.4163; Found 561.4169 ( $\Delta=1.1$ ppm); HRESIMS/MS (20 eV) m/z (\%): 561.1128 (39), 357.2262 (48), 153.0391 (100).

\subsubsection{2. (E)-7-(3,7-Dimethylocta-2,6-dien-1-yl)-3-methyl-3,7-dihydro-1H-purine-2,6-dione (29)}

3-Methylxanthine $(0.17 \mathrm{mmol}, 28.0 \mathrm{mg}), \mathrm{K}_{2} \mathrm{CO}_{3} / \mathrm{Na}_{2} \mathrm{CO}_{3}(1: 1,48.6 \mathrm{mg})$ and geranyl bromide $(0.36 \mathrm{mmol}, 77 \mathrm{mg})$ in DMF $(2 \mathrm{~mL})$ at $50^{\circ} \mathrm{C}$ for $48 \mathrm{~h}$ yielded 29 , with modified work up-the concentrated reaction was filtered from $\mathrm{DCM}$, and additionally recrystallised from PE after chromatography, 16.9 $\mathrm{mg}(5 \%)$, white powder. $\mathrm{R}_{f}=0.2(1: 2 \mathrm{EA} / \mathrm{PE}) ;{ }^{1} \mathrm{H} \mathrm{NMR}\left(600 \mathrm{MHz}, \mathrm{CDCl}_{3}\right): \delta 8.10(\mathrm{~s}, 1 \mathrm{H}, \mathrm{NH}), 7.55$ (s, $1 \mathrm{H}, \mathrm{H}-8), 5.43(\mathrm{t}, J=7.3 \mathrm{~Hz}, 1 \mathrm{H}, \mathrm{CH}=), 5.07-5.03(\mathrm{~m}, 1 \mathrm{H}, \mathrm{CH}=), 4.90\left(\mathrm{~d}, J=7.3 \mathrm{~Hz}, 2 \mathrm{H}, \mathrm{NCH}_{2}\right)$, $3.55\left(\mathrm{~s}, 3 \mathrm{H}, \mathrm{NCH}_{3}\right), 2.16-2.08\left(\mathrm{~m}, 4 \mathrm{H}, 2 \times \mathrm{CH}_{2}\right), 1.78\left(\mathrm{~s}, 3 \mathrm{H}, \mathrm{CH}_{3}\right), 1.68\left(\mathrm{~s}, 3 \mathrm{H}, \mathrm{CH}_{3}\right), 1.59\left(\mathrm{~s}, 3 \mathrm{H}, \mathrm{CH}_{3}\right)$; ${ }^{13} \mathrm{C}\left\{{ }^{1} \mathrm{H}\right\}$ NMR $\left(150 \mathrm{MHz}, \mathrm{CDCl}_{3}\right): \delta 154.5$ (C, C-6), 150.99 (C, C-2), 150.96 (C, C-4), 143.9 (C=), 140.8 (CH, C-8), $132.4(\mathrm{C}=), 123.5(\mathrm{CH}=), 117.1(\mathrm{CH}=), 107.4(\mathrm{C}, \mathrm{C}-5), 44.8\left(\mathrm{NCH}_{2}\right), 39.6\left(\mathrm{CH}_{2}\right), 29.2\left(\mathrm{NCH}_{3}\right)$, $26.2\left(\mathrm{CH}_{2}\right), 25.9\left(\mathrm{CH}_{3}\right), 17.9\left(\mathrm{CH}_{3}\right), 16.6\left(\mathrm{CH}_{3}\right)$; IR (film from $\left.\mathrm{CH}_{2} \mathrm{Cl}_{2}\right): v_{\max } 3121,3021,2964,2916,2826$, $1678 \mathrm{~cm}^{-1}$; HRESIMS m/z: $[\mathrm{M}+\mathrm{H}]^{+}$Calcd. for $\mathrm{C}_{16} \mathrm{H}_{23} \mathrm{~N}_{4} \mathrm{O}_{2}$ 303.1816; Found 303.1812 ( $\Delta=-1.3 \mathrm{ppm}$ ); HRESIMS/MS (40 eV) m/z (\%): 167.0538 (100), 149.0431 (8), 124.0487 (17).

3.2.13. 3-Methyl-7-((2Z,6E)-3,7,11-trimethyldodeca-2,6,10-trien-1-yl)-3,7-dihydro-1H-purine-2,6-dione (30) and 3-methyl-7-((2E,6E)-3,7,11-trimethyldodeca-2,6,10-trien-1-yl)-3,7-dihydro- $1 \mathrm{H}$ purine-2,6-dione (31)

3-Methylxanthine $(0.20 \mathrm{mmol}, 32.9 \mathrm{mg}), \mathrm{K}_{2} \mathrm{CO}_{3}(0.37 \mathrm{mmol}, 51.2 \mathrm{mg})$ and farnesyl bromide (0.34 mmol, $98 \mathrm{mg})$ in DMF $(2 \mathrm{~mL})$ for $21 \mathrm{~h}$ yielded 30 and 31 .

Compound 30: $4.6 \mathrm{mg}(8 \%)$, white solid; $\mathrm{R}_{f}=0.20(1: 1 \mathrm{EA} / \mathrm{PE}) ;{ }^{1} \mathrm{H} \mathrm{NMR}\left(600 \mathrm{MHz}, \mathrm{CDCl}_{3}\right): \delta$ $8.10(\mathrm{~s}, 1 \mathrm{H}, \mathrm{NH}), 7.55(\mathrm{~s}, 1 \mathrm{H}, \mathrm{H}-8), 5.44(\mathrm{t}, J=6.9 \mathrm{~Hz}, 1 \mathrm{H}, \mathrm{CH}=), 5.11-5.05(\mathrm{~m}, 2 \mathrm{H}, 2 \times \mathrm{CH}=), 4.88(\mathrm{~d}$, 
$\left.J=7.4 \mathrm{~Hz}, 2 \mathrm{H}, \mathrm{NCH}_{2}\right), 3.54\left(\mathrm{~s}, 3 \mathrm{H}, \mathrm{NCH}_{3}\right), 2.23-2.17\left(\mathrm{~m}, 2 \mathrm{H}, \mathrm{CH}_{2}\right), 2.15-2.10\left(\mathrm{~m}, 2 \mathrm{H}, \mathrm{CH}_{2}\right), 2.07-2.01$ $\left(\mathrm{m}, 2 \mathrm{H}, \mathrm{CH}_{2}\right), 1.99-1.93\left(\mathrm{~m}, 2 \mathrm{H}, \mathrm{CH}_{2}\right), 1.81\left(\mathrm{~s}, 3 \mathrm{H}, \mathrm{CH}_{3}\right), 1.67\left(\mathrm{~s}, 3 \mathrm{H}, \mathrm{CH}_{3}\right), 1.60\left(\mathrm{~s}, 3 \mathrm{H}, \mathrm{CH}_{3}\right), 1.59(\mathrm{~s}, 3 \mathrm{H}$, $\left.\mathrm{CH}_{3}\right) ;{ }^{13} \mathrm{C}\left\{{ }^{1} \mathrm{H}\right\} \mathrm{NMR}\left(150 \mathrm{MHz}, \mathrm{CDCl}_{3}\right): \delta 154.5$ (C, C-6), 151.0 (C, C-2), 150.9 (C, C-4), 143.7 (C=), 140.8 $(\mathrm{CH}, \mathrm{C}-8), 136.5(\mathrm{C}=), 131.6(\mathrm{C}=), 124.3(\mathrm{CH}=), 123.1(\mathrm{CH}=), 118.0(\mathrm{CH}=), 107.4(\mathrm{C}, \mathrm{C}-5), 44.6\left(\mathrm{NCH}_{2}\right)$, 39.8 $\left(\mathrm{CH}_{2}\right), 32.2\left(\mathrm{CH}_{2}\right), 29.2\left(\mathrm{NCH}_{3}\right), 26.7\left(\mathrm{CH}_{2}\right), 26.4\left(\mathrm{CH}_{2}\right), 25.9\left(\mathrm{CH}_{3}\right), 23.6\left(\mathrm{CH}_{3}\right), 17.8\left(\mathrm{CH}_{3}\right), 16.2$ $\left(\mathrm{CH}_{3}\right)$; IR (film from $\left.\mathrm{CH}_{2} \mathrm{Cl}_{2}\right): v_{\max } 3400,3162,3035,2969,2930,1683 \mathrm{~cm}^{-1}$; HRESIMS m/z: $[\mathrm{M}+\mathrm{H}]^{+}$ Calcd. for $\mathrm{C}_{21} \mathrm{H}_{31} \mathrm{~N}_{4} \mathrm{O}_{2}$ 371.2442; Found 371.2452 ( $\Delta=2.7$ ppm).

Compound 31: $33.1 \mathrm{mg}(45 \%)$, white solid; $\mathrm{R}_{f}=0.18$ (1:1, EA/PE); 2:1 E/Z, NMR data for major isomer: ${ }^{1} \mathrm{H}$ NMR $\left(600 \mathrm{MHz}, \mathrm{CDCl}_{3}\right): \delta 8.89(\mathrm{~s}, 1 \mathrm{H}, \mathrm{NH}), 7.56(\mathrm{~s}, 1 \mathrm{H}, \mathrm{H}-8), 5.42(\mathrm{t}, J=7.3 \mathrm{~Hz}, 1 \mathrm{H}, \mathrm{CH}=)$, $5.08-5.04(\mathrm{~m}, 2 \mathrm{H}, 2 \times \mathrm{CH}=), 4.90\left(\mathrm{~d}, J=7.3 \mathrm{~Hz}, 2 \mathrm{H}, \mathrm{NCH}_{2}\right), 3.54\left(\mathrm{~s}, 3 \mathrm{H}, \mathrm{NCH}_{3}\right), 2.16-2.07(\mathrm{~m}, 4 \mathrm{H}, 2 \times$ $\left.\mathrm{CH}_{2}\right), 2.06-1.99\left(\mathrm{~m}, 2 \mathrm{H}, \mathrm{CH}_{2}\right), 1.98-1.93\left(\mathrm{~m}, 2 \mathrm{H}, \mathrm{CH}_{2}\right), 1.78\left(\mathrm{~s}, 3 \mathrm{H}, \mathrm{CH}_{3}\right), 1.66\left(\mathrm{~s}, 3 \mathrm{H}, \mathrm{CH}_{3}\right), 1.58(\mathrm{~s}, 6 \mathrm{H}, 2$ $\left.\times \mathrm{CH}_{3}\right) ;{ }^{13} \mathrm{C}\left\{{ }^{1} \mathrm{H}\right\} \mathrm{NMR}\left(150 \mathrm{MHz}, \mathrm{CDCl}_{3}\right): \delta 154.9(\mathrm{C}, \mathrm{C}-6), 151.3(\mathrm{C}, \mathrm{C}-2), 150.9(\mathrm{C}, \mathrm{C}-4), 143.9$ (C=), $140.8(\mathrm{CH}, \mathrm{C}-8), 136.0(\mathrm{C}=), 131.5(\mathrm{C}=), 124.3(\mathrm{CH}=), 123.4(\mathrm{CH}=), 117.1(\mathrm{CH}=), 107.5(\mathrm{C}, \mathrm{C}-5), 44.7$ $\left(\mathrm{NCH}_{2}\right), 39.8\left(\mathrm{CH}_{2}\right), 39.6\left(\mathrm{CH}_{2}\right), 29.2\left(\mathrm{NCH}_{3}\right), 26.8\left(\mathrm{CH}_{2}\right), 26.2\left(\mathrm{CH}_{2}\right), 25.8\left(\mathrm{CH}_{3}\right), 17.8\left(\mathrm{CH}_{3}\right), 16.7\left(\mathrm{CH}_{3}\right)$, $16.2\left(\mathrm{CH}_{3}\right)$; HRESIMS $\mathrm{m} / z$ : $[\mathrm{M}+\mathrm{H}]^{+}$Calcd. for $\mathrm{C}_{21} \mathrm{H}_{31} \mathrm{~N}_{4} \mathrm{O}_{2}$ 371.2442; Found $371.2445(\Delta=0.8 \mathrm{ppm})$; HRESIMS/MS (40 eV) m/z (\%): 167.0552 (100), 124.0506 (87).

3.2.14. 3-Methyl-7-((2Z,6E,10E)-3,7,11,15-tetramethylhexadeca-2,6,10,14-tetraen-1-yl)-3, 7-dihydro-1H-purine-2,6-dione (32) and 3-methyl-7-((2E,6E,10E)-3,7,11,15-tetramethylhexadeca2,6,10,14-tetraen-1-yl)-3,7-dihydro-1H-purine-2,6-dione (33)

3-Methylxanthine $(0.35 \mathrm{mmol}, 40.9 \mathrm{mg}), \mathrm{K}_{2} \mathrm{CO}_{3}(0.38 \mathrm{mmol}, 52.5 \mathrm{mg})$ and geranylgeranyl bromide $(0.37 \mathrm{mmol}, 130 \mathrm{mg})$ in DMF $(1 \mathrm{~mL})$ for $44 \mathrm{~h}$ yielded 32 and 33.

Compound 32: $10.5 \mathrm{mg}(26 \%)$, white, waxy solid; $\mathrm{R}_{f}=0.20(1: 1, \mathrm{EA} / \mathrm{PE}) ;{ }^{1} \mathrm{H}$ NMR $(600 \mathrm{MHz}$, $\left.\mathrm{CDCl}_{3}\right): \delta 8.45(\mathrm{~s}, 1 \mathrm{H}, \mathrm{NH}), 7.55(\mathrm{~s}, 1 \mathrm{H}, \mathrm{H}-8), 5.44(\mathrm{t}, J=7.1 \mathrm{~Hz}, 1 \mathrm{H}, \mathrm{CH}=), 5.12-5.05(\mathrm{~m}, 3 \mathrm{H}, 3 \times \mathrm{CH}=)$, $4.88\left(\mathrm{~d}, J=7.2 \mathrm{~Hz}, 2 \mathrm{H}, \mathrm{NCH}_{2}\right), 3.54\left(\mathrm{~s}, 3 \mathrm{H}, \mathrm{NCH}_{3}\right), 2.23-2.18\left(\mathrm{~m}, 2 \mathrm{H}, \mathrm{CH}_{2}\right), 2.15-2.09\left(\mathrm{~m}, 2 \mathrm{H}, \mathrm{CH}_{2}\right)$, 2.08-2.01 (m, 4H, $\left.2 \times \mathrm{CH}_{2}\right), 2.00-1.93\left(\mathrm{~m}, 4 \mathrm{H}, 2 \times \mathrm{CH}_{2}\right), 1.80\left(\mathrm{~s}, 3 \mathrm{H}, \mathrm{CH}_{3}\right), 1.67\left(\mathrm{~s}, 3 \mathrm{H}, \mathrm{CH}_{3}\right), 1.60(\mathrm{~s}, 3 \mathrm{H}$, $\left.\mathrm{CH}_{3}\right), 1.59\left(\mathrm{~s}, 6 \mathrm{H}, 2 \times \mathrm{CH}_{3}\right) ;{ }^{13} \mathrm{C}\left\{{ }^{1} \mathrm{H}\right\}$ NMR $\left(150 \mathrm{MHz}, \mathrm{CDCl}_{3}\right): \delta 154.6(\mathrm{C}, \mathrm{C}-6), 151.1(\mathrm{C}, \mathrm{C}-2), 150.9(\mathrm{C}$, C-4), $143.7(\mathrm{C}=), 140.8(\mathrm{CH}, \mathrm{C}-8), 136.5(\mathrm{C}=), 135.3(\mathrm{C}=), 131.4(\mathrm{C}=), 124.5(\mathrm{CH}=), 124.1(\mathrm{CH}=), 123.1$ $(\mathrm{CH}=), 118.0(\mathrm{CH}=), 107.4(\mathrm{C}, \mathrm{C}-5), 44.6\left(\mathrm{NCH}_{2}\right), 39.9\left(\mathrm{CH}_{2}\right), 39.8\left(\mathrm{CH}_{2}\right), 32.3\left(\mathrm{CH}_{2}\right), 29.2\left(\mathrm{NCH}_{3}\right), 26.9$ $\left(\mathrm{CH}_{2}\right), 26.7\left(\mathrm{CH}_{2}\right), 26.5\left(\mathrm{CH}_{2}\right), 25.8\left(\mathrm{CH}_{3}\right), 23.6\left(\mathrm{CH}_{3}\right), 17.8\left(\mathrm{CH}_{3}\right), 16.20\left(\mathrm{CH}_{3}\right), 16.15\left(\mathrm{CH}_{3}\right)$; IR (film from $\left.\mathrm{CH}_{2} \mathrm{Cl}_{2}\right): v_{\max } 3458,3159,2968,2924,2852 \mathrm{~cm}^{-1}$; HRESIMS m/z: $[\mathrm{M}+\mathrm{H}]^{+}$Calcd. for $\mathrm{C}_{26} \mathrm{H}_{39} \mathrm{~N}_{4} \mathrm{O}_{2}$ 439.3068; Found 439.3036 ( $\Delta=-7.2 \mathrm{ppm}$ ); HRESIMS/MS (40 eV) m/z (\%): 168.0565 (9), 167.0533 (100), 124.0494 (43).

Compound 33: $22.1 \mathrm{mg}(18 \%)$, white waxy solid; $\mathrm{R}_{f}=0.12(1: 1 \mathrm{EA} / \mathrm{PE}) ;{ }^{1} \mathrm{H}$ NMR $(500 \mathrm{MHz}$, $\left.\mathrm{CDCl}_{3}\right): \delta 8.94(\mathrm{~s}, 1 \mathrm{H}, \mathrm{NH}), 7.56(\mathrm{~s}, 1 \mathrm{H}, \mathrm{H}-8), 5.43(\mathrm{t}, J=7.3 \mathrm{~Hz}, 1 \mathrm{H}, \mathrm{CH}=), 5.12-5.04(\mathrm{~m}, 3 \mathrm{H}, 3 \times \mathrm{CH}=)$, $4.90\left(\mathrm{~d}, J=7.3 \mathrm{~Hz}, 2 \mathrm{H}, \mathrm{NCH}_{2}\right), 3.54\left(\mathrm{~s}, 3 \mathrm{H}, \mathrm{NCH}_{3}\right), 2.16-2.08\left(\mathrm{~m}, 4 \mathrm{H}, 2 \times \mathrm{CH}_{2}\right), 2.07-2.00(\mathrm{~m}, 4 \mathrm{H}, 2 \times$ $\left.\left.\mathrm{CH}_{2}\right), 2.00-1.93\left(\mathrm{~m}, 4 \mathrm{H}, 2 \times \mathrm{CH}_{2}\right), 1.78\left(\mathrm{~s}, 3 \mathrm{H}, \mathrm{CH}_{3}\right), 1.66\left(\mathrm{~s}, 3 \mathrm{H}, \mathrm{CH}_{3}\right), 1.59\left(\mathrm{~s}, 9 \mathrm{H}, 3 \times \mathrm{CH}_{3}\right) ;{ }^{13} \mathrm{C}^{1}{ }^{1} \mathrm{H}\right\}$ NMR (150 MHz, CDCl 3 ): $\delta 154.9$ (C, C-6), 151.3 (C-2), 150.9 (C-4), 143.9 (C=), 140.8 (CH, C-8), 136.0 $(\mathrm{C}=), 135.2(\mathrm{C}=), 131.41(\mathrm{C}=), 124.5(\mathrm{CH}=), 124.2(\mathrm{CH}=), 123.4(\mathrm{CH}=), 117.1(\mathrm{CH}=), 107.5(\mathrm{C}, \mathrm{C}-5), 44.8$ $\left(\mathrm{NCH}_{2}\right), 39.84\left(\mathrm{CH}_{2}\right), 39.79\left(\mathrm{CH}_{2}\right), 39.6\left(\mathrm{CH}_{2}\right), 29.2\left(\mathrm{NCH}_{3}\right), 26.9\left(\mathrm{CH}_{2}\right), 26.7\left(\mathrm{CH}_{2}\right), 26.3\left(\mathrm{CH}_{2}\right), 25.8$ $\left(\mathrm{CH}_{3}\right), 17.8\left(\mathrm{CH}_{3}\right), 16.7\left(\mathrm{CH}_{3}\right), 16.2\left(\mathrm{CH}_{3}\right), 16.1\left(\mathrm{CH}_{3}\right)$; IR (film from $\left.\mathrm{CH}_{2} \mathrm{Cl}_{2}\right): v_{\max } 3158,3121,3029$, 2965, 2924, 2834, 1713, $1679 \mathrm{~cm}^{-1}$; HRESIMS $\mathrm{m} / z$ : $[\mathrm{M}+\mathrm{H}]^{+}$Calcd. for $\mathrm{C}_{26} \mathrm{H}_{39} \mathrm{~N}_{4} \mathrm{O}_{2}$ 439.3068; Found 439.3035 ( $\Delta=-7.5$ ppm); HRESIMS/MS (40 eV) m/z (\%): 168.0459 (9), 167.0437 (100), 124.0412 (39).

\subsubsection{5. (E)-7-(3,7-Dimethylocta-2,6-dien-1-yl)-1,3-dimethyl-3,7-dihydro-1H-purine-2,6-dione (34)}

Theophylline hydrate (2.0 mmol, $391.3 \mathrm{mg}), \mathrm{K}_{2} \mathrm{CO}_{3} / \mathrm{Na}_{2} \mathrm{CO}_{3}(1: 1,244 \mathrm{mg})$ and geranyl bromide $(4.0 \mathrm{mmol}, 869 \mathrm{mg})$ in DMF ( $3 \mathrm{~mL}$ ) for $3 \mathrm{~h}$ yielded 34 , with modified work up and modified purification $-\mathrm{H}_{2} \mathrm{O}(9 \mathrm{~mL})$ was added to the reaction and the resulting precipitate was isolated and recrystallised from PE, $277.5 \mathrm{mg}(45 \%)$, white crystals. ${ }^{1} \mathrm{H} \mathrm{NMR}\left(600 \mathrm{MHz}, \mathrm{CDCl}_{3}\right): \delta 7.53(\mathrm{~s}, 1 \mathrm{H}, \mathrm{H}-8)$, $5.43(\mathrm{t}, J=7.6 \mathrm{~Hz}, 1 \mathrm{H}, \mathrm{CH}=), 5.05(\mathrm{t}, J=6.2 \mathrm{~Hz}, 1 \mathrm{H}, \mathrm{CH}=), 4.93\left(\mathrm{~d}, J=7.3 \mathrm{~Hz}, 2 \mathrm{H}, \mathrm{NCH}_{2}\right), 3.59(\mathrm{~s}, 3 \mathrm{H}$, 
$\left.\mathrm{N}(3) \mathrm{CH}_{3}\right), 3.42\left(\mathrm{~s}, 3 \mathrm{H}, \mathrm{N}(1) \mathrm{CH}_{3}\right), 2.15-2.07\left(\mathrm{~m}, 4 \mathrm{H}, 2 \times \mathrm{CH}_{2}\right), 1.78\left(\mathrm{~s}, 3 \mathrm{H}, \mathrm{CH}_{3}\right), 1.68\left(\mathrm{~s}, 3 \mathrm{H}, \mathrm{CH}_{3}\right), 1.59$ $\left(\mathrm{s}, 3 \mathrm{H}, \mathrm{CH}_{3}\right) ;{ }^{13} \mathrm{C}\left\{{ }^{1} \mathrm{H}\right\}$ NMR $\left(150 \mathrm{MHz}, \mathrm{CDCl}_{3}\right): \delta 155.5(\mathrm{C}, \mathrm{C}-6), 151.9(\mathrm{C}, \mathrm{C}-2), 149.0(\mathrm{C}, \mathrm{C}-4), 143.5$ $(\mathrm{C}=), 140.3(\mathrm{CH}, \mathrm{C}-8), 132.4(\mathrm{C}=), 123.6(\mathrm{CH}=), 117.5(\mathrm{CH}=), 107.2(\mathrm{C}, \mathrm{C}-5), 44.7\left(\mathrm{NCH}_{2}\right), 39.6\left(\mathrm{CH}_{2}\right)$, $29.9\left(\mathrm{~N}(3) \mathrm{CH}_{3}\right), 28.1\left(\mathrm{~N}(1) \mathrm{CH}_{3}\right), 26.3\left(\mathrm{CH}_{2}\right), 25.9\left(\mathrm{CH}_{3}\right), 17.9\left(\mathrm{CH}_{3}\right), 16.6\left(\mathrm{CH}_{3}\right) ; \mathrm{IR}$ (neat): $v_{\max } 3098$, 2964, 2926, 2855, 1695, $1645 \mathrm{~cm}^{-1}$; HRESIMS $\mathrm{m} / z$ : $[\mathrm{M}+\mathrm{H}]^{+}$Calcd. for $\mathrm{C}_{17} \mathrm{H}_{25} \mathrm{~N}_{4} \mathrm{O}_{2}$ 317.1972; Found 317.1978 ( $\Delta=1.9$ ppm); HRESIMS/MS (40 eV) m/z (\%): 181.0714 (52), 124.0511 (100).

3.2.16. 1,3-Dimethyl-7-((2E,6E)-3,7,11-trimethyldodeca-2,6,10-trien-1-yl)-3,7-dihydro-1Hpurine-2,6-dione (35)

Theophylline hydrate $(1.85 \mathrm{mmol}, 370 \mathrm{mg}), \mathrm{K}_{2} \mathrm{CO}_{3} / \mathrm{Na}_{2} \mathrm{CO}_{3}(1: 1,170 \mathrm{mg})$ and farnesyl bromide (2.0 mmol, $570.5 \mathrm{mg})$. in DMF $(2 \mathrm{~mL})$ at $80^{\circ} \mathrm{C}$ for $5 \mathrm{~h}$ yielded 35 , after modified work up and modified purification as per $34,333.1 \mathrm{mg}(72 \%)$, white crystals. ${ }^{1} \mathrm{H}$ NMR $\left(600 \mathrm{MHz}, \mathrm{CDCl}_{3}\right): \delta 7.53(\mathrm{~s}, 1 \mathrm{H}, \mathrm{H}-8)$, $5.43(\mathrm{t}, J=7.3 \mathrm{~Hz}, 1 \mathrm{H}, \mathrm{CH}=), 5.09-5.05(\mathrm{~m}, 2 \mathrm{H}, 2 \times \mathrm{CH}=), 4.93\left(\mathrm{~d}, J=7.2 \mathrm{~Hz}, 2 \mathrm{H}, \mathrm{NCH}_{2}\right), 3.58(\mathrm{~s}, 3 \mathrm{H}$, $\left.\mathrm{N}(3) \mathrm{CH}_{3}\right), 3.41\left(\mathrm{~s}, 3 \mathrm{H}, \mathrm{N}(1) \mathrm{CH}_{3}\right), 2.16-2.07\left(\mathrm{~m}, 4 \mathrm{H}, 2 \times \mathrm{CH}_{2}\right), 2.03\left(\mathrm{~m}, 2 \mathrm{H}, \mathrm{CH}_{2}\right), 1.99-1.93(\mathrm{~m}, 2 \mathrm{H}$, $\left.\mathrm{CH}_{2}\right), 1.79\left(\mathrm{~s}, 3 \mathrm{H}, \mathrm{CH}_{3}\right), 1.67\left(\mathrm{~s}, 1 \mathrm{H}, \mathrm{CH}_{3}\right), 1.60\left(\mathrm{~s}, 3 \mathrm{H}, \mathrm{CH}_{3}\right), 1.59\left(\mathrm{~s}, 3 \mathrm{H}, \mathrm{CH}_{3}\right) ;{ }^{13} \mathrm{C}\left\{{ }^{1} \mathrm{H}\right\} \mathrm{NMR}(150$ $\left.\mathrm{MHz}, \mathrm{CDCl}_{3}\right): \delta 155.5$ (C, C-6), 151.9 (C, C-2), 149.0 (C, C-4), 143.5 (C=), $140.3(\mathrm{CH}, \mathrm{C}-8), 136.0(\mathrm{C}=)$, 131.6 $(\mathrm{C}=), 124.3(\mathrm{CH}=), 123.4(\mathrm{CH}=), 117.5(\mathrm{CH}=), 107.2(\mathrm{C}, \mathrm{C}-5), 44.7\left(\mathrm{NCH}_{2}\right), 39.8\left(\mathrm{CH}_{2}\right), 39.6\left(\mathrm{CH}_{2}\right)$, $29.9\left(\mathrm{~N}(3) \mathrm{CH}_{3}\right), 28.1\left(\mathrm{~N}(1) \mathrm{CH}_{3}\right), 26.8\left(\mathrm{CH}_{2}\right), 26.3\left(\mathrm{CH}_{2}\right), 25.9\left(\mathrm{CH}_{3}\right), 17.8\left(\mathrm{CH}_{3}\right), 16.7\left(\mathrm{CH}_{3}\right), 16.2\left(\mathrm{CH}_{3}\right)$; IR (film from $\mathrm{CH}_{2} \mathrm{Cl}_{2}$ ): $v_{\max }$ 3097, 2695, 2922, 1695, $1646 \mathrm{~cm}^{-1}$; HRESIMS $\mathrm{m} / z$ : $[\mathrm{M}+\mathrm{H}]^{+}$Calcd. for $\mathrm{C}_{22} \mathrm{H}_{33} \mathrm{~N}_{4} \mathrm{O}_{2}$ 385.2598; Found 385.2604 ( $\Delta=1.6$ ppm); HRESIMS/MS (40 eV) m/z (\%):181.0718 (100), 124.0506 (73).

3.2.17. 1,3-Dimethyl-7-((2Z,6E,10E)-3,7,11,15-tetramethylhexadeca-2,6,10,14-tetraen-1-yl)-3, 7-dihydro-1H-purine-2,6-dione (36) and 1,3-dimethyl-7-((2E,6E,10E)-3,7,11, 15-tetramethylhexadeca-2,6,10,14-tetraen-1-yl)-3,7-dihydro-1H-purine-2,6-dione (37)

Theophylline hydrate $(0.30 \mathrm{mmol}, 59.1 \mathrm{mg}), \mathrm{K}_{2} \mathrm{CO}_{3}(0.34 \mathrm{mmol}, 46.5 \mathrm{mg})$ and geranylgeranyl bromide $(0.32 \mathrm{mmol}, 111 \mathrm{mg})$ in DMF $(1 \mathrm{~mL})$ for $25 \mathrm{~h}$ yielded 36 and 37.

Compound 36: $13.1 \mathrm{mg}(36 \%)$, white solid; $\mathrm{R}_{\mathrm{f}}=0.16(1: 2 \mathrm{EA} / \mathrm{PE}) ;{ }^{1} \mathrm{H}$ NMR $\left(500 \mathrm{MHz}, \mathrm{CDCl}_{3}\right)$ : $\delta 7.52(\mathrm{~s}, 1 \mathrm{H}, \mathrm{H}-8), 5.44(\mathrm{t}, \mathrm{J}=7.1 \mathrm{~Hz}, 1 \mathrm{H}, \mathrm{CH}=), 5.15-5.01(\mathrm{~m}, 3 \mathrm{H}, 3 \times \mathrm{CH}=), 4.91(\mathrm{~d}, \mathrm{~J}=7.2 \mathrm{~Hz}, 2 \mathrm{H}$, $\left.\mathrm{NCH}_{2}\right), 3.58\left(\mathrm{~s}, 3 \mathrm{H}, \mathrm{N}(3) \mathrm{CH}_{3}\right), 3.41\left(\mathrm{~s}, 3 \mathrm{H}, \mathrm{N}(1) \mathrm{CH}_{3}\right), 2.24-2.19\left(\mathrm{~m}, 2 \mathrm{H}, \mathrm{CH}_{2}\right), 2.15-2.10\left(\mathrm{~m}, 2 \mathrm{H}, \mathrm{CH}_{2}\right)$, 2.08-2.02 (m, $\left.4 \mathrm{H}, 2 \times \mathrm{CH}_{2}\right), 2.00-1.94\left(\mathrm{~m}, 4 \mathrm{H}, 2 \times \mathrm{CH}_{2}\right), 1.80\left(\mathrm{~s}, 3 \mathrm{H}, \mathrm{CH}_{3}\right), 1.67\left(\mathrm{~s}, 3 \mathrm{H}, \mathrm{CH}_{3}\right), 1.60(\mathrm{~s}, 3 \mathrm{H}$, $\left.\mathrm{CH}_{3}\right), 1.59\left(\mathrm{~s}, 6 \mathrm{H}, 2 \times \mathrm{CH}_{3}\right) ;{ }^{13} \mathrm{C}\left\{{ }^{1} \mathrm{H}\right\} \mathrm{NMR}\left(150 \mathrm{MHz}, \mathrm{CDCl}_{3}\right): \delta 155.4(\mathrm{C}, \mathrm{C}-6), 151.9(\mathrm{C}, \mathrm{C}-2), 148.9(\mathrm{C}$, C-4), $143.3(\mathrm{C}=), 140.3(\mathrm{CH}, \mathrm{C}-8), 136.4(\mathrm{C}=), 135.3(\mathrm{C}=), 131.4(\mathrm{C}=), 124.5(\mathrm{CH}=), 124.1(\mathrm{CH}=), 123.1$ $(\mathrm{CH}=), 118.4(\mathrm{CH}=), 107.2(\mathrm{C}, \mathrm{C}-5), 44.5\left(\mathrm{NCH}_{2}\right), 39.9\left(\mathrm{CH}_{2}\right), 39.8\left(\mathrm{CH}_{2}\right), 32.3\left(\mathrm{CH}_{2}\right), 29.9\left(\mathrm{~N}(3) \mathrm{CH}_{3}\right)$, $28.1\left(\mathrm{~N}(1) \mathrm{CH}_{3}\right), 26.9\left(\mathrm{CH}_{2}\right), 26.7\left(\mathrm{CH}_{2}\right), 26.5\left(\mathrm{CH}_{2}\right), 25.9\left(\mathrm{CH}_{3}\right), 23.6\left(\mathrm{CH}_{3}\right), 17.8\left(\mathrm{CH}_{3}\right), 16.21\left(\mathrm{CH}_{3}\right)$, $16.15\left(\mathrm{CH}_{3}\right)$; IR (film from $\left.\mathrm{CH}_{2} \mathrm{Cl}_{2}\right): v_{\max } 3111,2917,2853,1704,1658 \mathrm{~cm}^{-1}$; HRESIMS m/z: $[\mathrm{M}+\mathrm{H}]^{+}$ Calcd. for $\mathrm{C}_{27} \mathrm{H}_{41} \mathrm{~N}_{4} \mathrm{O}_{2}$ 453.3224; Found 453.3215 ( $\Delta=-2.0 \mathrm{ppm}$ ); HRESIMS/MS (40 eV) $\mathrm{m} / \mathrm{z}(\%)$ : 181.0700 (100), 124.0496 (36).

Compound 37: $21.1 \mathrm{mg}(19 \%)$, white solid; $\mathrm{R}_{f}=0.20$ (2:3 EA/PE); $\left.{ }^{1} \mathrm{H} \mathrm{NMR} \mathrm{(500} \mathrm{MHz,} \mathrm{CDCl}_{3}\right)$ : $\delta 7.52(\mathrm{~s}, 1 \mathrm{H}, \mathrm{H}-8), 5.43(\mathrm{t}, J=7.1 \mathrm{~Hz}, 1 \mathrm{H}, \mathrm{CH}=), 5.12-5.04(\mathrm{~m}, 3 \mathrm{H}, 3 \times \mathrm{CH}=), 4.92(\mathrm{~d}, J=7.2 \mathrm{~Hz}, 2 \mathrm{H}$, $\left.\mathrm{NCH}_{2}\right), 3.58\left(\mathrm{~s}, 3 \mathrm{H}, \mathrm{N}(3) \mathrm{CH}_{3}\right), 3.40\left(\mathrm{~s}, 3 \mathrm{H}, \mathrm{N}(1) \mathrm{CH}_{3}\right), 2.15-2.07\left(\mathrm{~m}, 4 \mathrm{H}, 2 \times \mathrm{CH}_{2}\right), 2.07-2.01(\mathrm{~m}, 4 \mathrm{H}, 2 \times$ $\left.\mathrm{CH}_{2}\right), 1.99-1.93\left(\mathrm{~m}, 4 \mathrm{H}, 2 \times \mathrm{CH}_{2}\right), 1.78\left(\mathrm{~s}, 3 \mathrm{H}, \mathrm{CH}_{3}\right), 1.66\left(\mathrm{~s}, 3 \mathrm{H}, \mathrm{CH}_{3}\right), 1.58\left(\mathrm{~s}, 9 \mathrm{H}, 3 \times \mathrm{CH}_{3}\right) ;{ }^{13} \mathrm{C}\left\{{ }^{1} \mathrm{H}\right\}$ NMR (150 MHz, CDCl 3 ): $\delta 155.4$ (C, C-6), 151.8 (C, C-2), 148.9 (C, C-4), 143.5 (C=), 140.3 (CH, C-8), 136.0 (C=), $135.2(\mathrm{C}=), 131.4(\mathrm{C}=), 124.5(\mathrm{CH}=), 124.2(\mathrm{CH}=), 123.4(\mathrm{CH}=), 117.5(\mathrm{CH}=), 107.2(\mathrm{C}, \mathrm{C}-5)$, $44.6\left(\mathrm{NCH}_{2}\right), 39.8\left(\mathrm{CH}_{2}\right), 39.8\left(\mathrm{CH}_{2}\right), 39.6\left(\mathrm{CH}_{2}\right), 29.9\left(\mathrm{~N}(3) \mathrm{CH}_{3}\right), 28.1\left(\mathrm{~N}(1) \mathrm{CH}_{3}\right), 26.9\left(\mathrm{CH}_{2}\right), 26.7\left(\mathrm{CH}_{2}\right)$, $26.3\left(\mathrm{CH}_{2}\right), 25.8\left(\mathrm{CH}_{3}\right), 17.8\left(\mathrm{CH}_{3}\right), 16.7\left(\mathrm{CH}_{3}\right), 16.2\left(\mathrm{CH}_{3}\right), 16.1\left(\mathrm{CH}_{3}\right)$; IR (film from $\left.\mathrm{CH}_{2} \mathrm{Cl}_{2}\right)$ : $v_{\max }$ 3110, 2916, 2854, 1704, $1658 \mathrm{~cm}^{-1}$; HRESIMS $\mathrm{m} / z$ : $[\mathrm{M}+\mathrm{H}]^{+}$Calcd. for $\mathrm{C}_{27} \mathrm{H}_{41} \mathrm{~N}_{4} \mathrm{O}_{2}$ 453.3224; Found 453.3205 ( $\Delta=-4.2 \mathrm{ppm}$ ); HRESIMS/MS (40 eV) m/z (\%): 181.0693 (100), 124.0489 (31). 
3.2.18. (E)-7-(3,7-Dimethylocta-2,6-dien-1-yl)-3-methyl-2-thioxo-1,2,3,7-tetrahydro-6H-purin-6-one (38)

2-Mercapto-3-methylhypoxanthine $(0.30 \mathrm{mmol}, 54.7 \mathrm{mg}), \mathrm{K}_{2} \mathrm{CO}_{3}(0.61 \mathrm{mmol}, 84.3 \mathrm{mg})$ and geranyl bromide $(0.39 \mathrm{mmol}, 84.9 \mathrm{mg})$ in DMF $(2 \mathrm{~mL})$ at $70{ }^{\circ} \mathrm{C}$ for $30 \mathrm{~h}$ yielded 30 , after modified work up and modified purification- $\mathrm{H}_{2} \mathrm{O}(7 \mathrm{~mL})$ was added to the reaction and the resulting isolated precipitate was dissolved in in $\mathrm{MeOH}$ and DCM (1:1, $5 \mathrm{~mL})$. Partial evaporation yielded a precipitate isolated by filtration and washed with $\mathrm{MeOH}, 5.4 \mathrm{mg}(6 \%)$, off-white powder. ${ }^{1} \mathrm{H} \mathrm{NMR}\left(600 \mathrm{MHz}, \mathrm{CDCl}_{3}\right): \delta 9.24$ $(\mathrm{s}, 1 \mathrm{H}, \mathrm{NH}), 7.62(\mathrm{~s}, 1 \mathrm{H}, \mathrm{H}-8), 5.43(\mathrm{t}, J=7.3 \mathrm{~Hz}, 1 \mathrm{H}, \mathrm{CH}=), 5.07-5.03(\mathrm{~m}, 1 \mathrm{H}, \mathrm{CH}=), 4.92(\mathrm{~d}, J=7.3 \mathrm{~Hz}$, $\left.2 \mathrm{H}, \mathrm{NCH}_{2}\right), 3.93\left(\mathrm{~s}, 3 \mathrm{H}, \mathrm{NCH}_{3}\right), 2.16-2.08\left(\mathrm{~m}, 4 \mathrm{H}, 2 \times \mathrm{CH}_{2}\right), 1.78\left(\mathrm{~s}, 3 \mathrm{H}, \mathrm{CH}_{3}\right), 1.69\left(\mathrm{~s}, 3 \mathrm{H}, \mathrm{CH}_{3}\right), 1.60$ (s, 3H, CH $\left.\left.{ }_{3}\right) ;{ }^{13} \mathrm{C}^{1}{ }^{1} \mathrm{H}\right\}$ NMR (150 MHz, $\left.\mathrm{CDCl}_{3}\right): \delta 174.3(\mathrm{C}, \mathrm{C}-2), 152.4(\mathrm{C}, \mathrm{C}-6), 150.9(\mathrm{C}, \mathrm{C}-4), 144.5$ $(\mathrm{C}=), 141.2(\mathrm{CH}, \mathrm{C}-8), 132.5(\mathrm{C}=), 123.5(\mathrm{CH}=), 116.8(\mathrm{CH}=), 110.9(\mathrm{C}, \mathrm{C}-5), 45.0\left(\mathrm{NCH}_{2}\right), 39.6\left(\mathrm{CH}_{2}\right)$, $35.5\left(\mathrm{NCH}_{3}\right), 26.2\left(\mathrm{CH}_{2}\right), 25.9\left(\mathrm{CH}_{3}\right), 17.9\left(\mathrm{CH}_{3}\right), 16.7\left(\mathrm{CH}_{3}\right)$; IR (neat): $v_{\max } 3122,2964,2912,2853$, $1708 \mathrm{~cm}^{-1}$; HRESIMS $m / z$ : [M + H] $]^{+}$Calcd. for $\mathrm{C}_{16} \mathrm{H}_{23} \mathrm{~N}_{4} \mathrm{OS} 319.1587$; Found 319.1591 ( $\Delta=1.3 \mathrm{ppm}$ ); HRESIMS/MS (40 eV) m/z (\%): 183.033 (48), 149.0452 (19), 126.99579 (11), 124.0503 (100), 96.0557 (21), $81.0702(46)$.

3.2.19. 3-Methyl-2-thioxo-7-((6E)-3,7,11-trimethyldodeca-2,6,10-trien-1-yl)-1,2,3,7-tetrahydro-6Hpurin-6-one (39)

2-Mercapto-3-methylhypoxanthine $(0.32 \mathrm{mmol}, 57.8 \mathrm{mg}), \mathrm{K}_{2} \mathrm{CO}_{3}(0.61 \mathrm{mmol}, 84.7 \mathrm{mg})$ and farnesyl bromide $(0.39 \mathrm{mmol}, 111 \mathrm{mg})$ in DMF $(2 \mathrm{~mL})$ at $50{ }^{\circ} \mathrm{C}$ for $41 \mathrm{~h}$ yielded $39,3.3 \mathrm{mg}(3 \%)$, off-white powder. $\mathrm{R}_{f}=0.19(1: 2 \mathrm{EA} / \mathrm{PE}) ; 2: 1 \mathrm{E} / \mathrm{Z}, \mathrm{NMR}$ data for major isomer: ${ }^{1} \mathrm{H} \mathrm{NMR}\left(600 \mathrm{MHz}, \mathrm{CDCl}_{3}\right): \delta 9.31(\mathrm{~s}, 1 \mathrm{H}$, $\mathrm{NH}), 7.62(\mathrm{~s}, 1 \mathrm{H}, \mathrm{H}-8), 5.43(\mathrm{t}, J=7.3 \mathrm{~Hz}, 1 \mathrm{H}, \mathrm{CH}=), 5.09-5.05(\mathrm{~m}, 2 \mathrm{H}, 2 \times \mathrm{CH}=), 4.92(\mathrm{~d}, J=7.3 \mathrm{~Hz}, 2 \mathrm{H}$, $\left.\mathrm{NCH}_{2}\right), 3.92\left(\mathrm{~s}, 3 \mathrm{H}, \mathrm{NCH}_{3}\right), 2.16-2.09\left(\mathrm{~m}, 4 \mathrm{H}, 2 \times \mathrm{CH}_{2}\right), 2.06-2.01\left(\mathrm{~m}, 4 \mathrm{H}, 2 \times \mathrm{CH}_{2}\right), 1.78\left(\mathrm{~s}, 3 \mathrm{H}, \mathrm{CH}_{3}\right)$, $\left.1.66\left(\mathrm{~s}, 3 \mathrm{H}, \mathrm{CH}_{3}\right), 1.59\left(\mathrm{~s}, 3 \mathrm{H}, \mathrm{CH}_{3}\right), 1.58\left(\mathrm{~s}, 3 \mathrm{H}, \mathrm{CH}_{3}\right) ;{ }^{13} \mathrm{C}^{1}{ }^{1} \mathrm{H}\right\} \mathrm{NMR}\left(150 \mathrm{MHz}, \mathrm{CDCl}_{3}\right): \delta 174.3(\mathrm{C}, \mathrm{C}-2)$, 152.4 (C, C-6), 150.9 (C, C-4), $144.5(\mathrm{C}=), 141.1(\mathrm{CH}, \mathrm{C}-8), 136.1(\mathrm{C}=), 131.6(\mathrm{C}=), 124.3(\mathrm{CH}=), 123.3$ $(\mathrm{CH}=), 116.8(\mathrm{CH}=), 110.9(\mathrm{C}, \mathrm{C}-5), 45.0\left(\mathrm{NCH}_{2}\right), 39.8\left(\mathrm{CH}_{2}\right), 39.6\left(\mathrm{CH}_{2}\right), 35.5\left(\mathrm{NCH}_{3}\right), 26.8\left(\mathrm{CH}_{2}\right), 26.2$ $\left(\mathrm{CH}_{2}\right), 25.9\left(\mathrm{CH}_{3}\right), 17.8\left(\mathrm{CH}_{3}\right), 16.7\left(\mathrm{CH}_{3}\right), 16.2\left(\mathrm{CH}_{3}\right)$; IR (film from $\left.\mathrm{CH}_{2} \mathrm{Cl}_{2}\right)$ : v $\max 3116,2922,2854$, $1691 \mathrm{~cm}^{-1}$; HRESIMS m/z: $[\mathrm{M}+\mathrm{H}]^{+}$Calcd. for $\mathrm{C}_{21} \mathrm{H}_{31} \mathrm{~N}_{4} \mathrm{OS} 387.2213$; Found 387.2216 ( $\Delta=0.8 \mathrm{ppm}$ ); HRESIMS/MS (40 eV) m/z (\%): 183.0316 (100), 149.0436 (13), 124.0493 (42).

3.2.20. 3-Methyl-7-((2Z,6E,10E)-3,7,11,15-tetramethylhexadeca-2,6,10,14-tetraen-1-yl)-2-thioxo-1,2,3, 7-tetrahydro-6H-purin-6-one (40) and 3-methyl-7-((2E,6E,10E)-3,7,11,15-tetramethylhexadeca-2, 6,10,14-tetraen-1-yl)-2-thioxo-1,2,3,7-tetrahydro-6H-purin-6-one (41)

2-Mercapto-3-methylhypoxanthine $(0.30 \mathrm{mmol}, 54.7 \mathrm{mg}), \mathrm{K}_{2} \mathrm{CO}_{3}(1.1 \mathrm{mmol}, 150.8 \mathrm{mg})$ and geranylgeranyl bromide $(0.32 \mathrm{mmol}, 111.3 \mathrm{mg})$ in DMF $(1 \mathrm{~mL})$ for $24 \mathrm{~h}$ yielded 40 and 41.

Compound 40: $3.2 \mathrm{mg}(9 \%)$, white powder; $\mathrm{R}_{f}=0.14(1: 3 \mathrm{EA} / \mathrm{PE}) ;{ }^{1} \mathrm{H} \mathrm{NMR}\left(500 \mathrm{MHz}, \mathrm{CDCl}_{3}\right)$ : $\delta$ $9.32(\mathrm{~s}, 1 \mathrm{H}, \mathrm{NH}), 7.64(\mathrm{~s}, 1 \mathrm{H}, \mathrm{H}-8), 5.45(\mathrm{t}, J=7.2 \mathrm{~Hz}, 1 \mathrm{H}, \mathrm{CH}=), 5.13-5.07(\mathrm{~m}, 3 \mathrm{H}, 3 \times \mathrm{CH}=), 4.92(\mathrm{~d}, J$ $\left.=7.3 \mathrm{~Hz}, 2 \mathrm{H}, \mathrm{NCH}_{2}\right), 3.94\left(\mathrm{~s}, 3 \mathrm{H}, \mathrm{NCH}_{3}\right), 2.26-2.19\left(\mathrm{~m}, 2 \mathrm{H}, \mathrm{CH}_{2}\right), 2.18-2.11\left(\mathrm{~m}, 2 \mathrm{H}, \mathrm{CH}_{2}\right), 2.10-2.04$ $\left(\mathrm{m}, 4 \mathrm{H}, 2 \times \mathrm{CH}_{2}\right), 2.02-1.96\left(\mathrm{~m}, 4 \mathrm{H}, 2 \times \mathrm{CH}_{2}\right), 1.83\left(\mathrm{~s}, 3 \mathrm{H}, \mathrm{CH}_{3}\right), 1.69\left(\mathrm{~s}, 3 \mathrm{H}, \mathrm{CH}_{3}\right), 1.62\left(\mathrm{~s}, 3 \mathrm{H}, \mathrm{CH}_{3}\right)$, $\left.1.61\left(\mathrm{~s}, 3 \mathrm{H}, \mathrm{CH}_{3}\right), 1.60\left(\mathrm{~s}, 3 \mathrm{H}, \mathrm{CH}_{3}\right) ;{ }^{13} \mathrm{C}^{1}{ }^{1} \mathrm{H}\right\} \mathrm{NMR}\left(150 \mathrm{MHz}, \mathrm{CDCl}_{3}\right): \delta 174.3$ (C, C-2), $152.4(\mathrm{C}, \mathrm{C}-6)$, 150.9 (C, C-4), $144.2(\mathrm{C}=), 141.2(\mathrm{CH}, \mathrm{C}-8), 136.6(\mathrm{C}=)$, $135.3(\mathrm{C}=), 131.5(\mathrm{C}=), 124.5(\mathrm{CH}=), 124.1(\mathrm{CH}=)$, 123.0 (CH=), $117.7(\mathrm{CH}=), 110.9(\mathrm{C}, \mathrm{C}-5), 44.8\left(\mathrm{NCH}_{2}\right), 39.9\left(\mathrm{CH}_{2}\right), 39.8\left(\mathrm{CH}_{2}\right), 35.5\left(\mathrm{NCH}_{3}\right), 32.3\left(\mathrm{CH}_{2}\right)$, $26.9\left(\mathrm{CH}_{2}\right), 26.7\left(\mathrm{CH}_{2}\right), 26.4\left(\mathrm{CH}_{2}\right), 25.9\left(\mathrm{CH}_{3}\right), 23.6\left(\mathrm{CH}_{3}\right), 17.8\left(\mathrm{CH}_{3}\right), 16.22\left(\mathrm{CH}_{3}\right), 16.16\left(\mathrm{CH}_{3}\right) ; \mathrm{IR}$ (film from $\mathrm{CH}_{2} \mathrm{Cl}_{2}$ ): $v_{\max } 3205,3118,2965,2917,2855,1696 \mathrm{~cm}^{-1}$; HRESIMS m/z: [M + H] ${ }^{+}$Calcd. for $\mathrm{C}_{26} \mathrm{H}_{39} \mathrm{~N}_{4} \mathrm{OS}$ 455.2839; Found 455.2851 ( $\Delta=2.6$ ppm); HRESIMS/MS (40 eV) m/z (\%): 183.0304 (100), 124.0487 (19).

Compound 41: $3.4 \mathrm{mg}(3 \%)$, white powder; $\mathrm{R}_{f}=0.10(1: 3 \mathrm{EA} / \mathrm{PE}) ;{ }^{1} \mathrm{H} \mathrm{NMR}\left(500 \mathrm{MHz}, \mathrm{CDCl}_{3}\right): \delta$ $9.29(\mathrm{~s}, 1 \mathrm{H}, \mathrm{NH}), 7.62(\mathrm{~s}, 1 \mathrm{H}, \mathrm{H}-8), 5.43(\mathrm{t}, J=7.0 \mathrm{~Hz}, 1 \mathrm{H}, \mathrm{CH}=), 5.13-5.05(\mathrm{~m}, 3 \mathrm{H}, 3 \times \mathrm{CH}=), 4.92(\mathrm{~d}$, $\left.J=7.3 \mathrm{~Hz}, 2 \mathrm{H}, \mathrm{NCH}_{2}\right), 3.92\left(\mathrm{~s}, 3 \mathrm{H}, \mathrm{NCH}_{3}\right), 2.17-2.10\left(\mathrm{~m}, 4 \mathrm{H}, 2 \times \mathrm{CH}_{2}\right), 2.09-2.02\left(\mathrm{~m}, 4 \mathrm{H}, 2 \times \mathrm{CH}_{2}\right)$, 2.01-1.93 (m, $\left.4 \mathrm{H}, 2 \times \mathrm{CH}_{2}\right), 1.79\left(\mathrm{~s}, 3 \mathrm{H}, \mathrm{CH}_{3}\right), 1.68\left(\mathrm{~s}, 3 \mathrm{H}, \mathrm{CH}_{3}\right), 1.60-1.58\left(\mathrm{~m}, 9 \mathrm{H}, 3 \times \mathrm{CH}_{3}\right) ;{ }^{13} \mathrm{C}\left\{{ }^{1} \mathrm{H}\right\}$ NMR (150 MHz, CDCl $)_{3}$ : $\delta 174.3$ (C, C-2), 152.4 (C, C-6), 150.9 (C, C-4), 144.5 (C=), 141.1 (CH, C-8), 
$136.1(\mathrm{C}=), 135.2(\mathrm{C}=), 131.5(\mathrm{C}=), 124.5(\mathrm{CH}=), 124.2(\mathrm{CH}=), 123.3(\mathrm{CH}=), 116.8(\mathrm{CH}=), 110.9(\mathrm{C}, \mathrm{C}-5)$, $45.0\left(\mathrm{NCH}_{2}\right), 39.9\left(\mathrm{CH}_{2}\right), 39.8\left(\mathrm{CH}_{2}\right), 39.6\left(\mathrm{CH}_{2}\right), 35.5\left(\mathrm{NCH}_{3}\right), 26.9\left(\mathrm{CH}_{2}\right), 26.7\left(\mathrm{CH}_{2}\right), 26.2\left(\mathrm{CH}_{2}\right), 25.9$ $\left(\mathrm{CH}_{3}\right), 17.8\left(\mathrm{CH}_{3}\right), 16.7\left(\mathrm{CH}_{3}\right), 16.23\left(\mathrm{CH}_{3}\right), 16.16\left(\mathrm{CH}_{3}\right)$; IR (film from $\left.\mathrm{CH}_{2} \mathrm{Cl}_{2}\right): v_{\max } 3212,3117,2964$, 2917, 2853, $1691 \mathrm{~cm}^{-1}$; HRESIMS $\mathrm{m} / z$ : $[\mathrm{M}+\mathrm{H}]^{+}$Calcd. for $\mathrm{C}_{26} \mathrm{H}_{39} \mathrm{~N}_{4} \mathrm{OS} 455.2839$; Found 455.2857 $(\Delta=4.0$ ppm); HRESIMS/MS (40 eV) m/z (\%): 183.0306 (100), 124.0487 (13).

\subsubsection{1. (E)-5-(3,7-Dimethylocta-2,6-dien-1-yl)-1,3-dimethyl-5,7-dihydro-1H-purine-2,6,8(3H)-trione (42)}

1,3-Dimethyluric acid $(0.12 \mathrm{mmol}, 22.6 \mathrm{mg}), \mathrm{K}_{2} \mathrm{CO}_{3}(0.119 \mathrm{mmol}, 16.5 \mathrm{mg})$ and geranyl bromide $(0.13 \mathrm{mmol}, 27.6 \mathrm{mg})$ in DMF $(2 \mathrm{~mL})$ for $24 \mathrm{~h}$ yielded $42,3.5 \mathrm{mg}(9 \%)$, white solid. $\mathrm{R}_{f}=0.23(1: 1 \mathrm{EA} / \mathrm{PE})$; ${ }^{1} \mathrm{H}$ NMR $\left(600 \mathrm{MHz}, \mathrm{CDCl}_{3}\right): \delta 6.07(\mathrm{~s}, 1 \mathrm{H}, \mathrm{NH}), 5.06-5.02(\mathrm{~m}, 1 \mathrm{H}, \mathrm{CH}=), 4.95(\mathrm{t}, J=8.1 \mathrm{~Hz}, 1 \mathrm{H}, \mathrm{CH}=)$, $3.49\left(\mathrm{~s}, 3 \mathrm{H}, \mathrm{N}(1) \mathrm{CH}_{3}\right), 3.28\left(\mathrm{~s}, 3 \mathrm{H}, \mathrm{N}(3) \mathrm{CH}_{3}\right), 2.67\left(\mathrm{~d}, J=8.0 \mathrm{~Hz}, 2 \mathrm{H}, \mathrm{NCH}_{2}\right), 2.12-1.99\left(\mathrm{~m}, 4 \mathrm{H}, 2 \times \mathrm{CH}_{2}\right)$, $1.70\left(\mathrm{~s}, 3 \mathrm{H}, \mathrm{CH}_{3}\right), 1.61\left(\mathrm{~s}, 3 \mathrm{H}, \mathrm{CH}_{3}\right), 1.58\left(\mathrm{~s}, 3 \mathrm{H}, \mathrm{CH}_{3}\right) ;{ }^{13} \mathrm{C}\left\{{ }^{1} \mathrm{H}\right\} \mathrm{NMR}\left(150 \mathrm{MHz}, \mathrm{CDCl}_{3}\right): \delta 176.9(\mathrm{C}$, C-6), $166.4(\mathrm{C}, \mathrm{C}-4), 165.4(\mathrm{C}, \mathrm{C}-8), 150.8(\mathrm{C}, \mathrm{C}-2), 145.6(\mathrm{C}=), 132.6(\mathrm{C}=), 123.6(\mathrm{CH}=), 112.8(\mathrm{CH}=), 68.1$ $(\mathrm{C}, \mathrm{C}-5), 40.6\left(\mathrm{NCH}_{2}\right), 39.9\left(\mathrm{CH}_{2}\right), 32.0\left(\mathrm{~N}(1) \mathrm{CH}_{3}\right), 29.2\left(\mathrm{~N}(3) \mathrm{CH}_{3}\right), 26.3\left(\mathrm{CH}_{2}\right), 25.8\left(\mathrm{CH}_{3}\right), 17.9\left(\mathrm{CH}_{3}\right)$, 16.4 $\left(\mathrm{CH}_{3}\right)$; IR (film from $\left.\mathrm{CH}_{2} \mathrm{Cl}_{2}\right): v_{\max } 3278,3106,2966,2921,2857,1750,1697,1609 \mathrm{~cm}^{-1}$; HRESIMS $m / z:[\mathrm{M}+\mathrm{H}]^{+}$Calcd. for $\mathrm{C}_{17} \mathrm{H}_{25} \mathrm{~N}_{4} \mathrm{O}_{3}$ 333.1910; Found 333.1921 ( $\left.\Delta=3.3 \mathrm{ppm}\right)$; HRESIMS/MS (40 eV) $m / z$ (\%): 197.0664 (95), 169.0712 (100), 140.0463 (32), 112.0505 (41).

3.2.22. 1,3-Dimethyl-5-((6E)-3,7,11-trimethyldodeca-2,6,10-trien-1-yl)-5,7-dihydro-1Hpurine-2,6,8(3H)-trione (43) and 1,3-dimethyl-9-((6E)-3,7,11-trimethyldodeca-2,6, 10-trien-1-yl)-7,9-dihydro-1H-purine-2,6,8(3H)-trione (44)

1,3-Dimethyluric acid $(0.12 \mathrm{mmol}, 23.3 \mathrm{mg}), \mathrm{K}_{2} \mathrm{CO}_{3}(0.12 \mathrm{mmol}, 16.6 \mathrm{mg})$ and farnesyl bromide (0.11 mmol, $32.0 \mathrm{mg})$ in DMF (2 mL) for $19 \mathrm{~h}$ yielded 43 and 44.

Compound 43: $19.2 \mathrm{mg}(40 \%)$, white solid; $\mathrm{R}_{f}=0.38$ (1:1 EA/PE); 2:1 E/Z NMR data for major isomer: ${ }^{1} \mathrm{H}$ NMR $\left(600 \mathrm{MHz}, \mathrm{CDCl}_{3}\right): \delta 6.39(\mathrm{~s}, 1 \mathrm{H}, \mathrm{NH}), 5.09-5.02(\mathrm{~m}, 2 \mathrm{H}, 2 \times \mathrm{CH}=), 4.95(\mathrm{t}, J=7.9 \mathrm{~Hz}$, $1 \mathrm{H}, \mathrm{CH}=), 3.48\left(\mathrm{~s}, 3 \mathrm{H}, \mathrm{N}(1) \mathrm{CH}_{3}\right), 3.27\left(\mathrm{~s}, 3 \mathrm{H}, \mathrm{N}(3) \mathrm{CH}_{3}\right), 2.68\left(\mathrm{~d}, J=8.1 \mathrm{~Hz}, 2 \mathrm{H}, \mathrm{NCH}_{2}\right), 2.09-2.00(\mathrm{~m}$, $\left.6 \mathrm{H}, 3 \times \mathrm{CH}_{2}\right), 2.00-1.93\left(\mathrm{~m}, 2 \mathrm{H}, \mathrm{CH}_{2}\right), 1.66\left(\mathrm{~s}, 3 \mathrm{H}, \mathrm{CH}_{3}\right), 1.59\left(\mathrm{~s}, 6 \mathrm{H}, 2 \times \mathrm{CH}_{3}\right), 1.58\left(\mathrm{~s}, 3 \mathrm{H}, \mathrm{CH}_{3}\right) ;{ }^{13} \mathrm{C}\left\{{ }^{1} \mathrm{H}\right\}$ NMR (150 MHz, CDCl $)$ : $\delta 176.8$ (C, C-6), 166.4 (C, C-4), 165.6 (C, C-8), 150.9 (C, C-2), 145.7 (C=), 136.0 $(\mathrm{C}=), 131.5(\mathrm{C}=), 124.4(\mathrm{CH}=), 123.4(\mathrm{CH}=), 112.7(\mathrm{CH}=), 68.2(\mathrm{C}, \mathrm{C}-5), 40.5\left(\mathrm{NCH}_{2}\right), 40.0\left(\mathrm{CH}_{2}\right), 39.8$ $\left(\mathrm{CH}_{2}\right), 32.0\left(\mathrm{~N}(1) \mathrm{CH}_{3}\right), 29.2\left(\mathrm{~N}(3) \mathrm{CH}_{3}\right), 26.8\left(\mathrm{CH}_{2}\right), 26.3\left(\mathrm{CH}_{2}\right), 25.8\left(\mathrm{CH}_{3}\right), 17.8\left(\mathrm{CH}_{3}\right), 16.4\left(\mathrm{CH}_{3}\right), 16.2$ $\left(\mathrm{CH}_{3}\right)$; IR (film from $\mathrm{CH}_{2} \mathrm{Cl}_{2}$ ): $v_{\max } 3307,3098,2964,2924,2855,1695,1645,1612 \mathrm{~cm}^{-1}$; HRESIMS $\mathrm{m} / z$ : $[\mathrm{M}+\mathrm{H}]^{+}$Calcd. for $\mathrm{C}_{22} \mathrm{H}_{33} \mathrm{~N}_{4} \mathrm{O}_{3}$ 401.2547; Found 401.2538 ( $\Delta=-2.2 \mathrm{ppm}$ ); HRESIMS/MS (40 eV) $\mathrm{m} / \mathrm{z}$ (\%): 197.0639 (100), 169.0699 (40).

Compound 44: $3.3 \mathrm{mg}(7 \%)$, white solid; $\mathrm{R}_{f}=0.13$ (1:1 EA/PE); 3:2 E/Z, NMR data for major isomer: ${ }^{1} \mathrm{H}$ NMR $\left(600 \mathrm{MHz}, \mathrm{CDCl}_{3}\right): \delta 8.95(\mathrm{br} \mathrm{s}, 1 \mathrm{H}, \mathrm{NH}), 5.16-5.11(\mathrm{~m}, 1 \mathrm{H}, \mathrm{CH}=), 5.11-5.00(\mathrm{~m}, 2 \mathrm{H}$, $2 \times \mathrm{CH}=), 4.66\left(\mathrm{~d}, J=5.8 \mathrm{~Hz}, 2 \mathrm{H}, \mathrm{NCH}_{2}\right), 3.67\left(\mathrm{~s}, 3 \mathrm{H}, \mathrm{N}(3) \mathrm{CH}_{3}\right), 3.40\left(\mathrm{~d}, J=2.3 \mathrm{~Hz}, 3 \mathrm{H}, \mathrm{N}(1) \mathrm{CH}_{3}\right)$, 2.13-2.07 (m, 2H, $\left.\mathrm{CH}_{2}\right), 2.07-1.98\left(\mathrm{~m}, 4 \mathrm{H}, 2 \times \mathrm{CH}_{2}\right), 1.97-1.91\left(\mathrm{~m}, 2 \mathrm{H}, \mathrm{CH}_{2}\right), 1.75\left(\mathrm{~s}, 3 \mathrm{H}, \mathrm{CH}_{3}\right), 1.67$ $\left(\mathrm{s}, 3 \mathrm{H}, \mathrm{CH}_{3}\right), 1.58\left(\mathrm{~s}, 6 \mathrm{H}, 2 \times \mathrm{CH}_{3}\right) ;{ }^{13} \mathrm{C}\left\{{ }^{1} \mathrm{H}\right\} \mathrm{NMR}\left(150 \mathrm{MHz}, \mathrm{CDCl}_{3}\right): \delta 153.2(\mathrm{C}, \mathrm{C}-6), 151.8(\mathrm{C}, \mathrm{C}-8)$, 151.0 (C, C-2), 140.9 (C=), $136.2(\mathrm{C}=), 136.0(\mathrm{C}, \mathrm{C}-4), 131.6(\mathrm{C}=), 124.3(\mathrm{CH}=), 123.3(\mathrm{CH}=), 119.5(\mathrm{CH}=)$, $98.4(\mathrm{C}, \mathrm{C}-5), 41.6\left(\mathrm{NCH}_{2}\right), 39.8\left(\mathrm{CH}_{2}\right), 39.4\left(\mathrm{CH}_{2}\right), 31.3\left(\mathrm{~N}(3) \mathrm{CH}_{3}\right), 28.6\left(\mathrm{~N}(1) \mathrm{CH}_{3}\right), 26.8\left(\mathrm{CH}_{2}\right), 26.3$ $\left(\mathrm{CH}_{2}\right), 25.9\left(\mathrm{CH}_{3}\right), 17.8\left(\mathrm{CH}_{3}\right), 17.0\left(\mathrm{CH}_{3}\right), 16.2\left(\mathrm{CH}_{3}\right)$; IR (film from $\left.\mathrm{CH}_{2} \mathrm{Cl}_{2}\right)$ : $v_{\max } 3487,3174,3078$, 2918, 2854, 1687, $1651 \mathrm{~cm}^{-1}$; HRESIMS $m / z$ : $[\mathrm{M}+\mathrm{H}]^{+}$Calcd. for $\mathrm{C}_{22} \mathrm{H}_{33} \mathrm{~N}_{4} \mathrm{O}_{3}$ 401.2547; Found 401.2551 ( $\Delta=1.0$ ppm); HRESIMS/MS (40 eV) m/z (\%): 197.0658 (100), 169.0707 (57).

\subsubsection{3. (E)-5-(3,7-Dimethylocta-2,6-dien-1-yl)-5H-pyrazolo[3,4-d]pyrimidin-4-ol (46)}

Allopurinol ( $0.80 \mathrm{mmol}, 109.2 \mathrm{mg}), \mathrm{K}_{2} \mathrm{CO}_{3} / \mathrm{Na}_{2} \mathrm{CO}_{3}(1: 1,150.8 \mathrm{mg})$ and geranyl bromide $(0.50 \mathrm{mmol}$, $108 \mathrm{mg})$ in DMF $(10 \mathrm{~mL})$ for $24 \mathrm{~h}$ yielded 46 -additionally recrystallised from MeOH after chromatography, $4.5 \mathrm{mg}(2 \%)$, white powder. $\mathrm{R}_{f}=0.06(1: 4 \mathrm{EA} / \mathrm{PE}) ;{ }^{1} \mathrm{H} \mathrm{NMR}\left(600 \mathrm{MHz}, \mathrm{CDCl}_{3}\right): \delta 11.32(\mathrm{br} \mathrm{s}, 1 \mathrm{H}, \mathrm{OH})$, $8.18(\mathrm{~s}, 1 \mathrm{H}, \mathrm{H}-3), 8.02(\mathrm{~s}, 1 \mathrm{H}, \mathrm{H}-6), 5.34-5.26(\mathrm{~m}, 1 \mathrm{H}, \mathrm{CH}=), 5.07-5.02(\mathrm{~m}, 1 \mathrm{H}, \mathrm{CH}=), 4.64(\mathrm{~d}, J=7.2$ $\left.\mathrm{Hz}, 2 \mathrm{H}, \mathrm{NCH}_{2}\right), 2.16-2.03\left(\mathrm{~m}, 4 \mathrm{H}, 2 \times \mathrm{CH}_{2}\right), 1.82\left(\mathrm{~s}, 3 \mathrm{H}, \mathrm{CH}_{3}\right), 1.67\left(\mathrm{~s}, 3 \mathrm{H}, \mathrm{CH}_{3}\right), 1.59\left(\mathrm{~s}, 3 \mathrm{H}, \mathrm{CH}_{3}\right)$; 
${ }^{13} \mathrm{C}\left\{{ }^{1} \mathrm{H}\right\} \mathrm{NMR}\left(150 \mathrm{MHz}, \mathrm{CDCl}_{3}\right): \delta 157.4$ (C, C-4), 153.4 (C, C-7a), $149.4(\mathrm{CH}, \mathrm{C}-6), 143.0(\mathrm{C}=), 136.4$ $(\mathrm{CH}, \mathrm{C}-3), 132.3(\mathrm{C}=), 123.6(\mathrm{CH}=), 118.1(\mathrm{CH}=), 105.9(\mathrm{C}, \mathrm{C}-3 \mathrm{a}), 43.5\left(\mathrm{NCH}_{2}\right), 39.6\left(\mathrm{CH}_{2}\right), 26.3\left(\mathrm{CH}_{2}\right)$, $25.8\left(\mathrm{CH}_{3}\right), 17.9\left(\mathrm{CH}_{3}\right), 16.7\left(\mathrm{CH}_{3}\right)$; IR (film from $\left.\mathrm{CH}_{2} \mathrm{Cl}_{2}\right): v_{\max } 3188,3080,2967,2905,2791,1678$, $1568 \mathrm{~cm}^{-1}$; HRESIMS $\mathrm{m} / z$ : $[\mathrm{M}+\mathrm{H}]^{+}$Calcd. for $\mathrm{C}_{15} \mathrm{H}_{21} \mathrm{~N}_{4} \mathrm{O}$ 273.1710; Found 273.1715 ( $\Delta=1.8 \mathrm{ppm}$ ); HRESIMS/MS (40 eV) m/z (\%): 137.0454 (100), 110.0349 (39).

3.2.24. 1,5-Bis((6E)-3,7,11-trimethyldodeca-2,6,10-trien-1-yl)-1,5-dihydro-4H-pyrazolo[3,4- $d]$ pyrimidin-4-one (47), 2,7-bis((6E)-3,7,11-trimethyldodeca-2,6,10-trien-1-yl)-2,7-dihydro$4 H$-pyrazolo[3,4-d]pyrimidin-4-one (48), and 5-((2E,6E)-3,7,11-trimethyldodeca2,6,10-trien-1-yl)-5H-pyrazolo[3,4-d]pyrimidin-4-ol (49)

Allopurinol (0.48 mmol, $65.2 \mathrm{mg}), \mathrm{K}_{2} \mathrm{CO}_{3}(0.51 \mathrm{mmol}, 70.5 \mathrm{mg})$ and farnesyl bromide $(0.55 \mathrm{mmol}$, $157.0 \mathrm{mg})$ in DMF $(2 \mathrm{~mL})$ at $70{ }^{\circ} \mathrm{C}$ for $27 \mathrm{~h}$ yielded 47,48 , and 49.

Compound 47: $17.2 \mathrm{mg}(12 \%)$, colourless oil; $\mathrm{R}_{f}=0.24(1: 5 \mathrm{EA} / \mathrm{PE}) ; 2: 1 \mathrm{E} / \mathrm{Z}$, NMR data for major isomer: ${ }^{1} \mathrm{H}$ NMR $\left(500 \mathrm{MHz}, \mathrm{CDCl}_{3}\right): \delta 8.09-8.08(\mathrm{~m}, 1 \mathrm{H}, \mathrm{H}-6), 7.95-7.94(\mathrm{~m}, 1 \mathrm{H}, \mathrm{H}-3), 5.48-5.41(\mathrm{~m}, 1 \mathrm{H}$, $\mathrm{CH}=), 5.34-5.28(\mathrm{~m}, 1 \mathrm{H}, \mathrm{CH}=), 5.13-5.04(\mathrm{~m}, 4 \mathrm{H}, 4 \times \mathrm{CH}=), 4.94\left(\mathrm{~d}, J=6.9 \mathrm{~Hz}, 2 \mathrm{H}, \mathrm{NCH}_{2}\right), 4.61(\mathrm{~d}$, $\left.J=7.2 \mathrm{~Hz}, 2 \mathrm{H}, \mathrm{NCH}_{2}\right), 2.18-1.99\left(\mathrm{~m}, 14 \mathrm{H}, 7 \times \mathrm{CH}_{2}\right), 1.99-1.92\left(\mathrm{~m}, 2 \mathrm{H}, \mathrm{CH}_{2}\right), 1.85\left(\mathrm{~s}, 3 \mathrm{H}, \mathrm{CH}_{3}\right), 1.83$ $\left.\left(\mathrm{s}, 3 \mathrm{H}, \mathrm{CH}_{3}\right), 1.68\left(\mathrm{~s}, 9 \mathrm{H}, 3 \times \mathrm{CH}_{3}\right), 1.60\left(\mathrm{~s}, 9 \mathrm{H}, 3 \times \mathrm{CH}_{3}\right) ;{ }^{13} \mathrm{C}^{1}{ }^{1} \mathrm{H}\right\} \mathrm{NMR}\left(150 \mathrm{MHz}, \mathrm{CDCl}_{3}\right): \delta 157.4$ (C, C-4), $151.0(\mathrm{C}, \mathrm{C}-7 \mathrm{a}), 148.4(\mathrm{CH}, \mathrm{C}-6), 142.7(\mathrm{C}=), 141.0(\mathrm{C}=), 135.9(\mathrm{C}=), 135.6(\mathrm{C}=), 135.1(\mathrm{CH}$, C-3), $131.49(\mathrm{C}=), 131.46(\mathrm{C}=), 124.42(\mathrm{CH}=), 124.37(\mathrm{CH}=), 123.7(\mathrm{CH}=), 123.5(\mathrm{CH}=), 118.4(\mathrm{CH}=)$, $118.3(\mathrm{CH}=), 105.9(\mathrm{C}, \mathrm{C}-3 \mathrm{a}), 45.4\left(\mathrm{NCH}_{2}\right), 43.2\left(\mathrm{NCH}_{2}\right), 39.80\left(\mathrm{CH}_{2}\right), 39.78\left(\mathrm{CH}_{2}\right), 39.64\left(\mathrm{CH}_{2}\right), 39.59$ $\left(\mathrm{CH}_{2}\right), 26.83\left(\mathrm{CH}_{2}\right), 26.81\left(\mathrm{CH}_{2}\right), 26.34\left(\mathrm{CH}_{2}\right), 26.30\left(\mathrm{CH}_{2}\right), 25.9\left(\mathrm{CH}_{3}\right), 25.8\left(\mathrm{CH}_{3}\right), 17.8\left(2 \times \mathrm{CH}_{3}\right), 16.74$ $\left(\mathrm{CH}_{3}\right), 16.69\left(\mathrm{CH}_{3}\right), 16.19\left(\mathrm{CH}_{3}\right), 16.15\left(\mathrm{CH}_{3}\right)$; IR (film from $\left.\mathrm{CH}_{2} \mathrm{Cl}_{2}\right): v_{\max } 3368,2964,2925,2856,1696$, $1582 \mathrm{~cm}^{-1}$; HRESIMS m/z: $[\mathrm{M}+\mathrm{H}]^{+}$Calcd. for $\mathrm{C}_{35} \mathrm{H}_{53} \mathrm{~N}_{4} \mathrm{O}$ 545.4214; Found 545.4223 ( $\Delta=1.7 \mathrm{ppm}$ ); HRESIMS/MS (40 eV) $\mathrm{m} / z$ (\%): 137.0458 (100), 81.702 (12).

Compound 48: $6.4 \mathrm{mg}(4 \%)$, colourless oil; $\mathrm{R}_{f}=0.48$ (1:1 EA/PE); 3:2 E/Z, NMR data for major isomer: ${ }^{1} \mathrm{H} \mathrm{NMR}\left(500 \mathrm{MHz}, \mathrm{CDCl}_{3}\right): \delta 8.06(\mathrm{~s}, 1 \mathrm{H}, \mathrm{H}-3), 7.95(\mathrm{~s}, 1 \mathrm{H}, \mathrm{H}-6), 5.51(\mathrm{t}, J=6.5 \mathrm{~Hz}, 1 \mathrm{H}, \mathrm{CH}=)$, 5.32-5.26 (m, 1H, CH=), 5.13-5.05 (m, 4H, $4 \times \mathrm{CH}=), 4.89\left(\mathrm{~d}, J=7.4 \mathrm{~Hz}, 2 \mathrm{H}, \mathrm{NCH}_{2}\right), 4.57(\mathrm{~d}, J=7.1 \mathrm{~Hz}$, $\left.2 \mathrm{H}, \mathrm{NCH}_{2}\right), 2.20-1.93\left(\mathrm{~m}, 16 \mathrm{H}, 8 \times \mathrm{CH}_{2}\right), 1.81\left(\mathrm{~s}, 3 \mathrm{H}, \mathrm{CH}_{3}\right), 1.79\left(\mathrm{~s}, 3 \mathrm{H}, \mathrm{CH}_{3}\right), 1.68\left(\mathrm{~s}, 6 \mathrm{H}, 2 \times \mathrm{CH}_{3}\right)$, 1.62-1.57 $\left(\mathrm{m}, 12 \mathrm{H}, 4 \times \mathrm{CH}_{3}\right) ;{ }^{13} \mathrm{C}\left\{{ }^{1} \mathrm{H}\right\}$ NMR $\left(150 \mathrm{MHz}, \mathrm{CDCl}_{3}\right): \delta 158.9(\mathrm{C}, \mathrm{C}-4), 158.6(\mathrm{C}, 7 \mathrm{a}), 148.5(\mathrm{CH}$, C-6), $144.5(\mathrm{C}=), 142.1(\mathrm{C}=), 136.0(\mathrm{C}=), 135.8(\mathrm{C}=), 131.7(\mathrm{C}=), 131.4(\mathrm{C}=), 127.0(\mathrm{CH}, \mathrm{C}-3), 124.4(\mathrm{CH}=)$, $124.3(\mathrm{CH}=), 123.5(\mathrm{CH}=), 123.4(\mathrm{CH}=), 118.5(\mathrm{CH}=), 116.7(\mathrm{CH}=), 107.1(\mathrm{C}, \mathrm{C}-3 \mathrm{a}), 51.2\left(\mathrm{NCH}_{2}\right), 43.0$ $\left(\mathrm{NCH}_{2}\right), 39.77\left(\mathrm{CH}_{2}\right), 39.76\left(\mathrm{CH}_{2}\right), 39.64\left(\mathrm{CH}_{2}\right), 39.62\left(\mathrm{CH}_{2}\right), 26.8\left(\mathrm{CH}_{2}\right), 26.7\left(\mathrm{CH}_{2}\right), 26.4\left(\mathrm{CH}_{2}\right), 26.3$ $\left(\mathrm{CH}_{2}\right), 25.85\left(\mathrm{CH}_{3}\right), 25.84\left(\mathrm{CH}_{3}\right), 17.82\left(\mathrm{CH}_{3}\right), 17.81\left(\mathrm{CH}_{3}\right), 16.8\left(\mathrm{CH}_{3}\right), 16.7\left(\mathrm{CH}_{3}\right), 16.19\left(\mathrm{CH}_{3}\right), 16.15$ $\left(\mathrm{CH}_{3}\right)$; IR (film from $\mathrm{CH}_{2} \mathrm{Cl}_{2}$ ): $\gamma_{\max } 3404,2973,2934,1687 \mathrm{~cm}^{-1}$; HRESIMS $\mathrm{m} / \mathrm{z}:[\mathrm{M}+\mathrm{H}]^{+}$Calcd. for $\mathrm{C}_{35} \mathrm{H}_{53} \mathrm{~N}_{4} \mathrm{O}$ 545.4214; Found 545.4225 ( $\Delta=2.0$ ppm); HRESIMS/MS (40 eV) m/z (\%): 137.0451 (100), 81.0699 (30).

Compound 49: $33.6 \mathrm{mg}(21 \%)$, white solid; $\mathrm{R}_{f}=0.16$ (1:1 EA/PE); 3:2 E/Z, NMR data for major isomer: ${ }^{1} \mathrm{H}$ NMR $\left(600 \mathrm{MHz}, \mathrm{CDCl}_{3}\right): \delta 12.64$ (br s, $\left.1 \mathrm{H}, \mathrm{OH}\right), 8.20$ (s, 1H, H-3), 8.08 (s, 1H, H-6), 5.34-5.28 $(\mathrm{m}, 1 \mathrm{H}, \mathrm{CH}=), 5.09-5.01(\mathrm{~m}, 2 \mathrm{H}, 2 \times \mathrm{CH}=), 4.64\left(\mathrm{~d}, J=7.3 \mathrm{~Hz}, 2 \mathrm{H}, \mathrm{NCH}_{2}\right), 2.14-2.04\left(\mathrm{~m}, 4 \mathrm{H}, 2 \times \mathrm{CH}_{2}\right)$, 2.04-1.96 (m, 2H, CH $), 1.96-1.92\left(\mathrm{~m}, 2 \mathrm{H}, \mathrm{CH}_{2}\right), 1.82\left(\mathrm{~s}, 3 \mathrm{H}, \mathrm{CH}_{3}\right), 1.64\left(\mathrm{~s}, 3 \mathrm{H}, \mathrm{CH}_{3}\right), 1.57\left(\mathrm{~s}, 3 \mathrm{H}, \mathrm{CH}_{3}\right)$, $\left.1.56\left(\mathrm{~s}, 3 \mathrm{H}, \mathrm{CH}_{3}\right) ;{ }^{13} \mathrm{C}^{1}{ }^{1} \mathrm{H}\right\}$ NMR (150 MHz, CDCl $): \delta 157.4$ (C, C-4), 153.3 (C, C-7a), 149.4 (CH, C-6), $143.0(\mathrm{C}=), 136.1(\mathrm{CH}, \mathrm{C}-3) 135.9(\mathrm{C}=), 131.5(\mathrm{C}=), 124.3(\mathrm{CH}=), 123.4(\mathrm{CH}=), 118.0(\mathrm{CH}=), 105.9(\mathrm{C}$, C-3a), $43.5\left(\mathrm{NCH}_{2}\right), 39.7\left(\mathrm{CH}_{2}\right), 39.6\left(\mathrm{CH}_{2}\right), 26.8\left(\mathrm{CH}_{2}\right), 26.3\left(\mathrm{CH}_{2}\right), 25.8\left(\mathrm{CH}_{3}\right), 17.8\left(\mathrm{CH}_{3}\right), 16.7\left(\mathrm{CH}_{3}\right)$, $16.2\left(\mathrm{CH}_{3}\right)$; IR (film from $\mathrm{CH}_{2} \mathrm{Cl}_{2}$ ): $v_{\max } 3188,3108,2967,2917,1676 \mathrm{~cm}^{-1}$; HRESIMS m/z: $[\mathrm{M}+\mathrm{H}]^{+}$ Calcd. for $\mathrm{C}_{20} \mathrm{H}_{29} \mathrm{~N}_{4} \mathrm{O}$ 341.2336; Found 341.2340 ( $\Delta=1.2 \mathrm{ppm}$ ); HRESIMS/MS (40 eV) $\mathrm{m} / \mathrm{z}(\%)$ : 137.0451 (100), $110.0344(9)$.

3.2.25. 1,5-Bis((2E,6E,10E)-3,7,11,15-tetramethylhexadeca-2,6,10,14-tetraen-1-yl)-1,5-dihydro$4 H$-pyrazolo[3,4-d]pyrimidin-4-one (50)

Allopurinol (0.71 mmol, $96.6 \mathrm{mg}), \mathrm{K}_{2} \mathrm{CO}_{3}(0.81 \mathrm{mmol}, 111.9 \mathrm{mg})$ and geranylgeranyl bromide $(0.73 \mathrm{mmol}, 259.7 \mathrm{mg})$ in DMF $(1 \mathrm{~mL})$ for $27 \mathrm{~h}$ yielded $50,6.8 \mathrm{mg}(2 \%)$, colourless oil. $\mathrm{R}_{f}=0.26(1: 5$ 
EA/PE); ${ }^{1} \mathrm{H}$ NMR $\left(600 \mathrm{MHz}, \mathrm{CDCl}_{3}\right): \delta 8.07(\mathrm{~s}, 1 \mathrm{H}, \mathrm{H}-3), 7.93(\mathrm{~s}, 1 \mathrm{H}, \mathrm{H}-6), 5.43(\mathrm{t}, J=6.8 \mathrm{~Hz}, 1 \mathrm{H}, \mathrm{CH}=)$, $5.30(\mathrm{t}, J=7.2 \mathrm{~Hz}, 1 \mathrm{H}, \mathrm{CH}=), 5.11-5.04(\mathrm{~m}, 6 \mathrm{H}, 6 \times \mathrm{CH}=), 4.93\left(\mathrm{~d}, J=6.9 \mathrm{~Hz}, 2 \mathrm{H}, \mathrm{NCH}_{2}\right), 4.60(\mathrm{~d}, J=7.3$ $\left.\mathrm{Hz}, 2 \mathrm{H}, \mathrm{NCH}_{2}\right), 2.14-2.01\left(\mathrm{~m}, 16 \mathrm{H}, 8 \times \mathrm{CH}_{2}\right), 1.99-1.93\left(\mathrm{~m}, 8 \mathrm{H}, 4 \times \mathrm{CH}_{2}\right), 1.83\left(\mathrm{~s}, 3 \mathrm{H}, \mathrm{CH}_{3}\right), 1.81(\mathrm{~s}, 3 \mathrm{H}$, $\left.\mathrm{CH}_{3}\right), 1.67\left(\mathrm{~s}, 6 \mathrm{H}, 2 \times \mathrm{CH}_{3}\right), 1.59\left(\mathrm{~s}, 6 \mathrm{H}, 2 \times \mathrm{CH}_{3}\right), 1.584\left(\mathrm{~s}, 3 \mathrm{H}, \mathrm{CH}_{3}\right), 1.579\left(\mathrm{~s}, 6 \mathrm{H}, 2 \times \mathrm{CH}_{3}\right), 1.56(\mathrm{~s}$, $\left.\left.3 \mathrm{H}, \mathrm{CH}_{3}\right) ;{ }^{13} \mathrm{C}^{1} \mathrm{H}\right\} \mathrm{NMR}\left(150 \mathrm{MHz}, \mathrm{CDCl}_{3}\right): \delta 157.4(\mathrm{C}, \mathrm{C}-4), 151.0(\mathrm{C}, \mathrm{C}-7 \mathrm{a}), 148.4(\mathrm{CH}, \mathrm{C}-6), 142.7$ $(\mathrm{C}=), 141.1(\mathrm{C}=), 135.9(\mathrm{C}=), 135.6(\mathrm{C}=), 135.13(\mathrm{C}=$ and $\mathrm{CH}, \mathrm{C}-3), 135.09(\mathrm{C}=), 131.43(\mathrm{C}=), 131.41(\mathrm{C}=)$, $124.50(\mathrm{CH}=), 124.48(\mathrm{CH}=), 124.3(\mathrm{CH}=), 124.2(\mathrm{CH}=), 123.7(\mathrm{CH}=), 123.5(\mathrm{CH}=), 118.4(\mathrm{CH}=), 118.3$ $(\mathrm{CH}=), 105.9(\mathrm{C}, \mathrm{C}-3 \mathrm{a}), 45.4\left(\mathrm{NCH}_{2}\right), 43.2\left(\mathrm{NCH}_{2}\right), 39.86\left(\mathrm{CH}_{2}\right), 39.85\left(\mathrm{CH}_{2}\right), 39.80\left(\mathrm{CH}_{2}\right), 39.78\left(\mathrm{CH}_{2}\right)$, $39.7\left(\mathrm{CH}_{2}\right), 39.6\left(\mathrm{CH}_{2}\right), 26.9\left(2 \times \mathrm{CH}_{2}\right), 26.73\left(\mathrm{CH}_{2}\right), 26.71\left(\mathrm{CH}_{2}\right), 26.38\left(\mathrm{CH}_{2}\right), 26.35\left(\mathrm{CH}_{2}\right), 25.9(2 \times$ $\left.\mathrm{CH}_{3}\right), 17.8\left(2 \times \mathrm{CH}_{3}\right), 16.8\left(\mathrm{CH}_{3}\right), 16.7\left(\mathrm{CH}_{3}\right), 16.2\left(2 \times \mathrm{CH}_{3}\right), 16.1\left(2 \times \mathrm{CH}_{3}\right)$; IR (film from $\left.\mathrm{CH}_{2} \mathrm{Cl}_{2}\right)$ : $v_{\max } 3392,2975,2937,1699 \mathrm{~cm}^{-1}$; HRESIMS $\mathrm{m} / z$ : $[\mathrm{M}+\mathrm{H}]^{+}$Calcd. for $\mathrm{C}_{45} \mathrm{H}_{69} \mathrm{~N}_{4} \mathrm{O}$ 681.5466; Found $681.5470(\Delta=0.6 \mathrm{ppm}) ;$ HRESIMS/MS (40 eV) m/z (\%): 341.01647 (72), 281.0500 (20), 266.9983 (21), 221.0823 (24), 207.0312 (25), 147.0648 (32), 137.0451 (100).

\subsubsection{6. (E)-1-(3,7-Dimethylocta-2,6-dien-1-yl)pyrimidine-2,4(1H,3H)-dione (54)}

Uracil $(0.53 \mathrm{mmol}, 59.9 \mathrm{mg}), \mathrm{K}_{2} \mathrm{CO}_{3}(0.51 \mathrm{mmol}, 68.9 \mathrm{mg})$ and geranyl bromide $(0.65 \mathrm{mmol}$, $141.1 \mathrm{mg})$ in DMF $(2 \mathrm{~mL})$ at $50{ }^{\circ} \mathrm{C}$ for $21 \mathrm{~h}$ yielded 54 , after modified work up and modified purification - the reaction was filtered, $\mathrm{H}_{2} \mathrm{O}(6 \mathrm{~mL})$ was added to the filtrate and stored in the fridge until precipitate formed. The isolated solid was recrystallised from PE, $15.8 \mathrm{mg}(12 \%)$, white crystals. ${ }^{1} \mathrm{H}$ NMR $\left(500 \mathrm{MHz}, \mathrm{CDCl}_{3}\right): \delta 8.42(\mathrm{br} \mathrm{s}, 1 \mathrm{H}, \mathrm{NH}), 7.16(\mathrm{~d}, J=7.9 \mathrm{~Hz}, 1 \mathrm{H}, \mathrm{H}-6), 5.68(\mathrm{dd}, J=7.9,2.1 \mathrm{~Hz}$, $1 \mathrm{H}, \mathrm{H}-5), 5.22(\mathrm{t}, J=7.3,1 \mathrm{H}, \mathrm{CH}=), 5.04(\mathrm{t}, J=6.6 \mathrm{~Hz}, 1 \mathrm{H}, \mathrm{CH}=), 4.35\left(\mathrm{~d}, J=7.3 \mathrm{~Hz}, 2 \mathrm{H}, \mathrm{NCH}_{2}\right), 2.11(\mathrm{~m}$, $\left.4 \mathrm{H}, 2 \times \mathrm{CH}_{2}\right), 1.75\left(\mathrm{~s}, 3 \mathrm{H}, \mathrm{CH}_{3}\right), 1.68\left(\mathrm{~s}, 3 \mathrm{H}, \mathrm{CH}_{3}\right), 1.60\left(\mathrm{~s}, 3 \mathrm{H}, \mathrm{CH}_{3}\right) ;{ }^{13} \mathrm{C}\left\{{ }^{1} \mathrm{H}\right\} \mathrm{NMR}\left(150 \mathrm{MHz}, \mathrm{CDCl}_{3}\right):$ $\delta 163.4$ (C, C-4), 150.9 (C, C-2), 143.7 (C=), 143.6 (CH, C-6), $132.4(\mathrm{C}=), 123.5(\mathrm{CH}=), 117.3(\mathrm{CH}=), 102.2$ $(\mathrm{CH}, \mathrm{C}-5), 45.2\left(\mathrm{NCH}_{2}\right), 39.6\left(\mathrm{CH}_{2}\right), 26.2\left(\mathrm{CH}_{2}\right), 25.9\left(\mathrm{CH}_{3}\right), 17.9\left(\mathrm{CH}_{3}\right), 16.6\left(\mathrm{CH}_{3}\right)$; IR (neat): $v_{\max } 3121$, 2967, 2929, 2808, 1696, $1657 \mathrm{~cm}^{-1}$; HRESIMS $\mathrm{m} / z$ : $[\mathrm{M}+\mathrm{H}]^{+}$Calcd. for $\mathrm{C}_{14} \mathrm{H}_{21} \mathrm{~N}_{2} \mathrm{O}_{2}$ 249.1598; Found 249.1595 ( $\Delta=-1.2 \mathrm{ppm}$ ); HRESIMS/MS (40 eV) m/z (\%): 113.0346 (100), 81.0700 (18), 70.0289 (7).

\subsubsection{1-((6E)-3,7,11-Trimethyldodeca-2,6,10-trien-1-yl)pyrimidine-2,4(1H,3H)-dione (55)}

Uracil $(0.49 \mathrm{mmol}, 54.9 \mathrm{mg}), \mathrm{K}_{2} \mathrm{CO}_{3}(0.51 \mathrm{mmol}, 69.9 \mathrm{mg})$ and farnesyl bromide $(0.54 \mathrm{mmol}$, $150 \mathrm{mg})$ in DMF $(2 \mathrm{~mL})$ at $70{ }^{\circ} \mathrm{C}$ for $24 \mathrm{~h}$ yielded 55 , after modified work up and modified purification as per 54, $38.6 \mathrm{mg}(25 \%)$, white crystals. 3:2 $\mathrm{E} / \mathrm{Z}$, NMR data for major isomer: ${ }^{1} \mathrm{H}$ NMR $(600 \mathrm{MHz}$, $\left.\mathrm{CDCl}_{3}\right): \delta 8.46(\mathrm{~s}, 1 \mathrm{H}, \mathrm{NH}), 7.16(\mathrm{~d}, J=7.9 \mathrm{~Hz}, 1 \mathrm{H}, \mathrm{H}-6), 5.68(\mathrm{dd} \mathrm{J}=8.0,2.2 \mathrm{~Hz}, 1 \mathrm{H}, \mathrm{H}-5), 5.24-5.19(\mathrm{~m}$, $1 \mathrm{H}, \mathrm{CH}=), 5.09-5.04(\mathrm{~m}, 2 \mathrm{H}, 2 \times \mathrm{CH}=), 4.34\left(\mathrm{~d}, J=7.3 \mathrm{~Hz}, 2 \mathrm{H}, \mathrm{NCH}_{2}\right), 2.16-2.01\left(\mathrm{~m}, 6 \mathrm{H}, 3 \times \mathrm{CH}_{2}\right)$, 1.99-1.94 (m, 2H, $\left.\mathrm{CH}_{2}\right), 1.75\left(\mathrm{~s}, 3 \mathrm{H}, \mathrm{CH}_{3}\right), 1.68\left(\mathrm{~s}, 3 \mathrm{H}, \mathrm{CH}_{3}\right), 1.62\left(\mathrm{~s}, 3 \mathrm{H}, \mathrm{CH}_{3}\right), 1.59\left(\mathrm{~s}, 3 \mathrm{H}, \mathrm{CH}_{3}\right) ;{ }^{13} \mathrm{C}\left\{{ }^{1} \mathrm{H}\right\}$ NMR (150 MHz, CDCl $): \delta 163.5$ (C, C-4), 150.9 (C, C-2), 143.8 (C=), 143.6 (CH, C-6), 136.0 (C=), 131.6 $(\mathrm{C}=), 124.3(\mathrm{CH}=), 123.4(\mathrm{CH}=), 117.2(\mathrm{CH}=), 102.2(\mathrm{CH}, \mathrm{C}-5), 45.3\left(\mathrm{NCH}_{2}\right), 39.8\left(\mathrm{CH}_{2}\right), 39.6\left(\mathrm{CH}_{2}\right), 26.8$ $\left(\mathrm{CH}_{2}\right), 26.2\left(\mathrm{CH}_{2}\right), 25.9\left(\mathrm{CH}_{3}\right), 17.8\left(\mathrm{CH}_{3}\right), 16.6\left(\mathrm{CH}_{3}\right), 16.2\left(\mathrm{CH}_{3}\right)$; IR (film from $\left.\mathrm{CH}_{2} \mathrm{Cl}_{2}\right)$ : v $\max 3054$, 2979, 2930, $1683 \mathrm{~cm}^{-1}$; HRESIMS $\mathrm{m} / z$ : $[\mathrm{M}+\mathrm{H}]^{+}$Calcd. for $\mathrm{C}_{19} \mathrm{H}_{29} \mathrm{~N}_{2} \mathrm{O}_{2}$ 317.2224; Found 317.2222 $(\Delta=-0.6 \mathrm{ppm}) ;$ HRESIMS/MS (40 eV) $\mathrm{m} / \mathrm{z}(\%): 113.0340$ (87), 81.0698 (100).

3.2.28. 1-((2Z,6E,10E)-3,7,11,15-Tetramethylhexadeca-2,6,10,14-tetraen-1-yl)pyrimidine-2, $4(1 H, 3 H)$-dione (56)

Uracil $(0.29 \mathrm{mmol}, 32.7 \mathrm{mg}), \mathrm{K}_{2} \mathrm{CO}_{3}(0.36 \mathrm{mmol}, 50.1 \mathrm{mg})$ and geranylgeranyl bromide $(0.32 \mathrm{mmol}$, $111 \mathrm{mg})$ in DMF (1 mL) for $48 \mathrm{~h}$ yielded $56,9.4 \mathrm{mg}(31 \%)$, white solid. $\mathrm{R}_{f}=0.23(2: 3 \mathrm{EA} / \mathrm{PE}) ;{ }^{1} \mathrm{H} \mathrm{NMR}$ $\left(500 \mathrm{MHz}, \mathrm{CDCl}_{3}\right): \delta 8.78(\mathrm{~s}, 1 \mathrm{H}, \mathrm{NH}), 7.15(\mathrm{dd}, J=7.9,0.8 \mathrm{~Hz}, 1 \mathrm{H}, \mathrm{H}-6), 5.68(\mathrm{dd}, J=7.9,1.4 \mathrm{~Hz}, 1 \mathrm{H}$, $\mathrm{H}-5), 5.22(\mathrm{t}, J=7.2 \mathrm{~Hz}, 1 \mathrm{H}, \mathrm{CH}=), 5.13-5.04(\mathrm{~m}, 3 \mathrm{H}, 3 \times \mathrm{CH}=), 4.33\left(\mathrm{~d}, J=7.3 \mathrm{~Hz}, 2 \mathrm{H}, \mathrm{NCH}_{2}\right), 2.20-2.10$ $\left(\mathrm{m}, 4 \mathrm{H}, 2 \times \mathrm{CH}_{2}\right), 2.10-2.02\left(\mathrm{~m}, 4 \mathrm{H}, 2 \times \mathrm{CH}_{2}\right), 2.01-1.93\left(\mathrm{~m}, 4 \mathrm{H}, 2 \times \mathrm{CH}_{2}\right), 1.79\left(\mathrm{~s}, 3 \mathrm{H}, \mathrm{CH}_{3}\right), 1.68(\mathrm{~s}, 3 \mathrm{H}$, $\left.\mathrm{CH}_{3}\right), 1.61\left(\mathrm{~s}, 3 \mathrm{H}, \mathrm{CH}_{3}\right), 1.60\left(\mathrm{~s}, 6 \mathrm{H}, 2 \times \mathrm{CH}_{3}\right) ;{ }^{13} \mathrm{C}\left\{{ }^{1} \mathrm{H}\right\} \mathrm{NMR}\left(150 \mathrm{MHz}, \mathrm{CDCl}_{3}\right): \delta 163.6(\mathrm{C}, \mathrm{C}-4), 150.9$ $(\mathrm{C}, \mathrm{C}-2), 143.7(\mathrm{C}=), 143.6(\mathrm{CH}, \mathrm{C}-6), 136.5(\mathrm{C}=), 135.3(\mathrm{C}=), 131.5(\mathrm{C}=), 124.5(\mathrm{CH}=), 124.1(\mathrm{CH}=), 123.1$ $(\mathrm{CH}=), 118.1(\mathrm{CH}=), 102.2(\mathrm{CH}, \mathrm{C}-5), 45.1\left(\mathrm{NCH}_{2}\right), 39.9\left(2 \times \mathrm{CH}_{2}\right), 32.2\left(\mathrm{CH}_{2}\right), 26.9\left(\mathrm{CH}_{2}\right), 26.7\left(\mathrm{CH}_{2}\right)$, 
26.5 $\left(\mathrm{CH}_{2}\right), 25.9\left(\mathrm{CH}_{3}\right), 23.6\left(\mathrm{CH}_{3}\right), 17.8\left(\mathrm{CH}_{3}\right), 16.20\left(\mathrm{CH}_{3}\right), 16.16\left(\mathrm{CH}_{3}\right)$; IR (film from $\left.\mathrm{CH}_{2} \mathrm{Cl}_{2}\right)$ : $v_{\max }$ 3425, 3197, 3054, 2970, 2930, 2875, $1686 \mathrm{~cm}^{-1}$; HRESIMS m/z: $[\mathrm{M}+\mathrm{H}]^{+}$Calcd. $\mathrm{C}_{24} \mathrm{H}_{37} \mathrm{~N}_{2} \mathrm{O}_{2}$ 385.2850; Found $385.2817(\Delta=-8.6 \mathrm{ppm})$; HRESIMS/MS (40 eV) m/z (\%):113.0331 (100), 107.0389 (21).

\subsubsection{9. (E)-1-(3,7-Dimethylocta-2,6-dien-1-yl)-5-methylpyrimidine-2,4-(1H,3H)-dione (57)}

Thymine (0.48 mmol, $61.0 \mathrm{mg}), \mathrm{K}_{2} \mathrm{CO}_{3}(0.50 \mathrm{mmol}, 69.4 \mathrm{mg})$ and geranyl bromide $(0.65 \mathrm{mmol}$, $141.1 \mathrm{mg}$ ) in DMF ( $2 \mathrm{~mL}$ ) for $20 \mathrm{~h}$ yielded 57 , after modified work up and modified purification as per $54,6.8 \mathrm{mg}(5 \%)$, white crystals. ${ }^{1} \mathrm{H}$ NMR $\left(600 \mathrm{MHz}, \mathrm{CDCl}_{3}\right): \delta 8.20(\mathrm{br} \mathrm{s}, 1 \mathrm{H}, \mathrm{NH}), 6.95(\mathrm{~d}, J=1.2 \mathrm{~Hz}$, $1 \mathrm{H}, \mathrm{H}-6), 5.21(\mathrm{t}, J=7.1 \mathrm{~Hz}, 1 \mathrm{H}, \mathrm{CH}=), 5.05(\mathrm{t}, J=6.9 \mathrm{~Hz}, 1 \mathrm{H}, \mathrm{CH}=), 4.32\left(\mathrm{~d}, J=7.3 \mathrm{~Hz}, 2 \mathrm{H}, \mathrm{NCH}_{2}\right)$, 2.14-2.05 (m, 4H, $\left.2 \times \mathrm{CH}_{2}\right), 1.92\left(\mathrm{~s}, 3 \mathrm{H}, \mathrm{C}(5) \mathrm{CH}_{3}\right), 1.75\left(\mathrm{~s}, 3 \mathrm{H}, \mathrm{CH}_{3}\right), 1.67\left(\mathrm{~s}, 3 \mathrm{H}, \mathrm{CH}_{3}\right), 1.60(\mathrm{~s}, 3 \mathrm{H}$, $\left.\mathrm{CH}_{3}\right) ;{ }^{13} \mathrm{C}\left\{{ }^{1} \mathrm{H}\right\}$ NMR $\left(150 \mathrm{MHz}, \mathrm{CDCl}_{3}\right): \delta 163.9$ (C, C-4), 150.8 (C, C-2), $142.9(\mathrm{C}=), 139.7$ (CH, C-6), 132.3 $(\mathrm{C}=), 123.5(\mathrm{CH}=), 117.7(\mathrm{CH}=), 110.7(\mathrm{C}, \mathrm{C}-5), 45.1\left(\mathrm{NCH}_{2}\right), 39.6\left(\mathrm{CH}_{2}\right), 26.3\left(\mathrm{CH}_{2}\right), 25.9\left(\mathrm{CH}_{3}\right)$, $17.9\left(\mathrm{CH}_{3}\right), 16.6\left(\mathrm{CH}_{3}\right), 12.6\left(\mathrm{C}(5) \underline{\mathrm{CH}}_{3}\right)$; IR (film from $\left.\mathrm{CH}_{2} \mathrm{Cl}_{2}\right)$ : $v_{\max } 3152,2975,2919,2830,1685,1645$ $\mathrm{cm}^{-1}$; HRESIMS $\mathrm{m} / \mathrm{z}$ : $[\mathrm{M}+\mathrm{H}]^{+}$Calcd. for $\mathrm{C}_{15} \mathrm{H}_{23} \mathrm{~N}_{2} \mathrm{O}_{2}$ 263.1754; Found 263.1752 ( $\Delta=-0.8 \mathrm{ppm}$ ); HRESIMS/MS (10 eV) m/z (\%): 128.0524 (7), 127.0501 (100), 81.07 (19).

\subsubsection{5-Methyl-1-((6E)-3,7,11-trimethyldodeca-2,6,10-trien-1-yl)pyrimidine-2,4(1H,3H)-dione (58)}

Thymine ( $0.49 \mathrm{mmol}, 62.4 \mathrm{mg}), \mathrm{K}_{2} \mathrm{CO}_{3}(0.51 \mathrm{mmol}, 70.5 \mathrm{mg})$ and farnesyl bromide $(0.62 \mathrm{mmol}$, $176.9 \mathrm{mg})$ in DMF $(2 \mathrm{~mL})$ at $70{ }^{\circ} \mathrm{C}$ for $24 \mathrm{~h}$ yielded 58 , after modified work up and modified purification as per 54, $31.9 \mathrm{mg}(20 \%)$, white crystals. 3:2 E/Z, NMR data for major isomer: ${ }^{1} \mathrm{H} \mathrm{NMR}(600 \mathrm{MHz}$, $\left.\mathrm{CDCl}_{3}\right): \delta 8.41(\mathrm{br} \mathrm{s}, 1 \mathrm{H}, \mathrm{NH}), 6.95(\mathrm{~s}, 1 \mathrm{H}, \mathrm{H}-6), 5.24-5.19(\mathrm{~m}, 1 \mathrm{H}, \mathrm{CH}=), 5.11-5.01(\mathrm{~m}, 2 \mathrm{H}, 2 \times \mathrm{CH}=)$, $4.32\left(\mathrm{~d}, J=7.5 \mathrm{~Hz}, 2 \mathrm{H}, \mathrm{NCH}_{2}\right), 2.14-2.02\left(\mathrm{~m}, 6 \mathrm{H}, 3 \times \mathrm{CH}_{2}\right), 1.98-1.95\left(\mathrm{~m}, 2 \mathrm{H}, \mathrm{CH}_{2}\right), 1.91\left(\mathrm{~s}, 3 \mathrm{H}, \mathrm{C}(5) \mathrm{CH}_{3}\right)$, $1.76\left(\mathrm{~s}, 3 \mathrm{H}, \mathrm{CH}_{3}\right), 1.67\left(\mathrm{~s}, 6 \mathrm{H}, 2 \times \mathrm{CH}_{3}\right), 1.59\left(\mathrm{~s}, 3 \mathrm{H}, \mathrm{CH}_{3}\right) ;{ }^{13} \mathrm{C}\left\{{ }^{1} \mathrm{H}\right\} \mathrm{NMR}\left(150 \mathrm{MHz}, \mathrm{CDCl}_{3}\right): \delta 164.0$ (C, C-4), $150.9(\mathrm{C}, \mathrm{C}-2), 142.9(\mathrm{C}=), 139.7(\mathrm{CH}, \mathrm{C}-6), 135.9(\mathrm{C}=), 131.6(\mathrm{C}=), 124.3(\mathrm{CH}=), 123.4(\mathrm{CH}=)$, 117.7 (CH=), $110.7(\mathrm{C}, \mathrm{C}-5), 45.1\left(\mathrm{NCH}_{2}\right), 39.8\left(\mathrm{CH}_{2}\right), 39.6\left(\mathrm{CH}_{2}\right), 26.8\left(\mathrm{CH}_{2}\right), 26.2\left(\mathrm{CH}_{2}\right), 25.9\left(\mathrm{CH}_{3}\right)$, $17.8\left(\mathrm{CH}_{3}\right), 16.7\left(\mathrm{CH}_{3}\right), 16.2\left(\mathrm{CH}_{3}\right), 12.6\left(\mathrm{C}(5) \mathrm{CH}_{3}\right) ; \mathrm{IR}\left(\right.$ film from $\left.\mathrm{CH}_{2} \mathrm{Cl}_{2}\right): v_{\max } 3177,3052,2966,2927$, $1665 \mathrm{~cm}^{-1}$; HRESIMS m/z: $[\mathrm{M}+\mathrm{H}]^{+}$Calcd. for $\mathrm{C}_{20} \mathrm{H}_{31} \mathrm{~N}_{2} \mathrm{O}_{2}$ 331.2380; Found $331.2372(\Delta=-2.4 \mathrm{ppm}$ ); HRESIMS/MS (40 eV) m/z (\%): 127.0487 (100), 110.0219 (46).

3.2.31. 5-Methyl-1-((2E,6E,10E)-3,7,11,15-tetramethylhexadeca-2,6,10,14-tetraen-1-yl)pyrimidine-2, $4(1 H, 3 H)$-dione (59)

Thymine $(0.31 \mathrm{mmol}, 38.7 \mathrm{mg}), \mathrm{K}_{2} \mathrm{CO}_{3}(0.36 \mathrm{mmol}, 49.6 \mathrm{mg})$ and geranylgeranyl bromide $(0.32 \mathrm{mmol}, 111 \mathrm{mg})$ in DMF $(1 \mathrm{~mL})$ for $24 \mathrm{~h}$ yielded $59,10.1 \mathrm{mg}(11 \%)$, waxy white solid. $\mathrm{R}_{f}=0.22$ (2:3 EA/PE); ${ }^{1} \mathrm{H}$ NMR (500 MHz, $\left.\mathrm{CDCl}_{3}\right): \delta 8.67(\mathrm{br} \mathrm{s}, 1 \mathrm{H}, \mathrm{NH}), 6.95(\mathrm{~d}, J=1.1 \mathrm{~Hz}, 1 \mathrm{H}, \mathrm{H}-6), 5.21(\mathrm{t}$, $J=6.7 \mathrm{~Hz}, 1 \mathrm{H}, \mathrm{CH}=), 5.12-5.04(\mathrm{~m}, 3 \mathrm{H}, 3 \times \mathrm{CH}=), 4.32\left(\mathrm{~d}, J=7.1 \mathrm{~Hz}, 2 \mathrm{H}, \mathrm{NCH}_{2}\right), 2.16-2.02(\mathrm{~m}, 8 \mathrm{H}, 4 \times$ $\left.\mathrm{CH}_{2}\right), 2.01-1.94\left(\mathrm{~m}, 4 \mathrm{H}, 2 \times \mathrm{CH}_{2}\right), 1.91\left(\mathrm{~s}, 3 \mathrm{H}, \mathrm{C}(5) \mathrm{CH}_{3}\right), 1.76\left(\mathrm{~s}, 3 \mathrm{H}, \mathrm{CH}_{3}\right), 1.68\left(\mathrm{~s}, 3 \mathrm{H}, \mathrm{CH}_{3}\right), 1.60(\mathrm{~s}, 6 \mathrm{H}$, $\left.2 \times \mathrm{CH}_{3}\right), 1.59\left(\mathrm{~s}, 3 \mathrm{H}, \mathrm{CH}_{3}\right)$; IR (film from $\mathrm{CH}_{2} \mathrm{Cl}_{2}$ ): $v_{\max } 3427,3176,3043,2968,2925,2855,1668 \mathrm{~cm}^{-1}$; ${ }^{13} \mathrm{C}\left\{{ }^{1} \mathrm{H}\right\}$ NMR (150 MHz, CDCl $): \delta 164.1(\mathrm{C}, \mathrm{C}-4), 151.0(\mathrm{C}, \mathrm{C}-2), 143.0(\mathrm{C}=), 139.7(\mathrm{CH}, \mathrm{C}-6), 135.9$ $(\mathrm{C}=), 135.2(\mathrm{C}=), 131.4(\mathrm{C}=), 124.5(\mathrm{CH}=) 124.2(\mathrm{CH}=), 123.5(\mathrm{CH}=), 117.7(\mathrm{CH}=), 110.8(\mathrm{C}, \mathrm{C}-5), 45.1$ $\left(\mathrm{NCH}_{2}\right), 39.9\left(\mathrm{CH}_{2}\right), 39.8\left(\mathrm{CH}_{2}\right), 39.7\left(\mathrm{CH}_{2}\right), 26.9\left(\mathrm{CH}_{2}\right), 26.7\left(\mathrm{CH}_{2}\right), 26.3\left(\mathrm{CH}_{2}\right), 25.9\left(\mathrm{CH}_{3}\right), 17.8\left(\mathrm{CH}_{3}\right)$, $16.7\left(\mathrm{CH}_{3}\right), 16.21\left(\mathrm{CH}_{3}\right), 16.15\left(\mathrm{CH}_{3}\right), 12.6\left(\mathrm{C}(5) \underline{\mathrm{C}} \mathrm{H}_{3}\right)$; HRESIMS m/z: $[\mathrm{M}+\mathrm{H}]^{+}$Calcd. for $\mathrm{C}_{25} \mathrm{H}_{39} \mathrm{~N}_{2} \mathrm{O}_{2}$ 399.3006; Found 399.2995 ( $\Delta=-2.8$ ppm); HRESIMS/MS m/z (20 eV) (\%): 399.2980 (8), 283.2625 (13), 127.0501 (100).

3.2.32. $N$-(-1,3-Bis((E)-3,7-dimethylocta-2,6-dien-1-yl)-2-oxo-2,3-dihydropyrimidin-4(1H)ylidene)formamide (60) and 1,3-bis((E)-3,7-dimethylocta-2,6-dien-1-yl)-4-imino-3, 4-dihydropyrimidin-2(1H)-one (61)

Cytosine $(1.0 \mathrm{mmol}, 112.4 \mathrm{mg}), \mathrm{K}_{2} \mathrm{CO}_{3}(1.0 \mathrm{mmol}, 152.0 \mathrm{mg})$ and geranyl bromide $(1.1 \mathrm{mmol}$, $238.5 \mathrm{mg}$ ) in DMF (4 mL) for $27 \mathrm{~h}$ yielded 60 and 61. 
Compound 60: $4.5 \mathrm{mg}(2 \%)$, pale-yellow oil; $\mathrm{R}_{f}=0.40(1: 1 \mathrm{EA} / \mathrm{PE}) ;{ }^{1} \mathrm{H} \mathrm{NMR}\left(600 \mathrm{MHz}, \mathrm{CDCl}_{3}\right)$ : $\delta 9.14(\mathrm{~s}, 1 \mathrm{H}, \mathrm{HC}=\mathrm{O}), 7.10(\mathrm{~d}, J=7.9 \mathrm{~Hz}, 1 \mathrm{H}, \mathrm{H}-6), 6.4(\mathrm{~d}, J=7.9 \mathrm{~Hz}, 1 \mathrm{H}, \mathrm{H}-5), 5.25(\mathrm{t}, J=7.0 \mathrm{~Hz}$, $1 \mathrm{H}, \mathrm{CH}=), 5.22(\mathrm{t}, J=7.0 \mathrm{~Hz}, 1 \mathrm{H}, \mathrm{CH}=), 5.08-5.02(\mathrm{~m}, 2 \mathrm{H}, 2 \times \mathrm{CH}=), 4.75\left(\mathrm{~d}, J=7.1 \mathrm{~Hz}, 2 \mathrm{H}, \mathrm{NCH}_{2}\right)$, $4.39\left(\mathrm{~d}, J=7.2 \mathrm{~Hz}, 2 \mathrm{H}, \mathrm{NCH}_{2}\right), 2.15-2.03\left(\mathrm{~m}, 6 \mathrm{H}, 3 \times \mathrm{CH}_{2}\right), 2.02-1.97\left(\mathrm{~m}, 2 \mathrm{H}, \mathrm{CH}_{2}\right), 1.82\left(\mathrm{~s}, 3 \mathrm{H}, \mathrm{CH}_{3}\right)$, $1.74\left(\mathrm{~s}, 3 \mathrm{H}, \mathrm{CH}_{3}\right), 1.68\left(\mathrm{~s}, 3 \mathrm{H}, \mathrm{CH}_{3}\right), 1.66\left(\mathrm{~s}, 3 \mathrm{H}, \mathrm{CH}_{3}\right), 1.60\left(\mathrm{~s}, 3 \mathrm{H}, \mathrm{CH}_{3}\right), 1.58\left(\mathrm{~s}, 3 \mathrm{H}, \mathrm{CH}_{3}\right) ;{ }^{13} \mathrm{C}\left\{{ }^{1} \mathrm{H}\right\}$ NMR (150 MHz, CDCl $)_{3}$ : $\delta 172.8(\mathrm{HC}=\mathrm{O}), 159.8$ (C, C-4), 150.5 (C, C-2), 144.3 (C=), 141.2 (C=), 140.8 $(\mathrm{CH}, \mathrm{C}-6), 132.4(\mathrm{C}=), 131.7(\mathrm{C}=), 124.1(\mathrm{CH}=), 123.5(\mathrm{CH}=), 117.4(\mathrm{CH}=), 117.0(\mathrm{CH}=), 97.4(\mathrm{CH}, \mathrm{C}-5)$, $46.6\left(\mathrm{NCH}_{2}\right), 42.0\left(\mathrm{NCH}_{2}\right), 39.8\left(\mathrm{CH}_{2}\right), 39.6\left(\mathrm{CH}_{2}\right), 26.6\left(\mathrm{CH}_{2}\right), 26.2\left(\mathrm{CH}_{2}\right), 25.89\left(\mathrm{CH}_{3}\right), 25.85\left(\mathrm{CH}_{3}\right)$, $17.89\left(\mathrm{CH}_{3}\right), 17.85\left(\mathrm{CH}_{3}\right), 16.8\left(\mathrm{CH}_{3}\right), 16.7\left(\mathrm{CH}_{3}\right)$; IR (film from $\left.\mathrm{CH}_{2} \mathrm{Cl}_{2}\right): v_{\max } 3306,2964,2915,2854$, 1654, 1684, $1403 \mathrm{~cm}^{-1}$; HRESIMS $\mathrm{m} / z$ : $[\mathrm{M}+\mathrm{H}]^{+}$Calcd. for $\mathrm{C}_{25} \mathrm{H}_{38} \mathrm{~N}_{3} \mathrm{O}_{2}$ 412.2959; Found 412.2985 ( $\Delta=6.3$ ppm); HRESIMS/MS m/z (10 eV) (\%): 412.0949 (11), 276.1708 (35), 140.0447 (100).

Compound 61: $18.3 \mathrm{mg}$ (9\%), pale-yellow oil; $\mathrm{R}_{f}=0.19(1: 2 \mathrm{EA} / \mathrm{PE}) ;{ }^{1} \mathrm{H} \mathrm{NMR}\left(600 \mathrm{MHz}, \mathrm{CDCl}_{3}\right)$ : $\delta 6.59(\mathrm{~d}, J=7.9 \mathrm{~Hz}, 1 \mathrm{H}, \mathrm{H}-6), 5.53(\mathrm{~d}, J=7.9 \mathrm{~Hz}, 1 \mathrm{H}, \mathrm{H}-5), 5.23(\mathrm{t}, J=6.3 \mathrm{~Hz}, 1 \mathrm{H}, \mathrm{CH}=), 5.21-5.16(\mathrm{~m}$, $1 \mathrm{H}, \mathrm{CH}=), 5.09-5.02(\mathrm{~m}, 2 \mathrm{H}, 2 \times \mathrm{CH}=), 4.62\left(\mathrm{~d}, J=6.4 \mathrm{~Hz}, 2 \mathrm{H}, \mathrm{NCH}_{2}\right), 4.25\left(\mathrm{~d}, J=7.2 \mathrm{~Hz}, 2 \mathrm{H}, \mathrm{NCH}_{2}\right)$, 2.14-2.03 (m, $\left.6 \mathrm{H}, 3 \times \mathrm{CH}_{2}\right), 2.01-1.97\left(\mathrm{~m}, 2 \mathrm{H}, \mathrm{CH}_{2}\right), 1.80\left(\mathrm{~s}, 3 \mathrm{H}, \mathrm{CH}_{3}\right), 1.71\left(\mathrm{~s}, 3 \mathrm{H}, \mathrm{CH}_{3}\right), 1.66(\mathrm{~s}, 3 \mathrm{H}$, $\left.\left.\mathrm{CH}_{3}\right), 1.65\left(\mathrm{~s}, 3 \mathrm{H}, \mathrm{CH}_{3}\right), 1.58\left(\mathrm{~s}, 3 \mathrm{H}, \mathrm{CH}_{3}\right), 1.57\left(\mathrm{~s}, 3 \mathrm{H}, \mathrm{CH}_{3}\right) ;{ }^{13} \mathrm{C}^{1}{ }^{1} \mathrm{H}\right\} \mathrm{NMR}\left(150 \mathrm{MHz}, \mathrm{CDCl}_{3}\right): \delta 158.2$ (C, C-4), $151.3(\mathrm{C}, \mathrm{C}-2), 142.3(\mathrm{C}=), 139.6(\mathrm{C}=), 135.2(\mathrm{CH}, \mathrm{C}-6), 132.1(\mathrm{C}=), 131.6(\mathrm{C}=), 124.2(\mathrm{CH}=)$, $123.7(\mathrm{CH}=), 118.6(\mathrm{CH}=), 118.3(\mathrm{CH}=), 102.0(\mathrm{CH}, \mathrm{C}-5), 45.7\left(\mathrm{NCH}_{2}\right), 40.5\left(\mathrm{NCH}_{2}\right), 39.8\left(\mathrm{CH}_{2}\right), 39.6$ $\left(\mathrm{CH}_{2}\right), 26.6\left(\mathrm{CH}_{2}\right), 26.3\left(\mathrm{CH}_{2}\right), 25.83\left(\mathrm{CH}_{3}\right), 25.81\left(\mathrm{CH}_{3}\right), 17.9\left(\mathrm{CH}_{3}\right), 17.8\left(\mathrm{CH}_{3}\right), 16.7\left(\mathrm{CH}_{3}\right), 16.5\left(\mathrm{CH}_{3}\right)$; IR (film from $\mathrm{CH}_{2} \mathrm{Cl}_{2}$ ): $v_{\max } 3305,3083,2966,2915,2855,1651 \mathrm{~cm}^{-1}$; HRESIMS m/z: $[\mathrm{M}+\mathrm{H}]^{+} \mathrm{Calcd}$. for $\mathrm{C}_{24} \mathrm{H}_{38} \mathrm{~N}_{3} \mathrm{O}$ 384.3009; Found 384.3023 ( $\Delta=3.6$ ppm); HRESIMS/MS $m / z(20 \mathrm{eV})(\%): 384.3018(0.1)$, 248.1764 (100), 113.0529 (0.09).

3.2.33. N-(-2-Oxo-1,3-bis((6E)-3,7,11-trimethyldodeca-2,6,10-trien-1-yl)-2,3-dihydropyrimidin$4(1 H)$-ylidene)formamide (62) and 4-imino-1,3-bis((6E)-3,7,11-trimethyldodeca-2,6, 10-trien-1-yl)-3,4-dihydropyrimidin-2(1H)-one (63)

Cytosine (1.0 mmol, $114.8 \mathrm{mg}), \mathrm{K}_{2} \mathrm{CO}_{3}(1.5 \mathrm{mmol}, 204.4 \mathrm{mg})$ and farnesyl bromide (1.2 mmol, $341 \mathrm{mg}$ ) in DMF (2 mL) for $25 \mathrm{~h}$ yielded 62 and 63.

Compound 62: $11.3 \mathrm{mg}(3 \%)$, pale-yellow oil; $\mathrm{R}_{f}=0.16(1: 4 \mathrm{EA} / \mathrm{PE}) ; 3: 2 \mathrm{E} / \mathrm{Z}$, data for major isomer: ${ }^{1} \mathrm{H} \mathrm{NMR}\left(600 \mathrm{MHz}, \mathrm{CDCl}_{3}\right): \delta 9.13(\mathrm{~s}, 1 \mathrm{H}, \mathrm{HC}=\mathrm{O}), 7.1(\mathrm{~d}, J=7.8 \mathrm{~Hz}, 1 \mathrm{H}, \mathrm{H}-6), 6.39(\mathrm{~d}, J=7.8 \mathrm{~Hz}, 1 \mathrm{H}$, $\mathrm{H}-5), 5.28-5.20(\mathrm{~m}, 2 \mathrm{H}, 2 \times \mathrm{CH}=), 5.12-5.04(\mathrm{~m}, 4 \mathrm{H}, 4 \times \mathrm{CH}=), 4.75\left(\mathrm{~d}, J=6.8 \mathrm{~Hz}, 2 \mathrm{H}, \mathrm{NCH}_{2}\right), 4.39(\mathrm{~d}, J$ $\left.=7.4 \mathrm{~Hz}, 2 \mathrm{H}, \mathrm{NCH}_{2}\right), 2.15-1.92\left(\mathrm{~m}, 16 \mathrm{H}, 8 \times \mathrm{CH}_{2}\right), 1.83\left(\mathrm{~s}, 3 \mathrm{H}, \mathrm{CH}_{3}\right), 1.75\left(\mathrm{~s}, 3 \mathrm{H}, \mathrm{CH}_{3}\right), 1.67(\mathrm{~s}, 6 \mathrm{H}, 2 \times$ $\left.\mathrm{CH}_{3}\right), 1.60\left(\mathrm{~s}, 3 \mathrm{H}, \mathrm{CH}_{3}\right), 1.59\left(\mathrm{~s}, 6 \mathrm{H}, 2 \times \mathrm{CH}_{3}\right), 1.57\left(\mathrm{~s}, 3 \mathrm{H}, \mathrm{CH}_{3}\right) ;{ }^{13} \mathrm{C}\left\{{ }^{1} \mathrm{H}\right\} \mathrm{NMR}\left(150 \mathrm{MHz}, \mathrm{CDCl}_{3}\right): \delta$ $172.8(\mathrm{C}, \mathrm{HC}=\mathrm{O}), 159.8(\mathrm{C}, \mathrm{C}-4), 150.5(\mathrm{C}, \mathrm{C}-2), 144.3(\mathrm{C}=), 141.3(\mathrm{C}=), 140.8(\mathrm{CH}, \mathrm{C}-6), 136.0(\mathrm{C}=), 135.4$ $(\mathrm{C}=), 131.6(\mathrm{C}=), 131.4(\mathrm{C}=), 124.5(\mathrm{CH}=), 124.3(\mathrm{CH}=), 124.0(\mathrm{CH}=), 123.3(\mathrm{CH}=), 117.4(\mathrm{CH}=), 116.9$ $(\mathrm{CH}=), 97.4(\mathrm{CH}, \mathrm{C}-5), 46.6\left(\mathrm{NCH}_{2}\right), 42.0\left(\mathrm{NCH}_{2}\right), 39.84\left(\mathrm{CH}_{2}\right), 39.82\left(2 \times \mathrm{CH}_{2}\right), 39.7\left(\mathrm{CH}_{2}\right), 26.9\left(\mathrm{CH}_{2}\right)$, $26.8\left(\mathrm{CH}_{2}\right), 26.5\left(\mathrm{CH}_{2}\right), 26.2\left(\mathrm{CH}_{2}\right), 25.9\left(2 \times \mathrm{CH}_{3}\right), 17.852\left(\mathrm{CH}_{3}\right), 17.846\left(\mathrm{CH}_{3}\right), 16.8\left(\mathrm{CH}_{3}\right), 16.7\left(\mathrm{CH}_{3}\right)$, $16.22\left(\mathrm{CH}_{3}\right), 16.16\left(\mathrm{CH}_{3}\right)$; IR (film from $\left.\mathrm{CH}_{2} \mathrm{Cl}_{2}\right): v_{\max } 2964,2915,2854,1650,1450 \mathrm{~cm}^{-1}$; HRESIMS m/z: $[\mathrm{M}+\mathrm{H}]^{+}$Calcd. for $\mathrm{C}_{35} \mathrm{H}_{54} \mathrm{~N}_{3} \mathrm{O}_{2}$ 548.4211; Found 548.4233 ( $\Delta=4.0 \mathrm{ppm}$ ).

Compound 63: $96.4 \mathrm{mg}(31 \%)$, pale-yellow oil; $\mathrm{R}_{f}=0.19$ (1:1 EA/PE); 3:2 E/Z, data for major isomer: ${ }^{1} \mathrm{H} \mathrm{NMR}\left(600 \mathrm{MHz}, \mathrm{CDCl}_{3}\right): \delta 6.59(\mathrm{~d}, J=7.9 \mathrm{~Hz}, 1 \mathrm{H}, \mathrm{H}-6), 5.53(\mathrm{~d}, J=7.7 \mathrm{~Hz}, 1 \mathrm{H}, \mathrm{H}-5), 5.24(\mathrm{t}$, $J=5.7 \mathrm{~Hz}, 1 \mathrm{H}, \mathrm{CH}=), 5.20(\mathrm{t}, J=6.8 \mathrm{~Hz}, 1 \mathrm{H}, \mathrm{CH}=), 5.13-5.04(\mathrm{~m}, 4 \mathrm{H}, 4 \times \mathrm{CH}=), 4.63(\mathrm{~d}, J=6.3 \mathrm{~Hz}, 2 \mathrm{H}$, $\left.\mathrm{NCH}_{2}\right), 4.26\left(\mathrm{~d}, J=7.2 \mathrm{~Hz}, 2 \mathrm{H}, \mathrm{NCH}_{2}\right), 2.15-1.91\left(\mathrm{~m}, 16 \mathrm{H}, 8 \times \mathrm{CH}_{2}\right), 1.81\left(\mathrm{~s}, 3 \mathrm{H}, \mathrm{CH}_{3}\right), 1.72\left(\mathrm{~s}, 3 \mathrm{H}, \mathrm{CH}_{3}\right)$, $1.68\left(\mathrm{~s}, 9 \mathrm{H}, 3 \times \mathrm{CH}_{3}\right), 1.59\left(\mathrm{~s}, 9 \mathrm{H}, 3 \times \mathrm{CH}_{3}\right) ;{ }^{13} \mathrm{C}\left\{{ }^{1} \mathrm{H}\right\} \mathrm{NMR}\left(150 \mathrm{MHz}, \mathrm{CDCl}_{3}\right): \delta 158.2(\mathrm{C}, \mathrm{C}-4), 151.4(\mathrm{C}$, $\mathrm{C}-2), 142.3(\mathrm{C}=), 139.6(\mathrm{C}=), 135.7(\mathrm{C}=), 135.1(\mathrm{C}=), 134.9(\mathrm{CH}, \mathrm{C}-6), 131.6(\mathrm{C}=), 131.4(\mathrm{C}=), 124.5(\mathrm{CH}=)$, $124.3(\mathrm{CH}=), 124.1(\mathrm{CH}=), 123.6(\mathrm{CH}=), 118.7(\mathrm{CH}=), 118.4(\mathrm{CH}=), 102.2(\mathrm{CH}, \mathrm{C}-5), 45.7\left(\mathrm{NCH}_{2}\right), 40.4$ $\left(\mathrm{NCH}_{2}\right), 39.84\left(\mathrm{CH}_{2}\right), 39.83\left(\mathrm{CH}_{2}\right), 39.77\left(\mathrm{CH}_{2}\right), 39.65\left(\mathrm{CH}_{2}\right), 26.9\left(\mathrm{CH}_{2}\right), 26.8\left(\mathrm{CH}_{2}\right), 26.6\left(\mathrm{CH}_{2}\right), 26.3$ $\left(\mathrm{CH}_{2}\right), 25.0\left(2 \times \mathrm{CH}_{3}\right), 17.9\left(2 \times \mathrm{CH}_{3}\right), 16.7\left(\mathrm{CH}_{3}\right), 16.6\left(\mathrm{CH}_{3}\right), 16.2\left(\mathrm{CH}_{3}\right), 16.1\left(\mathrm{CH}_{3}\right)$; IR (film from $\left.\mathrm{CH}_{2} \mathrm{Cl}_{2}\right): v_{\max }$ 3306, 2964, 2915, $28541654 \mathrm{~cm}^{-1}$; HRESIMS m/z: $[\mathrm{M}+\mathrm{H}]^{+}$Calcd. for $\mathrm{C}_{34} \mathrm{H}_{54} \mathrm{~N}_{3} \mathrm{O}$ 520.4261; Found 520.4269 ( $\Delta=1.5$ ppm); HRESIMS/MS m/z (20 eV) (\%): 316.2386 (21), 112.0511 (100). 
3.2.34. N-(-2-Oxo-1,3-bis((2E,6E,10E)-3,7,11,15-tetramethylhexadeca-2,6,10,14-tetraen-1-yl)-2, 3-dihydropyrimidin-4(1H)-ylidene)formamide (64)

Cytosine $(0.41 \mathrm{mmol}, 45.7 \mathrm{mg}), \mathrm{K}_{2} \mathrm{CO}_{3}(0.84 \mathrm{mmol}, 116.4 \mathrm{mg})$, and geranylgeranyl bromide (0.42 mmol, $148.4 \mathrm{mg})$ in DMF (2 mL) for $25 \mathrm{~h}$ yielded 64, $6.3 \mathrm{mg}(3 \%)$, pale-yellow oil. $\mathrm{R}_{f}=0.50$ (1:1 EA/PE); ${ }^{1} \mathrm{H}$ NMR (600 MHz, $\left.\mathrm{CDCl}_{3}\right): \delta 9.13$ (s, 1H, HC=O), 7.09 (d, J = $\left.7.9 \mathrm{~Hz}, 1 \mathrm{H}, \mathrm{H}-6\right), 6.39$ (d, $J=7.9 \mathrm{~Hz}, 1 \mathrm{H}, \mathrm{H}-5), 5.26(\mathrm{t}, J=7.0 \mathrm{~Hz}, 1 \mathrm{H}, \mathrm{CH}=), 5.24(\mathrm{t}, J=7.1 \mathrm{~Hz}, 1 \mathrm{H}, \mathrm{CH}=), 5.12-5.04(\mathrm{~m}, 6 \mathrm{H}, 6 \times$ $\mathrm{CH}=), 4.75\left(\mathrm{~d}, J=6.8 \mathrm{~Hz}, 2 \mathrm{H}, \mathrm{NCH}_{2}\right), 4.39\left(\mathrm{~d}, J=7.3 \mathrm{~Hz}, 2 \mathrm{H}, \mathrm{NCH}_{2}\right), 2.17-1.94\left(\mathrm{~m}, 24 \mathrm{H}, 12 \times \mathrm{CH}_{2}\right)$, $1.83\left(\mathrm{~s}, 3 \mathrm{H}, \mathrm{CH}_{3}\right), 1.75\left(\mathrm{~s}, 3 \mathrm{H}, \mathrm{CH}_{3}\right), 1.67\left(\mathrm{~s}, 6 \mathrm{H}, 2 \times \mathrm{CH}_{3}\right), 1.60\left(\mathrm{~s}, 9 \mathrm{H}, 3 \times \mathrm{CH}_{3}\right), 1.59\left(\mathrm{~s}, 6 \mathrm{H}, 2 \times \mathrm{CH}_{3}\right)$, $1.58\left(\mathrm{~s}, 3 \mathrm{H}, \mathrm{CH}_{3}\right) ;{ }^{13} \mathrm{C}\left\{{ }^{1} \mathrm{H}\right\} \mathrm{NMR}\left(150 \mathrm{MHz} \mathrm{CDCl}_{3}\right): \delta 172.8(\mathrm{HC}=\mathrm{O}), 159.8(\mathrm{C}, \mathrm{C}-4), 150.5(\mathrm{C}, \mathrm{C}-2)$, $144.3(\mathrm{C}=), 141.3(\mathrm{C}=), 140.8(\mathrm{C}, \mathrm{C}-6), 136.1(\mathrm{C}=), 135.4(\mathrm{C}=), 135.3(\mathrm{C}=), 135.1(\mathrm{C}=), 131.44(\mathrm{C}=), 131.40$ $(\mathrm{C}=), 124.53(\mathrm{CH}=), 124.48(\mathrm{CH}=), 124.4(\mathrm{CH}=), 124.1(\mathrm{CH}=), 124.0(\mathrm{CH}=), 123.4(\mathrm{CH}=), 117.4(\mathrm{CH}=)$, $116.9(\mathrm{CH}=), 97.4(\mathrm{C}, \mathrm{C}-5), 46.6\left(\mathrm{NCH}_{2}\right), 42.0\left(\mathrm{NCH}_{2}\right), 39.87\left(2 \times \mathrm{CH}_{2}\right), 39.86\left(\mathrm{CH}_{2}\right), 39.84\left(\mathrm{CH}_{2}\right), 39.82$ $\left(\mathrm{CH}_{2}\right), 39.7\left(\mathrm{CH}_{2}\right), 26.91\left(\mathrm{CH}_{2}\right), 26.90\left(\mathrm{CH}_{2}\right), 26.8\left(\mathrm{CH}_{2}\right), 26.7\left(\mathrm{CH}_{2}\right), 26.6\left(\mathrm{CH}_{2}\right), 26.3\left(\mathrm{CH}_{2}\right), 25.9(2 \times$ $\left.\mathrm{CH}_{3}\right), 17.8\left(2 \times \mathrm{CH}_{3}\right), 16.8\left(\mathrm{CH}_{3}\right), 16.7\left(\mathrm{CH}_{3}\right), 16.24\left(\mathrm{CH}_{3}\right), 16.18\left(\mathrm{CH}_{3}\right), 16.17\left(\mathrm{CH}_{3}\right), 16.16\left(\mathrm{CH}_{3}\right) ; \mathrm{IR}$ (film from $\mathrm{CH}_{2} \mathrm{Cl}_{2}$ ): $v_{\max } 2964,2916,2852,1622,1537,1452 \mathrm{~cm}^{-1}$; HRESIMS m/z: [M + H] $]^{+}$Calcd. for $\mathrm{C}_{45} \mathrm{H}_{70} \mathrm{~N}_{3} \mathrm{O}_{2}$ 684.5463; Found 684.5487 ( $\left.\Delta=3.5 \mathrm{ppm}\right) ;$ HRESIMS/MS (20 eV) m/z (\%): 684.2009 (2), 412.2985 (13), 140.0471 (100).

\subsubsection{5. (E)-2-(3,7-Dimethylocta-2,6-dien-1-yl)isoindoline-1,3-dione (67)}

Potassium phthalimide (2.6 mmol, $472.8 \mathrm{mg}), \mathrm{K}_{2} \mathrm{CO}_{3} / \mathrm{Na}_{2} \mathrm{CO}_{3}(1: 1,240 \mathrm{mg})$, and geranyl bromide (2.5 mmol, $543 \mathrm{mg}$ ) in DMF (10 mL) for $22 \mathrm{~h}$ yielded 67, additionally recrystallised from PE after chromatography, $170.2 \mathrm{mg}(24 \%)$, white crystals. $\mathrm{R}_{f}=0.59(1: 4 \mathrm{EA} / \mathrm{PE}) ;{ }^{1} \mathrm{H}$ and ${ }^{13} \mathrm{C} \mathrm{NMR}$, and IR data previously reported [56]; HRESIMS $m / z$ : $[\mathrm{M}+\mathrm{H}]^{+}$Calcd. for $\mathrm{C}_{18} \mathrm{H}_{22} \mathrm{NO}_{2} 284.1645$; Found 284.1640 $(\Delta=-1.8 \mathrm{ppm}) ;$ HRESIMS/MS (40 eV) m/z (\%): 160.0385 (100), 133.0287 (47), 81.0697 (22).

\subsubsection{2-((6E)-3,7,11-Trimethyldodeca-2,6,10-trien-1-yl)isoindoline-1,3-dione (68)}

Potassium phthalimide (2.9 mmol, $541.2 \mathrm{mg}), \mathrm{K}_{2} \mathrm{CO}_{3} / \mathrm{Na}_{2} \mathrm{CO}_{3}(1: 1,1.9 \mathrm{~g})$ and farnesyl bromide (2.0 mmol, $570.5 \mathrm{mg})$ in DMF $(10 \mathrm{~mL})$ for $19 \mathrm{~h}$ yielded $68,12.8 \mathrm{mg}(2 \%)$, colourless oil. $\mathrm{R}_{f}=0.23(1: 10$ $\mathrm{EA} / \mathrm{PE}) ; 5: 4 \mathrm{E} / \mathrm{Z},{ }^{1} \mathrm{H}$ and ${ }^{13} \mathrm{C} \mathrm{NMR}$ data for the (2E)-isomer previously reported [57]; NMR data for (2Z)-isomer: ${ }^{1} \mathrm{H}$ NMR (500 MHz, $\mathrm{CDCl}_{3}$ ): $\delta$ 7.84-7.81 (m, 2H, H-5), 7.71-7.68 (m, 2H, H-6), 5.30-5.24 $(\mathrm{m}, 1 \mathrm{H}, \mathrm{CH}=)$, 5.11-5.01 (m, 2H, $2 \times \mathrm{CH}=), 4.27\left(\mathrm{~d}, \mathrm{~J}=7.1 \mathrm{~Hz}, 2 \mathrm{H}, \mathrm{NCH}_{2}\right), 2.30-2.24\left(\mathrm{~m}, 2 \mathrm{H}, \mathrm{CH}_{2}\right)$, 2.01-2.03 (m, 2H, $\left.\mathrm{CH}_{2}\right), 2.03-1.97\left(\mathrm{~m}, 2 \mathrm{H}, \mathrm{CH}_{2}\right), 1.94-1.87\left(\mathrm{~m}, 2 \mathrm{H}, \mathrm{CH}_{2}\right), 1.82\left(\mathrm{~s}, 3 \mathrm{H}, \mathrm{CH}_{3}\right), 1.63(\mathrm{~s}, 3 \mathrm{H}$, $\left.\mathrm{CH}_{3}\right), 1.56\left(\mathrm{~s}, 6 \mathrm{H}, 2 \times \mathrm{CH}_{3}\right) ;{ }^{13} \mathrm{C}\left\{{ }^{1} \mathrm{H}\right\} \mathrm{NMR}\left(150 \mathrm{MHz} \mathrm{CDCl}_{3}\right): \delta 168.3(\mathrm{C}, \mathrm{C}-1), 140.8(\mathrm{C}=), 135.5(\mathrm{C}=)$, 133.9 (CH, C-6), 132.5 (C, C-4), $131.7(\mathrm{C}=), 124.6(\mathrm{CH}=), 124.4(\mathrm{CH}=), 123.3(\mathrm{CH}, \mathrm{C}-5), 118.1(\mathrm{CH}=)$, $39.9\left(\mathrm{CH}_{2}\right), 32.1\left(\mathrm{CH}_{2}\right), 35.9\left(\mathrm{NCH}_{2}\right), 26.7\left(\mathrm{CH}_{2}\right), 26.2\left(\mathrm{CH}_{2}\right), 25.9\left(\mathrm{CH}_{3}\right), 23.5\left(\mathrm{CH}_{3}\right), 17.8\left(\mathrm{CH}_{3}\right), 16.1$ $\left(\mathrm{CH}_{3}\right)$; IR (film from $\left.\mathrm{CH}_{2} \mathrm{Cl}_{2}\right): v_{\max } 2964,2917,2854,1710 \mathrm{~cm}^{-1} ; \mathrm{HRESIMS} \mathrm{m} / z:[\mathrm{M}+\mathrm{H}]^{+}$Calcd. for $\mathrm{C}_{23} \mathrm{H}_{30} \mathrm{NO}_{2}$ 352.2271; Found 352.2257 ( $\left.\Delta=-4.0 \mathrm{ppm}\right)$; HRESIMS/MS (40 eV) m/z (\%): 250.9685 (16), 160.0391(100).

\subsubsection{2-((2E,6E,10E)-3,7,11,15-Tetramethylhexadeca-2,6,10,14-tetraen-1-yl)isoindoline-1,3-dione (69)}

Following the general alkylation procedure, also previously published [58], potassium phthalimide $(0.30 \mathrm{mmol}, 54.8 \mathrm{mg}), \mathrm{K}_{2} \mathrm{CO}_{3}(1.1 \mathrm{mmol}, 155.6 \mathrm{mg})$ and geranylgeranyl bromide $(0.32 \mathrm{mmol}, 111 \mathrm{mg})$ yielded 69, $42.6 \mathrm{mg}(45 \%)$, colourless oil. $\mathrm{R}_{f}=0.31(1: 9 \mathrm{EA} / \mathrm{PE}) ;{ }^{1} \mathrm{H} \mathrm{NMR}\left(500 \mathrm{MHz}, \mathrm{CDCl}_{3}\right): \delta 7.83(\mathrm{dd}$, $J=5.3,3.0 \mathrm{~Hz}, 1 \mathrm{H}, \mathrm{H}-5), 7.69(\mathrm{dd}, J=5.4,3.0 \mathrm{~Hz}, 1 \mathrm{H}, \mathrm{H}-6), 5.27(\mathrm{t}, J=7.2 \mathrm{~Hz}, 1 \mathrm{H}, \mathrm{CH}=), 5.13-5.02$ $(\mathrm{m}, 3 \mathrm{H}, 3 \times \mathrm{CH}=), 4.28\left(\mathrm{~d}, J=7.1 \mathrm{~Hz}, 2 \mathrm{H}, \mathrm{NCH}_{2}\right), 2.11-1.89\left(\mathrm{~m}, 12 \mathrm{H}, 6 \times \mathrm{CH}_{2}\right), 1.83\left(\mathrm{~s}, 3 \mathrm{H}, \mathrm{CH}_{3}\right), 1.67$ $\left.\left(\mathrm{s}, 3 \mathrm{H}, \mathrm{CH}_{3}\right), 1.59\left(\mathrm{~s}, 3 \mathrm{H}, \mathrm{CH}_{3}\right), 1.57\left(\mathrm{~s}, 6 \mathrm{H}, 2 \times \mathrm{CH}_{3}\right) ;{ }^{13} \mathrm{C}^{1} \mathrm{H}\right\} \mathrm{NMR}\left(150 \mathrm{MHz}, \mathrm{CDCl}_{3}\right): \delta 168.2(\mathrm{C}$, C-1), $140.8(\mathrm{C}=), 135.4(\mathrm{C}=), 134.9(\mathrm{C}=), 133.9$ (CH, C-6), $132.4(\mathrm{C}, \mathrm{C}-4), 131.3(\mathrm{C}=), 124.5(\mathrm{CH}=), 124.3$ $(\mathrm{CH}=), 123.7(\mathrm{CH}=), 123.2(\mathrm{CH}, \mathrm{C}-5), 118.0(\mathrm{CH}=), 39.8\left(\mathrm{CH}_{2}\right), 39.7\left(\mathrm{CH}_{2}\right), 39.6\left(\mathrm{CH}_{2}\right), 35.9\left(\mathrm{NCH}_{2}\right), 26.8$ $\left(\mathrm{CH}_{2}\right), 26.7\left(\mathrm{CH}_{2}\right), 26.3\left(\mathrm{CH}_{2}\right), 25.8\left(\mathrm{CH}_{3}\right), 17.8\left(\mathrm{CH}_{3}\right), 16.5\left(\mathrm{CH}_{3}\right), 16.10\left(\mathrm{CH}_{3}\right), 16.07\left(\mathrm{CH}_{3}\right)$; IR (film 
from $\mathrm{CH}_{2} \mathrm{Cl}_{2}$ ): $v_{\max } 3057,2930,1710 \mathrm{~cm}^{-1}$; HRESIMS m/z: $[\mathrm{M}+\mathrm{H}]^{+}$Calcd. for $\mathrm{C}_{28} \mathrm{H}_{38} \mathrm{NO}_{2}$ 420.2897; Found $420.2889(\Delta=-1.9 \mathrm{ppm})$.

\subsubsection{8. (E)-1-(3,7-Dimethylocta-2,6-dien-1-yl)-1H-imidazole (70)}

Following the general alkylation procedure, also previously published [59], imidazole $(0.57 \mathrm{mmol}$, $38.7 \mathrm{mg}), \mathrm{K}_{2} \mathrm{CO}_{3}(0.66 \mathrm{mmol}, 91.4 \mathrm{mg})$ and geranyl bromide $(0.60 \mathrm{mmol}, 130 \mathrm{mg})$ in DMF (2 mL) for $46 \mathrm{~h}$ yielded 70, $36.7 \mathrm{mg}(32 \%)$, colourless oil. $\mathrm{R}_{f}=0.20(1: 1 \mathrm{EA} / \mathrm{PE}) ;{ }^{1} \mathrm{H}$ NMR data reported previously [60]; ${ }^{13} \mathrm{C}\left\{{ }^{1} \mathrm{H}\right\} \mathrm{NMR}\left(120 \mathrm{MHz}, \mathrm{CDCl}_{3}\right): \delta 141.7(\mathrm{C}=), 136.8(\mathrm{CH}, \mathrm{C}-2), 132.2(\mathrm{C}=), 129.3(\mathrm{CH}, \mathrm{C}-4), 123.6$ $(\mathrm{CH}=), 118.7(\mathrm{CH}, \mathrm{C}-5), 118.6(\mathrm{CH}=), 44.6\left(\mathrm{NCH}_{2}\right), 39.4\left(\mathrm{CH}_{2}\right), 26.2\left(\mathrm{CH}_{2}\right), 25.8\left(\mathrm{CH}_{3}\right), 17.8\left(\mathrm{CH}_{3}\right), 16.3$ $\left(\mathrm{CH}_{3}\right)$; IR (film from $\mathrm{CH}_{2} \mathrm{Cl}_{2}$ ): $v_{\max } 3110,2966,2916,2855 \mathrm{~cm}^{-1}$; HRESIMS $m / z$ : $[\mathrm{M}+\mathrm{H}]^{+}$Calcd. for $\mathrm{C}_{13} \mathrm{H}_{21} \mathrm{~N}_{2}$ 205.1699; Found $205.1700(\Delta=0.5 \mathrm{ppm}$ ); HRESIMS/MS (40 eV) $\mathrm{m} / \mathrm{z}(\%): 81.0716$ (21), 79.0559 (18), 69.0470 (100).

\subsubsection{1-((6E)-3,7,11-Trimethyldodeca-2,6,10-trien-1-yl)-1H-imidazole (71)}

Following the general alkylation procedure, also previously published [59], imidazole (0.51 $\mathrm{mmol}$, $34.6 \mathrm{mg}), \mathrm{K}_{2} \mathrm{CO}_{3}(0.65 \mathrm{mmol}, 90.4 \mathrm{mg})$ and farnesyl bromide $(0.60 \mathrm{mmol}, 171 \mathrm{mg})$ in DMF $(2 \mathrm{~mL})$ for $48 \mathrm{~h}$ yielded 71, $11.4 \mathrm{mg}(8 \%)$, colourless oil. $\mathrm{R}_{f}=0.10$ (1:1 EA/PE); 7:2 E/Z, NMR data for major isomer: ${ }^{1} \mathrm{H}$ NMR $\left(600 \mathrm{MHz}, \mathrm{CDCl}_{3}\right): \delta 7.46$ (s, 1H, H-2), 7.04 (s, 1H, H-4), 6.88 (s, 1H, H-5), 5.38-5.33 (m, 1H, $\mathrm{CH}=), 5.12-5.05(\mathrm{~m}, 2 \mathrm{H}, 2 \times \mathrm{CH}=), 4.52\left(\mathrm{~d}, J=7.1 \mathrm{~Hz}, 2 \mathrm{H}, \mathrm{NCH}_{2}\right), 2.19-1.94\left(\mathrm{~m}, 8 \mathrm{H}, 4 \times \mathrm{CH}_{2}\right), 1.75(\mathrm{~s}$, $\left.3 \mathrm{H}, \mathrm{CH}_{3}\right), 1.67\left(\mathrm{~s}, 3 \mathrm{H}, \mathrm{CH}_{3}\right), 1.60\left(\mathrm{~s}, 3 \mathrm{H}, \mathrm{CH}_{3}\right), 1.59\left(\mathrm{~s}, 3 \mathrm{H}, \mathrm{CH}_{3}\right) ;{ }^{13} \mathrm{C}\left\{{ }^{1} \mathrm{H}\right\} \mathrm{NMR}\left(150 \mathrm{MHz}, \mathrm{CDCl}_{3}\right): \delta$ $141.9(\mathrm{C}=) 136.8(\mathrm{CH}, \mathrm{C}-2), 135.9(\mathrm{C}=), 131.5(\mathrm{C}=), 129.2(\mathrm{CH}, \mathrm{C}-4), 124.4(\mathrm{CH}=), 123.5(\mathrm{CH}=), 118.8$ $(\mathrm{CH}, \mathrm{C}-5), 118.6(\mathrm{CH}=), 44.7\left(\mathrm{NCH}_{2}\right), 39.8\left(\mathrm{CH}_{2}\right), 39.5\left(\mathrm{CH}_{2}\right), 26.8\left(\mathrm{CH}_{2}\right), 26.3\left(\mathrm{CH}_{2}\right), 25.8\left(\mathrm{CH}_{3}\right), 17.8$ $\left(\mathrm{CH}_{3}\right), 16.5\left(\mathrm{CH}_{3}\right), 16.2\left(\mathrm{CH}_{3}\right)$; IR (film from $\left.\mathrm{CH}_{2} \mathrm{Cl}_{2}\right): v_{\max } 2965,2917,2856 \mathrm{~cm}^{-1}$; HRESIMS m/z: [M $+\mathrm{H}]^{+}$Calcd. for $\mathrm{C}_{18} \mathrm{H}_{29} \mathrm{~N}_{2}$ 273.2325; Found 273.2326 ( $\left.\Delta=0.4 \mathrm{ppm}\right) ;$ HRESIMS/MS (20 eV) $\mathrm{m} / \mathrm{z}(\%)$ : 81.0700 (45), 69.0457 (100).

\subsubsection{1-((2E,6E,10E)-3,7,11,15-Tetramethylhexadeca-2,6,10,14-tetraen-1-yl)-1H-imidazole (72)}

Imidazole $(0.30 \mathrm{mmol}, 20.4 \mathrm{mg}), \mathrm{K}_{2} \mathrm{CO}_{3}(0.34 \mathrm{mmol}, 46.4 \mathrm{mg})$ and geranylgeranyl bromide $(0.32$ $\mathrm{mmol}, 111 \mathrm{mg})$ in DMF (1 mL) for $48 \mathrm{~h}$ yielded $72,16.5 \mathrm{mg}(20 \%)$, colourless oil. $\mathrm{R}_{f}=0.18(2: 1 \mathrm{EA} / \mathrm{PE})$; ${ }^{1} \mathrm{H}$ NMR (500 MHz, CDCl $)$ ): $\delta 7.47$ (s, 1H, H-2), 7.05 (s, 1H, H-4), 6.89 (s, 1H, H-5), $5.36(\mathrm{t}, J=6.7 \mathrm{~Hz}$, $1 \mathrm{H}, \mathrm{CH}=), 5.12-5.05(\mathrm{~m}, 3 \mathrm{H}, 3 \times \mathrm{CH}=), 4.52\left(\mathrm{~d}, J=7.1 \mathrm{~Hz}, 2 \mathrm{H}, \mathrm{NCH}_{2}\right), 2.17-2.01\left(\mathrm{~m}, 8 \mathrm{H}, 4 \times \mathrm{CH}_{2}\right)$, 2.01-1.92 (m, 4H, $\left.\left.2 \times \mathrm{CH}_{2}\right), 1.75\left(\mathrm{~s}, 3 \mathrm{H}, \mathrm{CH}_{3}\right), 1.67\left(\mathrm{~s}, 3 \mathrm{H}, \mathrm{CH}_{3}\right), 1.59\left(\mathrm{~s}, 9 \mathrm{H}, 3 \times \mathrm{CH}_{3}\right) ;{ }^{13} \mathrm{C}^{1} \mathrm{H}\right\} \mathrm{NMR}$ $\left(150 \mathrm{MHz}, \mathrm{CDCl}_{3}\right): \delta 142.0(\mathrm{C}=), 136.8(\mathrm{CH}, \mathrm{C}-2), 135.9(\mathrm{C}=), 135.1(\mathrm{C}=), 131.4(\mathrm{C}=), 129.1(\mathrm{CH}, \mathrm{C}-4)$, 124.5 (CH=), $124.2(\mathrm{CH}=), 123.5(\mathrm{CH}=), 118.8(\mathrm{CH}, \mathrm{C}-5), 118.5(\mathrm{CH}=), 44.7\left(\mathrm{NCH}_{2}\right), 39.9\left(\mathrm{CH}_{2}\right), 39.8$ $\left(\mathrm{CH}_{2}\right), 39.5\left(\mathrm{CH}_{2}\right), 26.9\left(\mathrm{CH}_{2}\right), 26.7\left(\mathrm{CH}_{2}\right), 26.3\left(\mathrm{CH}_{2}\right), 25.8\left(\mathrm{CH}_{3}\right), 17.8\left(\mathrm{CH}_{3}\right), 16.5\left(\mathrm{CH}_{3}\right), 16.2\left(\mathrm{CH}_{3}\right)$, $16.1\left(\mathrm{CH}_{3}\right)$; IR (film from $\mathrm{CH}_{2} \mathrm{Cl}_{2}$ ): $v_{\max } 3118,2966,2925 \mathrm{~cm}^{-1}$; HRESIMS $\mathrm{m} / z$ : $[\mathrm{M}+\mathrm{H}]^{+}$Calcd. for $\mathrm{C}_{23} \mathrm{H}_{37} \mathrm{~N}_{2}$ 341.2951; Found 341.2934 ( $\left.\Delta=-5.0 \mathrm{ppm}\right) ;$ HRESIMS/MS (40 eV) $\mathrm{m} / \mathrm{z}(\%): 121.1001$ (95), 109.1006 (58), 107.0849 (100).

\subsection{General Formylation Procedure for Synthesis of 73-77}

\subsection{1. (E)-N-(3,7-Dimethylocta-2,6-dien-1-yl)formamide (73)}

Acetic anhydride $(3.6 \mathrm{mmol}, 0.336 \mathrm{~g}, 339 \mu \mathrm{L})$ was stirred on an ice bath for $10 \mathrm{~min}$ under nitrogen before addition of formic acid $(3.9 \mathrm{mmol}, 180 \mathrm{mg}, 147.6 \mu \mathrm{L})$. The ice bath was removed, and the reaction was heated at $55^{\circ} \mathrm{C}$ in an oil bath for $2.5 \mathrm{~h}$. The reaction was cooled to RT and geranylamine $(1.6 \mathrm{mmol}$, $250 \mathrm{mg}$ ) was added and reaction was stirred for $3 \mathrm{~h} . \mathrm{H}_{2} \mathrm{O}(3 \mathrm{~mL})$ was added and the mixture was extracted with EA $(3 \times 2 \mathrm{~mL})$. The combined extracts were washed with $\mathrm{H}_{2} \mathrm{O}(3 \times 2 \mathrm{~mL})$, then brine $(1 \times 2 \mathrm{~mL})$ and dried over anhydrous $\mathrm{MgSO}_{4}$. The solvent was removed under reduced pressure and the residue was purified by silica gel flash chromatography (2:3 EA/PE, $\left.\mathrm{R}_{f}=0.21\right)$ to yield $73,43.3 \mathrm{mg}$ (30\%), pale-yellow oil. ${ }^{1} \mathrm{H}$ and ${ }^{13} \mathrm{C}$ NMR data previously reported [61]; IR (film from $\mathrm{CH}_{2} \mathrm{Cl}_{2}$ ): $v_{\max }$ 
3277, 3045, 2968, 2915, 2856, $1655 \mathrm{~cm}^{-1}$; HRESIMS $m / z$ : [M + H] $]^{+}$Calcd. for $\mathrm{C}_{11} \mathrm{H}_{20} \mathrm{NO}$ 182.1539; Found 182.1528 ( $\Delta=-6.0$ ppm); HRESIMS/MS (20 eV) m/z (\%): 182.1502 (7), 137.1316 (100), 109.0999 (15).

3.3.2. $N-((2 Z, 6 E)-3,7,11-T r i m e t h y l d o d e c a-2,6,10$-trien-1-yl)formamide (74) and $\mathrm{N}$-((6E)-3,7,11-trimethyldodeca-2,6,10-trien-1-yl)formamide (75)

Acetic anhydride ( $2.5 \mathrm{mmol}, 254 \mathrm{mg}, 235 \mu \mathrm{L})$, formic acid $(2.7 \mathrm{mmol}, 124 \mathrm{mg}, 102 \mu \mathrm{L})$, and farnesylamine (1.13 mmol, $250 \mathrm{mg})$ for $5 \mathrm{~h}$ yielded 74 and 75.

Compound 74: $3.6 \mathrm{mg}(3 \%)$, colourless oil; $\mathrm{R}_{f}=0.18$ (1:2 EA/PE); $3: 1$ rotamers, IR, ${ }^{1} \mathrm{H}$ and ${ }^{13} \mathrm{C} \mathrm{NMR}$ data for the (2Z)-isomer previously reported [62]; IR (film from $\mathrm{CH}_{2} \mathrm{Cl}_{2}$ ): $v_{\max } 3024,2964,2919,2855$, $1656 \mathrm{~cm}^{-1}$; HRESIMS $\mathrm{m} / z$ : $[\mathrm{M}+\mathrm{H}]^{+}$Calcd. for $\mathrm{C}_{16} \mathrm{H}_{28} \mathrm{NO} 250.2165$; Found $250.2161(\Delta=-1.6 \mathrm{ppm})$; HRESIMS/MS (40 eV) m/z (\%): 109.1014 (74), 107.0841 (100).

Compound 75: $12.2 \mathrm{mg}(7 \%)$, colourless oil; $\mathrm{R}_{f}=0.14$ (1:2 EA/PE); 3:2 E/Z, 7:2 rotamers. ${ }^{1} \mathrm{H}$ and ${ }^{13} \mathrm{C}$ NMR data for the (2E)-isomer [63] and (2Z)-isomer [62] previously reported; IR (film from $\mathrm{CH}_{2} \mathrm{Cl}_{2}$ ): $v_{\max } 3279,2965,2916,2854,1657 \mathrm{~cm}^{-1}$; HRESIMS m/z: [M + H] $]^{+}$Calcd. for $\mathrm{C}_{16} \mathrm{H}_{28} \mathrm{NO} 250.2165$; Found 250.2159 ( $\Delta=-2.4$ ppm); HRESIMS/MS (40 eV) m/z (\%): 121.0998 (60), 109.1014 (100).

3.3.3. $\mathrm{N}-((2 Z, 6 E, 10 E)-3,7,11,15-$ Tetramethylhexadeca-2,6,10,14-tetraen-1-yl)formamide (76) and $\mathrm{N}-((2 E, 6 E, 10 E)-3,7,11,15$-tetramethylhexadeca-2,6,10,14-tetraen-1-yl)formamide (77)

Acetic anhydride $(2.3 \mathrm{mmol}, 233 \mathrm{mg}, 215.5 \mu \mathrm{L})$, formic acid $(2.5 \mathrm{mmol}, 115 \mathrm{mg}, 94 \mu \mathrm{L})$, and geranylgeranylamine $(0.86 \mathrm{mmol}, 250 \mathrm{mg})$ for $5 \mathrm{~h}$ yielded 76 and 77.

Compound 76: $3.8 \mathrm{mg}(6 \%)$, pale-yellow oil; $\mathrm{R}_{f}=0.26$ (2:3 EA/PE); 2:1 rotamers, data for major rotamer: ${ }^{1} \mathrm{H} \mathrm{NMR}\left(300 \mathrm{MHz}, \mathrm{CDCl}_{3}\right): \delta 8.14(\mathrm{~s}, 1 \mathrm{H}, \mathrm{HC}=\mathrm{O}), 5.28(\mathrm{br} \mathrm{s}, 1 \mathrm{H}, \mathrm{NH}), 5.21(\mathrm{t}, J=8.4 \mathrm{~Hz}$, $1 \mathrm{H}, \mathrm{CH}=), 5.10(\mathrm{br} \mathrm{s}, 3 \mathrm{H}, 3 \times \mathrm{CH}=), 3.88\left(\mathrm{t}, J=6.1 \mathrm{~Hz}, 2 \mathrm{H}, \mathrm{NCH}_{2}\right), 2.15-1.90\left(\mathrm{~m}, 12 \mathrm{H}, 6 \times \mathrm{CH}_{2}\right), 1.74$ $\left.\left(\mathrm{s}, 3 \mathrm{H}, \mathrm{CH}_{3}\right), 1.68\left(\mathrm{~s}, 6 \mathrm{H}, 2 \times \mathrm{CH}_{3}\right), 1.60\left(\mathrm{~s}, 6 \mathrm{H}, 2 \times \mathrm{CH}_{3}\right) ;{ }^{13} \mathrm{C}^{1}{ }^{1} \mathrm{H}\right\} \mathrm{NMR}\left(150 \mathrm{MHz}, \mathrm{CDCl}_{3}\right): \delta 160.9$ $(\mathrm{HC}=\mathrm{O}), 141.0(\mathrm{C}=), 136.1(\mathrm{C}=), 135.3(\mathrm{C}=), 131.5(\mathrm{C}=), 124.5(\mathrm{CH}=), 124.2(\mathrm{CH}=), 123.6(\mathrm{CH}=), 120.2$ $(\mathrm{CH}=), 39.9\left(2 \times \mathrm{CH}_{2}\right), 36.0\left(\mathrm{NCH}_{2}\right), 32.1\left(\mathrm{CH}_{2}\right), 26.9\left(\mathrm{CH}_{2}\right), 26.7\left(\mathrm{CH}_{2}\right), 26.5\left(\mathrm{CH}_{2}\right), 25.9\left(\mathrm{CH}_{3}\right), 23.5$ $\left(\mathrm{CH}_{3}\right), 17.8\left(\mathrm{CH}_{3}\right), 16.17\left(\mathrm{CH}_{3}\right), 16.15\left(\mathrm{CH}_{3}\right)$; IR (film from $\left.\mathrm{CH}_{2} \mathrm{Cl}_{2}\right): v_{\max } 3299,3024,2964,2920,2874$, $1656 \mathrm{~cm}^{-1}$; HRESIMS $\mathrm{m} / z$ : $[\mathrm{M}+\mathrm{H}]^{+}$Calcd. for $\mathrm{C}_{21} \mathrm{H}_{36} \mathrm{NO} 318.2791$; Found $318.2780(\Delta=-3.5 \mathrm{ppm})$; HRESIMS/MS (20 eV) m/z (\%): 177.1655 (22), 107.0838 (100).

Compound 77: $6.5 \mathrm{mg}(3 \%)$, pale-yellow oil; $\mathrm{R}_{f}=0.21$ (2:3 EA/PE); 3:1 rotamers, NMR data for major rotamer: ${ }^{1} \mathrm{H} \mathrm{NMR}\left(300 \mathrm{MHz}, \mathrm{CDCl}_{3}\right): \delta 8.16(\mathrm{~s}, 1 \mathrm{H}, \mathrm{HC}=\mathrm{O}), 5.41(\mathrm{br} \mathrm{s}, 1 \mathrm{H}, \mathrm{NH}), 5.20(\mathrm{t}, J=6.4 \mathrm{~Hz}$, $1 \mathrm{H}, \mathrm{CH}=), 5.10(\mathrm{br} \mathrm{s}, 3 \mathrm{H}, 3 \times \mathrm{CH}=), 3.90\left(\mathrm{t}, J=6.1 \mathrm{~Hz}, 3 \mathrm{H}, \mathrm{NCH}_{2}\right), 2.16-1.90\left(\mathrm{~m}, 12 \mathrm{H}, 6 \times \mathrm{CH}_{2}\right), 1.68(\mathrm{~s}$, $\left.\left.6 \mathrm{H}, 2 \times \mathrm{CH}_{3}\right), 1.60\left(\mathrm{~s}, 9 \mathrm{H}, 3 \times \mathrm{CH}_{3}\right) ;{ }^{13} \mathrm{C}^{1}{ }^{1} \mathrm{H}\right\} \mathrm{NMR}\left(150 \mathrm{MHz}, \mathrm{CDCl}_{3}\right): \delta 161.0(\mathrm{HC}=\mathrm{O}), 140.8(\mathrm{C}=)$, $135.7(\mathrm{C}=), 135.2(\mathrm{C}=), 131.5(\mathrm{C}=), 124.5(\mathrm{CH}=), 124.3(\mathrm{CH}=), 123.8(\mathrm{CH}=), 119.4(\mathrm{CH}=), 39.9\left(\mathrm{CH}_{2}\right), 39.8$ $\left(\mathrm{CH}_{2}\right), 39.6\left(\mathrm{CH}_{2}\right), 36.2\left(\mathrm{NCH}_{2}\right), 26.9\left(\mathrm{CH}_{2}\right), 26.8\left(\mathrm{CH}_{2}\right), 26.4\left(\mathrm{CH}_{2}\right), 25.9\left(\mathrm{CH}_{3}\right), 17.8\left(\mathrm{CH}_{3}\right), 16.5\left(\mathrm{CH}_{3}\right)$, $16.18\left(\mathrm{CH}_{3}\right), 16.16\left(\mathrm{CH}_{3}\right)$; IR (film from $\left.\mathrm{CH}_{2} \mathrm{Cl}_{2}\right): v_{\max } 3293,2966,2915,2853,1660 \mathrm{~cm}^{-1}$; HRESIMS $\mathrm{m} / z$ : $[\mathrm{M}+\mathrm{H}]^{+}$Calcd. for $\mathrm{C}_{21} \mathrm{H}_{36} \mathrm{NO}$ 318.2791; Found $318.2784(\Delta=-2.2 \mathrm{ppm}) ; \operatorname{HRESIMS} / \mathrm{MS}(20 \mathrm{eV}) \mathrm{m} / \mathrm{z}$ (\%): 121.0997 (59), 109.0998 (82), 107.0846 (100).

\subsection{General Acetylation Procedure for Synthesis of $\mathbf{8 1 - 8 5}$}

\subsection{1. (E)-N-(3,7-Dimethylocta-2,6-dien-1-yl)acetamide (81)}

Triethylamine ( $4.9 \mathrm{mmol}, 497 \mathrm{mg}, 681.5 \mu \mathrm{L}$ ) and geranylamine (1.6 mmol, $250.1 \mathrm{mg}$ ) in THF $(15 \mathrm{~mL})$ were stirred on an ice bath for $10 \mathrm{~min}$. Acetyl chloride $(2.5 \mathrm{mmol}, 0.192 \mathrm{~g}, 174 \mu \mathrm{L})$ was added and the reaction was stirred for $5 \mathrm{~h}$ while allowed to warm to room temperature. The reaction was quenched with ice-cold $\mathrm{H}_{2} \mathrm{O}(10 \mathrm{~mL})$ and the mixture was extracted with $\mathrm{EA}(2 \times 10 \mathrm{~mL})$. The combined extracts were washed with $\mathrm{H}_{2} \mathrm{O}(2 \times 10 \mathrm{~mL})$, then brine $(1 \times 10 \mathrm{~mL})$ and dried over anhydrous $\mathrm{MgSO}_{4}$. The solvent was removed under reduced pressure and the resulting residue was purified by silica gel flash chromatography (1:1 EA/PE, $\left.\mathrm{R}_{f}=0.16\right)$ to yield $81,96.1 \mathrm{mg}(30 \%)$, pale-yellow oil. ${ }^{1} \mathrm{H}$ and ${ }^{13} \mathrm{C}$ NMR data previously reported [39]; IR (film from $\mathrm{CH}_{2} \mathrm{Cl}_{2}$ ): $v_{\max } 3293,3081,2970,2928,1649 \mathrm{~cm}^{-1}$; 
HRESIMS $m / z:[\mathrm{M}+\mathrm{H}]^{+}$Calcd. for $\mathrm{C}_{12} \mathrm{H}_{22} \mathrm{NO}$ 196.1696; Found 196.1708 ( $\Delta=6.1 \mathrm{ppm}$ ); HRESIMS/MS (40 eV) m/z (\%): 137.1312 (34), 109.0997 (79), 107.0473 (100).

3.4.2. $N-((2 Z, 6 E)-3,7,11-T r i m e t h y l d o d e c a-2,6,10$-trien-1-yl)acetamide (82) and $N-((2 E, 6 E)-3,7,11$-trimethyldodeca-2,6,10-trien-1-yl)acetamide (83)

Triethylamine (3.4 mmol, $342.7 \mathrm{mg}, 472 \mu \mathrm{L})$, farnesylamine $(1.1 \mathrm{mmol}, 250.1 \mathrm{mg})$, and acetyl chloride $(1.7 \mathrm{mmol}, 133 \mathrm{mg}, 120 \mu \mathrm{L})$ yielded 82 and 83 .

Compound 82: $9.9 \mathrm{mg}(9 \%)$, pale-yellow oil; $\mathrm{R}_{f}=0.30$ (1:1 EA/PE); ${ }^{1} \mathrm{H} \mathrm{NMR}\left(500 \mathrm{MHz}, \mathrm{CDCl}_{3}\right): \delta$ $5.32(\mathrm{br} \mathrm{s}, 1 \mathrm{H}, \mathrm{NH}), 5.20(\mathrm{t}, J=7.2 \mathrm{~Hz}, 1 \mathrm{H}, \mathrm{CH}=), 5.12-5.04(\mathrm{~m}, 2 \mathrm{H}, 2 \times \mathrm{CH}=), 3.82(\mathrm{t}, J=6.5 \mathrm{~Hz}, 2 \mathrm{H}$, $\left.\mathrm{NCH}_{2}\right), 2.11-1.97\left(\mathrm{~m}, 8 \mathrm{H}, 4 \times \mathrm{CH}_{2}\right), 1.96\left(\mathrm{~s}, 3 \mathrm{H}, \mathrm{CH}_{3} \mathrm{C}=\mathrm{O}\right), 1.72\left(\mathrm{~s}, 3 \mathrm{H}, \mathrm{CH}_{3}\right), 1.68\left(\mathrm{~s}, 3 \mathrm{H}, \mathrm{CH}_{3}\right), 1.60(\mathrm{~s}$, $\left.6 \mathrm{H}, 2 \times \mathrm{CH}_{3}\right) ;{ }^{13} \mathrm{C}\left\{{ }^{1} \mathrm{H}\right\} \mathrm{NMR}\left(150 \mathrm{MHz}, \mathrm{CDCl}_{3}\right): \delta 169.9(\mathrm{C}=\mathrm{O}), 140.5(\mathrm{C}=), 135.9(\mathrm{C}=), 131.6(\mathrm{C}=), 124.3$ $(\mathrm{CH}=), 123.6(\mathrm{CH}=), 120.7(\mathrm{CH}=), 39.9\left(\mathrm{CH}_{2}\right), 37.5\left(\mathrm{NCH}_{2}\right), 32.03\left(\mathrm{CH}_{2}\right), 26.8\left(\mathrm{CH}_{2}\right), 26.5\left(\mathrm{CH}_{2}\right), 25.9$ $\left(\mathrm{CH}_{3}\right), 23.5\left(\mathrm{CH}_{3} \mathrm{C}=\mathrm{O}\right), 23.4\left(\mathrm{CH}_{3}\right), 17.9\left(\mathrm{CH}_{3}\right), 16.2\left(\mathrm{CH}_{3}\right)$; IR (film from $\left.\mathrm{CH}_{2} \mathrm{Cl}_{2}\right): v_{\max } 3293,3086$, 2967, 2927, 2857, $1653 \mathrm{~cm}^{-1}$; HRESIMS m/z: $[\mathrm{M}+\mathrm{H}]^{+}$Calcd. for $\mathrm{C}_{17} \mathrm{H}_{30} \mathrm{NO} 264.2322$; Found 264.2319 $(\Delta=-1.1 \mathrm{ppm}) ;$ HRESIMS/MS (40 eV) $\mathrm{m} / \mathrm{z}(\%): 109.1008$ (95), 107.0850 (100).

Compound 83: $65.1 \mathrm{mg}(37 \%)$, pale-yellow oil; $\mathrm{R}_{f}=0.22(1: 1 \mathrm{EA} / \mathrm{PE}) ;{ }^{1} \mathrm{H}$ NMR data previously reported [41]; ${ }^{13} \mathrm{C}\left\{{ }^{1} \mathrm{H}\right\} \mathrm{NMR}\left(150 \mathrm{MHz}, \mathrm{CDCl}_{3}\right): \delta 169.9(\mathrm{C}=\mathrm{O}), 140.3(\mathrm{C}=), 135.6(\mathrm{C}=), 131.5(\mathrm{C}=), 124.4$ $(\mathrm{CH}=), 123.8(\mathrm{CH}=), 119.9(\mathrm{CH}=), 39.8\left(\mathrm{CH}_{2}\right), 39.6\left(\mathrm{CH}_{2}\right), 37.8\left(\mathrm{NCH}_{2}\right), 26.9\left(\mathrm{CH}_{2}\right), 26.4\left(\mathrm{CH}_{2}\right), 25.9$ $\left(\mathrm{CH}_{3}\right), 23.4\left(\mathrm{CH}_{3} \mathrm{C}=\mathrm{O}\right), 17.8\left(\mathrm{CH}_{3}\right), 16.4\left(\mathrm{CH}_{3}\right), 16.2\left(\mathrm{CH}_{3}\right)$; IR (film from $\left.\mathrm{CH}_{2} \mathrm{Cl}_{2}\right): v_{\max } 3279,3080$, 2966, 2917, 2855, $1659 \mathrm{~cm}^{-1}$; HRESIMS $\mathrm{m} / z$ : $[\mathrm{M}+\mathrm{H}]^{+}$Calcd. for $\mathrm{C}_{17} \mathrm{H}_{30} \mathrm{NO} 264.2322$; Found 264.2318 $(\Delta=-1.5 \mathrm{ppm}) ;$ HRESIMS/MS (40 eV) m/z (\%): 109.1000 (57), 107.0843 (100).

3.4.3. $N-((2 Z, 6 E, 10 E)-3,7,11,15-T e t r a m e t h y l h e x a d e c a-2,6,10,14-$ tetraen-1-yl)acetamide (84) and $N$-((2E,6E,10E)-3,7,11,15-tetramethylhexadeca-2,6,10,14-tetraen-1-yl)acetamide (85)

Triethylamine (3.16 mmol, $319 \mathrm{mg}, 440 \mu \mathrm{L})$, geranylgeranylamine $(1.0 \mathrm{mmol}, 300 \mathrm{mg})$, and acetyl chloride $(1.1 \mathrm{mmol}, 89 \mathrm{mg}, 81 \mu \mathrm{L})$ in THF $(10 \mathrm{~mL})$ yielded 84 and 85 .

Compound 84: $22.1 \mathrm{mg}(27 \%)$, pale-yellow oil; $\mathrm{R}_{f}=0.20(1: 1 \mathrm{EA} / \mathrm{PE}) ;{ }^{1} \mathrm{H}$ NMR $\left(300 \mathrm{MHz}, \mathrm{CDCl}_{3}\right)$ : $\delta 5.38(\mathrm{br} \mathrm{s}, 1 \mathrm{H}, \mathrm{NH}), 5.19(\mathrm{t}, J=7.2 \mathrm{~Hz}, 1 \mathrm{H}, \mathrm{CH}=), 5.14-5.03(\mathrm{~m}, 3 \mathrm{H}, 3 \times \mathrm{CH}=), 3.81(\mathrm{t}, J=6.1 \mathrm{~Hz}, 2 \mathrm{H}$, $\left.\mathrm{NCH}_{2}\right), 2.13-1.96\left(\mathrm{~m}, 12 \mathrm{H}, 6 \times \mathrm{CH}_{2}\right), 1.95\left(\mathrm{~s}, 3 \mathrm{H}, \mathrm{CH}_{3} \mathrm{C}=\mathrm{O}\right), 1.72\left(\mathrm{~s}, 3 \mathrm{H}, \mathrm{CH}_{3}\right), 1.67\left(\mathrm{~s}, 3 \mathrm{H}, \mathrm{CH}_{3}\right), 1.59$ $\left(\mathrm{s}, 9 \mathrm{H}, 3 \times \mathrm{CH}_{3}\right) ;{ }^{13} \mathrm{C}\left\{{ }^{1} \mathrm{H}\right\} \mathrm{NMR}\left(150 \mathrm{MHz}, \mathrm{CDCl}_{3}\right): \delta 169.9(\mathrm{C}=\mathrm{O}), 140.4(\mathrm{C}=), 136.0(\mathrm{C}=), 135.2(\mathrm{C}=)$, $131.4(\mathrm{C}=), 124.5(\mathrm{CH}=), 124.2(\mathrm{CH}=), 123.6(\mathrm{CH}=), 120.7(\mathrm{CH}=), 39.9\left(\mathrm{CH}_{2}\right), 39.8\left(\mathrm{CH}_{2}\right), 37.5\left(\mathrm{NCH}_{2}\right)$, 32.1 $\left(\mathrm{CH}_{2}\right), 26.9\left(\mathrm{CH}_{2}\right), 26.7\left(\mathrm{CH}_{2}\right), 26.5\left(\mathrm{CH}_{2}\right), 25.8\left(\mathrm{CH}_{3}\right), 23.5\left(\mathrm{CH}_{3}\right), 23.4\left(\mathrm{CH}_{3} \mathrm{C}=\mathrm{O}\right), 17.8\left(\mathrm{CH}_{3}\right), 16.2$ $\left(\mathrm{CH}_{3}\right), 16.1\left(\mathrm{CH}_{3}\right)$; IR (film from $\left.\mathrm{CH}_{2} \mathrm{Cl}_{2}\right)$ : $v_{\max } 3277,3078,2965,2916,2855,1649 \mathrm{~cm}^{-1}$; HRESIMS $\mathrm{m} / z$ : $[\mathrm{M}+\mathrm{H}]^{+}$Calcd. for $\mathrm{C}_{22} \mathrm{H}_{38} \mathrm{NO}$ 332.2948; Found 332.2951 ( $\left.\Delta=0.9 \mathrm{ppm}\right)$; HRESIMS/MS (10 eV) $\mathrm{m} / \mathrm{z}(\%)$ : 332.2946 (100), 273.2567 (9).

Compound 85: $95.5 \mathrm{mg}(38 \%)$, pale-yellow oil; $\mathrm{R}_{f}=0.14$ (1:1 EA/PE); ${ }^{1} \mathrm{H} \mathrm{NMR}\left(300 \mathrm{MHz}, \mathrm{CDCl}_{3}\right)$ : $\delta 5.32(\mathrm{br} \mathrm{s}, 1 \mathrm{H}, \mathrm{NH}), 5.19(\mathrm{t}, J=6.8 \mathrm{~Hz}, 1 \mathrm{H}, \mathrm{CH}=), 5.15-5.04(\mathrm{~m}, 3 \mathrm{H}, 3 \times \mathrm{CH}=), 3.84(\mathrm{t}, J=6.1 \mathrm{~Hz}$, $\left.2 \mathrm{H}, \mathrm{NCH}_{2}\right), 2.15-1.98\left(\mathrm{~m}, 12 \mathrm{H}, 6 \times \mathrm{CH}_{2}\right), 1.67\left(\mathrm{~s}, 6 \mathrm{H}, 2 \times \mathrm{CH}_{3}\right), 1.60\left(\mathrm{~s}, 9 \mathrm{H}, 3 \times \mathrm{CH}_{3}\right) ;{ }^{13} \mathrm{C}\left\{{ }^{1} \mathrm{H}\right\} \mathrm{NMR}$ $\left(150 \mathrm{MHz}, \mathrm{CDCl}_{3}\right): \delta 169.9(\mathrm{C}=\mathrm{O}), 140.3(\mathrm{C}=), 135.6(\mathrm{C}=), 135.2(\mathrm{C}=), 131.5(\mathrm{C}=), 124.5(\mathrm{CH}=), 124.3$ $(\mathrm{CH}=), 123.8(\mathrm{CH}=), 119.9(\mathrm{CH}=), 39.9\left(\mathrm{CH}_{2}\right), 39.8\left(\mathrm{CH}_{2}\right), 39.6\left(\mathrm{CH}_{2}\right), 37.8\left(\mathrm{NCH}_{2}\right), 26.9\left(\mathrm{CH}_{2}\right), 26.8$ $\left(\mathrm{CH}_{2}\right), 26.5\left(\mathrm{CH}_{2}\right), 25.9\left(\mathrm{CH}_{3}\right), 23.5\left(\mathrm{CH}_{3} \mathrm{C}=\mathrm{O}\right), 17.8\left(\mathrm{CH}_{3}\right), 16.5\left(\mathrm{CH}_{3}\right), 16.19\left(\mathrm{CH}_{3}\right), 16.17\left(\mathrm{CH}_{3}\right)$; IR (film from $\mathrm{CH}_{2} \mathrm{Cl}_{2}$ ): $v_{\max } 3279,3078,2967,2917,2854,1650 \mathrm{~cm}^{-1}$; HRESIMS m/z: $[\mathrm{M}+\mathrm{H}]^{+}$Calcd. for $\mathrm{C}_{22} \mathrm{H}_{38} \mathrm{NO}$ 332.2948; Found 332.2934 ( $\left.\Delta=-4.2 \mathrm{ppm}\right)$; HRESIMS/MS (20 eV) $\mathrm{m} / z(\%): 332.3002$ (100), 149.1318 (100).

\subsection{General Methylation Procedure for Synthesis of $\mathbf{7 8 - 8 0}$ and $\mathbf{8 6 - 8 8}$}

\subsection{1. (E)-N-(3,7-Dimethylocta-2,6-dien-1-yl)-N-methylformamide (78)}

Freshly powdered $\mathrm{KOH}(0.647 \mathrm{mmol}, 36.3 \mathrm{mg})$ was stirred in dry DMSO $(0.1 \mathrm{~mL})$ for $10 \mathrm{~min}$ before the addition of $73(0.17 \mathrm{mmol}, 30.0 \mathrm{mg}$, in $0.1 \mathrm{~mL} \mathrm{DMSO})$, followed immediately by the addition 
of methyl iodide $(0.5 \mathrm{mmol}, 71.0 \mathrm{mg}, 31.2 \mu \mathrm{L})$. The reaction was stirred for $2.5 \mathrm{~h}$, then poured onto $\mathrm{H}_{2} \mathrm{O}$ $(3 \mathrm{~mL})$ and extracted with DCM $(3 \times 2 \mathrm{~mL})$. The combined extracts were washed with $\mathrm{H}_{2} \mathrm{O}(5 \times 2 \mathrm{~mL})$, then brine $(1 \times 2 \mathrm{~mL})$ and dried over anhydrous $\mathrm{MgSO}_{4}$. The solvent was removed under reduced pressure and the resulting residue was purified by silica gel flash chromatography $\left(1: 3 \mathrm{EA} / \mathrm{PE}, \mathrm{R}_{f}=\right.$ $0.14)$ to yield $78,17.4 \mathrm{mg}(54 \%)$, colourless oil. $3: 2$ rotamers, data for major rotamer: ${ }^{1} \mathrm{H}$ NMR $(500 \mathrm{MHz}$, $\left.\mathrm{CDCl}_{3}\right): \delta 8.06(\mathrm{~s}, 1 \mathrm{H}, \mathrm{HC}=\mathrm{O}), 5.11-5.06(\mathrm{~m}, 1 \mathrm{H}, \mathrm{CH}=), 5.06-5.01(\mathrm{~m}, 1 \mathrm{H}, \mathrm{CH}=), 3.80(\mathrm{~d}, J=7.1 \mathrm{~Hz}$, $\left.2 \mathrm{H}, \mathrm{NCH}_{2}\right), 2.78\left(\mathrm{~s}, 3 \mathrm{H}, \mathrm{NCH}_{3}\right), 2.13-1.99\left(\mathrm{~m}, 4 \mathrm{H}, 2 \times \mathrm{CH}_{2}\right), 1.67\left(\mathrm{~s}, 3 \mathrm{H}, \mathrm{CH}_{3}\right), 1.66\left(\mathrm{~s}, 3 \mathrm{H}, \mathrm{CH}_{3}\right), 1.58$ $\left(\mathrm{s}, 3 \mathrm{H}, \mathrm{CH}_{3}\right) ;{ }^{13} \mathrm{C}\left\{{ }^{1} \mathrm{H}\right\} \mathrm{NMR}\left(150 \mathrm{MHz}, \mathrm{CDCl}_{3}\right): \delta 162.5(\mathrm{HC}=\mathrm{O}), 141.3(\mathrm{C}=), 132.1(\mathrm{C}=), 123.7(\mathrm{CH}=)$, 119.1 (CH=), 47.2 ( $\left.\mathrm{NCH}_{2}\right), 39.7\left(\mathrm{CH}_{2}\right), 29.2\left(\mathrm{NCH}_{3}\right), 26.3\left(\mathrm{CH}_{2}\right), 25.8\left(\mathrm{CH}_{3}\right), 17.8\left(\mathrm{CH}_{3}\right), 16.30\left(\mathrm{CH}_{3}\right) ; \mathrm{IR}$ (film from $\mathrm{CH}_{2} \mathrm{Cl}_{2}$ ): $v_{\max } 2965,2917,2854,1663 \mathrm{~cm}^{-1}$; HRESIMS $\mathrm{m} / z$ : $[\mathrm{M}+\mathrm{H}]^{+}$Calcd. for $\mathrm{C}_{12} \mathrm{H}_{22} \mathrm{NO}$ 196.1696; Found 196.1695 ( $\Delta=-0.5$ ppm); HRESIMS/MS (20 eV) m/z (\%): 196.1694 (17), 137.1319 (100), 109.1010 (21).

\subsubsection{N-Methyl-N-((6E)-3,7,11-trimethyldodeca-2,6,10-trien-1-yl)formamide (79)}

$\mathrm{KOH}(0.18 \mathrm{mmol}, 9.9 \mathrm{mg}), 75$ (0.040 mmol, $10 \mathrm{mg})$, and methyl iodide $(0.12 \mathrm{mmol}, 17 \mathrm{mg}, 7.5 \mu \mathrm{L})$ yielded 79, $5.9 \mathrm{mg}$ (56\%), colourless oil. $\mathrm{R}_{f}=0.10$ (1:4 EA/PE); 3:2 E/Z, 3:2 rotamers, data for major isomer and rotamer: ${ }^{1} \mathrm{H}$ NMR $\left(500 \mathrm{MHz}, \mathrm{CDCl}_{3}\right): \delta 8.08(\mathrm{~s}, 1 \mathrm{H}, \mathrm{CH}=\mathrm{O}), 5.13-5.04(\mathrm{~m}, 3 \mathrm{H}, 3 \times \mathrm{CH}=)$, $3.81\left(\mathrm{~d}, J=7.0 \mathrm{~Hz}, 2 \mathrm{H}, \mathrm{NCH}_{2}\right), 2.79\left(\mathrm{~s}, 3 \mathrm{H}, \mathrm{NCH}_{3}\right), 2.14-2.00\left(\mathrm{~m}, 6 \mathrm{H}, 3 \times \mathrm{CH}_{2}\right), 1.99-1.93\left(\mathrm{~m}, 2 \mathrm{H}, \mathrm{CH}_{2}\right)$, $\left.1.68\left(\mathrm{~s}, 3 \mathrm{H}, \mathrm{CH}_{3}\right), 1.64\left(\mathrm{~s}, 3 \mathrm{H}, \mathrm{CH}_{3}\right), 1.59\left(\mathrm{~s}, 6 \mathrm{H}, 2 \times \mathrm{CH}_{3}\right) ;{ }^{13} \mathrm{C}^{1}{ }^{1} \mathrm{H}\right\} \mathrm{NMR}\left(150 \mathrm{MHz}, \mathrm{CDCl}_{3}\right): \delta 162.6$ $(\mathrm{HC}=\mathrm{O}), 141.4(\mathrm{C}=), 135.8(\mathrm{C}=), 131.5(\mathrm{C}=), 124.4(\mathrm{CH}=), 123.6(\mathrm{CH}=), 119.0(\mathrm{CH}=), 47.3\left(\mathrm{NCH}_{2}\right), 39.9$ $\left(\mathrm{CH}_{2}\right), 39.7\left(\mathrm{CH}_{2}\right), 29.2\left(\mathrm{NCH}_{3}\right), 26.8\left(\mathrm{CH}_{2}\right), 26.3\left(\mathrm{CH}_{2}\right), 25.9\left(\mathrm{CH}_{3}\right), 17.8\left(\mathrm{CH}_{3}\right), 16.4\left(\mathrm{CH}_{3}\right), 16.2\left(\mathrm{CH}_{3}\right)$; IR (film from $\mathrm{CH}_{2} \mathrm{Cl}_{2}$ ): $v_{\max } 3495,2963,2916,2853,1677,1665 \mathrm{~cm}^{-1}$; HRESIMS $m / z$ : $[\mathrm{M}+\mathrm{H}]^{+}$Calcd. for $\mathrm{C}_{17} \mathrm{H}_{30} \mathrm{NO} 264.2322$; Found 264.2324 ( $\left.\Delta=0.8 \mathrm{ppm}\right)$; HRESIMS/MS (40 eV) $\mathrm{m} / \mathrm{z}(\%): 109.1001$ (53), 107.085 (100), 105.0694 (58).

\subsubsection{N-Methyl-N-((2E,6E,10E)-3,7,11,15-tetramethylhexadeca-2,6,10,14-tetraen-1-yl)formamide (80)}

$\mathrm{KOH}(0.201 \mathrm{mmol}, 11.3 \mathrm{mg}), 77(0.047 \mathrm{mmol}, 15 \mathrm{mg})$, and methyl iodide $(0.14 \mathrm{mmol}, 20 \mathrm{mg}, 8.8 \mu \mathrm{L})$ yielded 80, $5.2 \mathrm{mg}(33 \%)$, colourless oil. $\mathrm{R}_{f}=0.13(1: 3 \mathrm{EA} / \mathrm{PE}) ;{ }^{1} \mathrm{H} \mathrm{NMR}\left(500 \mathrm{MHz}, \mathrm{CDCl}_{3}\right): \delta 8.08$ (s, $1 \mathrm{H}, \mathrm{HC}=\mathrm{O}), 5.15-5.03(\mathrm{~m}, 4 \mathrm{H}, 4 \times \mathrm{CH}=), 3.81\left(\mathrm{~d}, J=7.0 \mathrm{~Hz}, 2 \mathrm{H}, \mathrm{NCH}_{2}\right), 2.79\left(\mathrm{~s}, 3 \mathrm{H}, \mathrm{NCH}_{3}\right), 2.14-2.01$ $\left(\mathrm{m}, 8 \mathrm{H}, 4 \times \mathrm{CH}_{2}\right), 2.01-1.88\left(\mathrm{~m}, 4 \mathrm{H}, 2 \times \mathrm{CH}_{2}\right), 1.69\left(\mathrm{~s}, 3 \mathrm{H}, \mathrm{CH}_{3}\right), 1.68\left(\mathrm{~s}, 3 \mathrm{H}, \mathrm{CH}_{3}\right), 1.61\left(\mathrm{~s}, 3 \mathrm{H}, \mathrm{CH}_{3}\right), 1.60$ $\left(\mathrm{s}, 6 \mathrm{H}, 2 \times \mathrm{CH}_{3}\right) ;{ }^{13} \mathrm{C}\left\{{ }^{1} \mathrm{H}\right\} \mathrm{NMR}\left(150 \mathrm{MHz}, \mathrm{CDCl}_{3}\right): \delta 162.5(\mathrm{HC}=\mathrm{O}), 141.4(\mathrm{C}=), 135.8(\mathrm{C}=), 135.2(\mathrm{C}=)$, 131.4 $(\mathrm{C}=), 124.5(\mathrm{CH}=), 124.2(\mathrm{CH}=), 123.6(\mathrm{CH}=), 119.0(\mathrm{CH}=), 47.3\left(\mathrm{NCH}_{2}\right), 39.9\left(\mathrm{CH}_{2}\right), 39.8\left(\mathrm{CH}_{2}\right)$, $39.7\left(\mathrm{CH}_{2}\right), 29.2\left(\mathrm{NCH}_{3}\right), 26.9\left(\mathrm{CH}_{2}\right), 26.7\left(\mathrm{CH}_{2}\right), 26.4\left(\mathrm{CH}_{2}\right), 25.9\left(\mathrm{CH}_{3}\right), 17.8\left(\mathrm{CH}_{3}\right), 16.4\left(\mathrm{CH}_{3}\right), 16.18$ $\left(\mathrm{CH}_{3}\right), 16.15\left(\mathrm{CH}_{3}\right)$; IR (film from $\left.\mathrm{CH}_{2} \mathrm{Cl}_{2}\right): v_{\max } 2962,2922,2854,1681 \mathrm{~cm}^{-1}$; HRESIMS $m / z:[\mathrm{M}+\mathrm{H}]^{+}$ Calcd. for $\mathrm{C}_{22} \mathrm{H}_{38} \mathrm{NO}$ 332.2948; Found 322.2955 ( $\Delta=2.2 \mathrm{ppm}$ ); HRESIMS/MS (40 eV) $\mathrm{m} / \mathrm{z}(\%): 123.1153$ (39), 121.003 (51), 109.1002 (74), 107.0846 (100).

\subsection{4. $N$-Methyl-N-((2E,6E)-3,7,11-trimethyldodeca-2,6,10-trien-1-yl)acetamide (86)}

$\mathrm{KOH}(0.18 \mathrm{mmol}, 9.9 \mathrm{mg}), 83$ (0.04 mmol, $10 \mathrm{mg})$, and methyl iodide $(0.12 \mathrm{mmol}, 17 \mathrm{mg}, 7.5 \mu \mathrm{L})$ yielded 86, $5.9 \mathrm{mg}(53 \%)$, colourless oil. $\mathrm{R}_{f}=0.06$ (1:4 EA/PE); E/Z 2:1, NMR data major isomer and rotamer: ${ }^{1} \mathrm{H}$ NMR $\left(500 \mathrm{MHz}, \mathrm{CDCl}_{3}\right): \delta 5.15-5.06(\mathrm{~m}, 3 \mathrm{H}, 3 \times \mathrm{CH}=), 4.01\left(\mathrm{~d}, J=7.0 \mathrm{~Hz}, 2 \mathrm{H}, \mathrm{NCH}_{2}\right), 2.91$ (s, 3H, $\left.\mathrm{CH}_{3} \mathrm{C}=\mathrm{O}\right), 2.14-2.10\left(\mathrm{~m}, 2 \mathrm{H}, \mathrm{CH}_{2}\right), 2.10\left(\mathrm{~s}, 3 \mathrm{H}, \mathrm{NCH}_{3}\right), 2.07-2.02\left(\mathrm{~m}, 4 \mathrm{H}, 2 \times \mathrm{CH}_{2}\right), 2.00-1.95$ $\left.\left(\mathrm{m}, 2 \mathrm{H}, \mathrm{CH}_{2}\right), 1.69\left(\mathrm{~s}, 3 \mathrm{H}, \mathrm{CH}_{3}\right), 1.68\left(\mathrm{~s}, 3 \mathrm{H}, \mathrm{CH}_{3}\right), 1.61\left(\mathrm{~s}, 6 \mathrm{H}, 2 \times \mathrm{CH}_{3}\right) ;{ }^{13} \mathrm{C}^{1}{ }^{1} \mathrm{H}\right\} \mathrm{NMR}(150 \mathrm{MHz}$, $\left.\mathrm{CDCl}_{3}\right): \delta 170.3(\mathrm{C}=\mathrm{O}), 139.6(\mathrm{C}=), 135.7(\mathrm{C}=), 131.5(\mathrm{C}=), 124.4(\mathrm{CH}=), 123.6(\mathrm{CH}=), 119.6(\mathrm{CH}=), 48.7$ $\left(\mathrm{NCH}_{2}\right), 39.9\left(\mathrm{CH}_{2}\right), 39.6\left(\mathrm{CH}_{2}\right), 35.2\left(\mathrm{NCH}_{3}\right), 26.9\left(\mathrm{CH}_{2}\right), 26.4\left(\mathrm{CH}_{2}\right), 25.8\left(\mathrm{CH}_{3}\right), 21.6\left(\mathrm{CH}_{3} \mathrm{C}=\mathrm{O}\right), 17.8$ $\left(\mathrm{CH}_{3}\right), 16.4\left(\mathrm{CH}_{3}\right), 16.2\left(\mathrm{CH}_{3}\right)$; IR (film from $\left.\mathrm{CH}_{2} \mathrm{Cl}_{2}\right): v_{\max } 2964,2916,2856,1646 \mathrm{~cm}^{-1}$; HRESIMS $\mathrm{m} / z$ : $[\mathrm{M}+\mathrm{H}]^{+}$Calcd. for $\mathrm{C}_{18} \mathrm{H}_{32} \mathrm{NO} 278.2478$; Found 278.2482 ( $\left.\Delta=1.4 \mathrm{ppm}\right)$; HRESIMS/MS (40 eV) $\mathrm{m} / \mathrm{z}(\%)$ : 121.0993(33), 107.0841 (100). 
3.5.5. N-Methyl-N-((2Z,6E,10E)-3,7,11,15-tetramethylhexadeca-2,6,10,14-tetraen-1-yl)acetamide (87)

$\mathrm{KOH}(0.32 \mathrm{mmol}, 18.0 \mathrm{mg}), 84(0.051 \mathrm{mmol}, 17.0 \mathrm{mg})$, and methyl iodide $(0.15 \mathrm{mmol}, 21.8 \mathrm{mg}$, $9.6 \mu \mathrm{L})$ yielded $87,5.1 \mathrm{mg}(29 \%)$, colourless oil. $\mathrm{R}_{f}=0.04(1: 5 \mathrm{EA} / \mathrm{PE}) ;{ }^{1} \mathrm{H} \mathrm{NMR}\left(500 \mathrm{MHz}, \mathrm{CDCl}_{3}\right): \delta$ 5.17-5.07 (m, 4H, $4 \times \mathrm{CH}=), 4.00\left(\mathrm{~d}, J=7.0 \mathrm{~Hz}, 2 \mathrm{H}, \mathrm{NCH}_{2}\right), 2.92\left(\mathrm{~s}, 3 \mathrm{H}, \mathrm{NCH}_{3}\right), 2.14-2.10(\mathrm{~m}, 4 \mathrm{H}, 2 \times$ $\left.\mathrm{CH}_{2}\right), 2.10\left(\mathrm{~s}, 3 \mathrm{H}, \mathrm{CH}_{3} \mathrm{C}=\mathrm{O}\right), 2.09-2.04\left(\mathrm{~m}, 4 \mathrm{H}, 2 \times \mathrm{CH}_{2}\right), 2.03-1.97\left(\mathrm{~m}, 4 \mathrm{H}, 2 \times \mathrm{CH}_{2}\right), 1.77\left(\mathrm{~s}, 3 \mathrm{H}, \mathrm{CH}_{3}\right)$, $\left.1.69\left(\mathrm{~s}, 3 \mathrm{H}, \mathrm{CH}_{3}\right), 1.63\left(\mathrm{~s}, 3 \mathrm{H}, \mathrm{CH}_{3}\right), 1.61\left(\mathrm{~s}, 6 \mathrm{H}, 2 \times \mathrm{CH}_{3}\right) ;{ }^{13} \mathrm{C}^{1}{ }^{1} \mathrm{H}\right\} \mathrm{NMR}\left(150 \mathrm{MHz}, \mathrm{CDCl}_{3}\right): \delta 170.5$ $(\mathrm{C}=\mathrm{O}), 139.8(\mathrm{C}=), 136.1(\mathrm{C}=), 135.8(\mathrm{C}=), 131.4(\mathrm{C}=), 124.5(\mathrm{CH}=)$ 124.3 $(\mathrm{CH}=), 124.1(\mathrm{CH}=), 120.3$ $(\mathrm{CH}=), 48.5\left(\mathrm{NCH}_{2}\right), 39.9\left(2 \times \mathrm{CH}_{2}\right), 35.3\left(\mathrm{NCH}_{3}\right), 32.2\left(\mathrm{CH}_{2}\right), 26.9\left(\mathrm{CH}_{2}\right), 26.7\left(\mathrm{CH}_{2}\right), 26.4\left(\mathrm{CH}_{2}\right), 25.9$ $\left(\mathrm{CH}_{3}\right), 23.5\left(\mathrm{CH}_{3}\right), 22.0\left(\mathrm{CH}_{3} \mathrm{C}=\mathrm{O}\right), 17.8\left(\mathrm{CH}_{3}\right), 16.17\left(\mathrm{CH}_{3}\right), 16.16\left(\mathrm{CH}_{3}\right)$; IR (film from $\left.\mathrm{CH}_{2} \mathrm{Cl}_{2}\right)$ : $v_{\max }$ 2965, 2915, 2854, $1650 \mathrm{~cm}^{-1}$; HRESIMS m/z: $[\mathrm{M}+\mathrm{H}]^{+}$Calcd. for $\mathrm{C}_{23} \mathrm{H}_{40} \mathrm{NO} 346.3104$; Found 346.3113 $(\Delta=2.6$ ppm); HRESIMS/MS (40 eV) m/z (\%):123.1163 (46), 121.1009 (100).

\subsection{6. $N$-Methyl-N-((2E,6E,10E)-3,7,11,15-tetramethylhexadeca-2,6,10,14-tetraen-1-yl)acetamide (88)}

$\mathrm{KOH}(0.36 \mathrm{mmol}, 20.3 \mathrm{mg}), 85(0.090 \mathrm{mmol}, 30 \mathrm{mg})$, and methyl iodide $(0.27 \mathrm{mmol}, 38.7 \mathrm{mg}$, $17.0 \mu \mathrm{L}$ ) yielded 88, $4.7 \mathrm{mg}(15 \%)$, colourless oil. $\mathrm{R}_{f}=0.05(1: 5 \mathrm{EA} / \mathrm{PE}) ;{ }^{1} \mathrm{H} \mathrm{NMR}\left(500 \mathrm{MHz}, \mathrm{CDCl}_{3}\right)$ : 反 5.17-5.07 (m, 4H, $4 \times \mathrm{CH}=), 4.02\left(\mathrm{~d}, J=7.0 \mathrm{~Hz}, 2 \mathrm{H}, \mathrm{NCH}_{2}\right), 2.92\left(\mathrm{~s}, 3 \mathrm{H}, \mathrm{NCH}_{3}\right), 2.15-2.11(\mathrm{~m}, 4 \mathrm{H}$, $\left.2 \times \mathrm{CH}_{2}\right), 2.10\left(\mathrm{~s}, 3 \mathrm{H}, \mathrm{CH}_{3} \mathrm{C}=\mathrm{O}\right), 2.08-2.04\left(\mathrm{~m}, 4 \mathrm{H}, 2 \times \mathrm{CH}_{2}\right), 2.01-1.96\left(\mathrm{~m}, 4 \mathrm{H}, 2 \times \mathrm{CH}_{2}\right), 1.69(\mathrm{~s}$, $\left.\left.6 \mathrm{H}, 2 \times \mathrm{CH}_{3}\right), 1.64\left(\mathrm{~s}, 3 \mathrm{H}, \mathrm{CH}_{3}\right), 1.61\left(\mathrm{~s}, 6 \mathrm{H}, 2 \times \mathrm{CH}_{3}\right) ;{ }^{13} \mathrm{C}^{1}{ }^{1} \mathrm{H}\right\} \mathrm{NMR}\left(150 \mathrm{MHz}, \mathrm{CDCl}_{3}\right): \delta 170.5$ $(\mathrm{C}=\mathrm{O}), 139.7(\mathrm{C}=), 135.7(\mathrm{C}=), 135.2(\mathrm{C}=), 131.4(\mathrm{C}=), 124.5(\mathrm{CH}=), 124.2(\mathrm{CH}=), 123.6(\mathrm{CH}=), 119.4$ $(\mathrm{CH}=), 48.7\left(\mathrm{NCH}_{2}\right), 39.9\left(2 \times \mathrm{CH}_{2}\right), 39.6\left(\mathrm{CH}_{2}\right), 35.2\left(\mathrm{NCH}_{3}\right), 26.9\left(2 \times \mathrm{CH}_{2}\right), 26.4\left(\mathrm{CH}_{2}\right), 25.9\left(\mathrm{CH}_{3}\right)$, $22.0\left(\mathrm{CH}_{3} \mathrm{C}=\mathrm{O}\right), 17.8\left(\mathrm{CH}_{3}\right), 16.4\left(\mathrm{CH}_{3}\right), 16.19\left(\mathrm{CH}_{3}\right), 16.15\left(\mathrm{CH}_{3}\right)$; IR (film from $\left.\mathrm{CH}_{2} \mathrm{Cl}_{2}\right): v_{\max } 2965$, 2916, 2854, $1650 \mathrm{~cm}^{-1}$; HRESIMS $\mathrm{m} / z$ : $[\mathrm{M}+\mathrm{H}]^{+}$Calcd. for $\mathrm{C}_{23} \mathrm{H}_{40} \mathrm{NO} 346.3104$; Found 346.3109 $(\Delta=1.4$ ppm); HRESIMS/MS (40 eV) m/z (\%):123.1161 (47), 107.0851 (100).

\subsection{Purification of TbHsp70, TbHsp70.4, HsHSPA8 and HsDNAJB2}

Escherichia coli (E. coli.) bacterial cells transformed with the respective expression vector were grown at $37{ }^{\circ} \mathrm{C}$ in $2 \times$ YT medium supplemented with respective antibiotic and were grown to mid-logarithmic phase $\left(\mathrm{A}_{600}\right.$ 0.4-0.6). Protein production was induced by the addition of $1 \mathrm{mM}$ IPTG (isopropyl- $\beta$-D-thiogalactopyranoside), and the bacterial cultures were incubated at $37^{\circ} \mathrm{C}$ for $3 \mathrm{~h}$ for TbHsp70, HsHSPA8, HsDNAJB2, and $1 \mathrm{~h}$ for TbHsp70.4. Bacterial cells expressing the recombinant proteins were harvested by centrifugation $\left(10,000 \mathrm{~g} ; 15 \mathrm{~min} ; 4^{\circ} \mathrm{C}\right)$ and the cell pellet was resuspended in lysis buffer (100 mM Tris-HCl, pH 7.5, $300 \mathrm{mM} \mathrm{NaCl}, 20 \mathrm{mM}$ imidazole, $1 \mathrm{mM}$ PMSF, $1 \mathrm{mg} / \mathrm{mL}$ lysozyme), allowed to stand for $30 \mathrm{~min}$ at room temperature and then frozen at $-80{ }^{\circ} \mathrm{C}$ overnight. The cells were then thawed on ice and sonicated at $4{ }^{\circ} \mathrm{C}$. The resulting lysate was cleared by centrifugation $\left(13,000 \mathrm{~g}, 40 \mathrm{~min}, 4^{\circ} \mathrm{C}\right)$ and the supernatant was incubated with cOmplete His-tag purification resin (Roche, Germany) and allowed to bind overnight at $4{ }^{\circ} \mathrm{C}$ with gentle agitation. The resin was then pelleted by centrifugation ( $4500 \mathrm{~g} ; 4 \mathrm{~min}$ ) to remove unbound proteins and washed three times using native wash buffer (100 mM Tris- $\mathrm{HCl}, \mathrm{pH} 7.5,300 \mathrm{mM} \mathrm{NaCl}, 50 \mathrm{mM}$ imidazole, $1 \mathrm{mM}$ PMSF) to remove non-specific contaminants. The bound protein was eluted three times by re-suspending the resin in elution buffer (10 mM Tris- $\mathrm{HCl}, \mathrm{pH} 7.5,300 \mathrm{mM} \mathrm{NaCl}, 750 \mathrm{mM}$ imidazole). The eluted proteins were extensively dialyzed using SnakeSkin dialysis tubing (Pierce-MWCO 10,000; Thermo Scientific, Waltham, MA, USA) into the appropriate assay buffer for functional studies and then subsequently concentrated against PEG 20,000 (Merck, Darmstadt, Germany). The protein yield was estimated using the Bradford assay (Sigma-Aldrich, St. Louis, MO, USA) with BSA as the standard. SDS-PAGE (10\%) and Western analysis using mouse monoclonal anti-His primary antibody and HRP-conjugated goat anti-mouse IgG secondary antibody (Santa Cruz Biotechnology, Inc., Dallas, TX, USA) were conducted to assess the expression and purification of the recombinant proteins (Figure S5). HRP-conjugated goat anti-rabbit (Santa Cruz Biotechnology, Inc., Dallas, TX, USA) was used as the secondary antibody. Imaging of the protein bands on the blot was conducted using the ECL kit (Thermo Scientific, Waltham, 
MA, USA) as per the manufacturer's instructions. Images were captured using the ChemiDoc Imaging system (Bio-Rad, Hercules, CA, USA).

\subsection{Purification of Tbj2}

Recombinant N-terminal His-tagged Tbj2 was expressed and purified under native conditions using nickel affinity chromatography from E. coli BL21 (DE3) cells as previously described [64]. Samples were dialyzed into the appropriate assay buffer for functional studies.

\subsection{Growth and Maintenance of T. $b$. brucei Cultures}

Bloodstream form T. $b$. brucei Lister 927 variant 221 strain parasites were cultured in filter sterilized complete Iscoves Modified Dulbeccos Media (IMDM) based HM1-9 medium (IMDM base powder, $3.6 \mathrm{mM}$ sodium bicarbonate, $1 \mathrm{mM}$ hypoxanthine, $1 \mathrm{mM}$ sodium pyruvate, $0.16 \mathrm{mM}$ thymidine, $0.05 \mathrm{mM}$ bathocuprone sulphate acid, $10 \%(v / v)$ heat inactivated foetal bovine serum, $1.5 \mathrm{mM}$ L-cysteine, $0.2 \mathrm{mM} \beta$-mercaptoethanol, $\mathrm{pH}$ 7.5) in a humidified chamber at $37{ }^{\circ} \mathrm{C}$ with an atmosphere of $5 \% \mathrm{CO}_{2}$. Parasite growth was monitored using a Neubauer haemocytometer to count the cell number, after which cells were diluted, according to their density, in the described pre-warmed media.

\subsection{Assessment of the Anti-Trypanosomal Activity of the Compounds on Bloodstream Form T. b. bruce Parasites}

All compounds of interest were resuspended to stocks of $30 \mathrm{mM}$ in DMSO and stored at $-80{ }^{\circ} \mathrm{C}$ prior to use in in vitro experiments. For assessment of anti-trypanosomal activity, compounds were added to in vitro cultures of bloodstream form T. b. brucei parasites $\left(1 \times 10^{5}\right.$ cells $\left./ \mathrm{mL}\right)$ in 96 -well plates at a fixed concentration of $20 \mu \mathrm{M}$. After an incubation period of $48 \mathrm{~h}$, the number of parasites surviving drug exposure were determined using a resazurin-based cytotoxicity assay [65]. Resazurin is an oxidation-reduction sensitive dye that is reduced by living cells to resorufin. Resorufin is a fluorophore (Excitation $560 /$ Emission $_{590}$ ) and thus was quantified in a multi-well fluorescence plate reader. Results are expressed as \% parasite viability-the resorufin fluorescence in small molecule-treated wells relative to untreated controls. Assessment of each small molecule was conducted in duplicate, with error bars representing standard deviation (SD). The compounds that displayed $80 \%$ parasite growth inhibition when tested at $20 \mu \mathrm{M}$ were evaluated in a dose-response experiment. The compounds were added to in vitro cultures of bloodstream form T. b. brucei parasites $\left(1 \times 10^{5}\right.$ cells $\left./ \mathrm{mL}\right)$ in 96-well plates in a 3-fold dilution series with $100 \mu \mathrm{M}$ as the highest concentration. After an incubation period of $48 \mathrm{~h}$, the number of parasites surviving drug exposure were determined as previously mentioned. The \% parasite viability was determined as previously mentioned. The $\mathrm{IC}_{50}$ (the concentration of compound required to decrease cell viability of T. $b$. brucei parasites by $50 \%$ compared to those grown in the absence of the compound) values for each of the compounds were determined from a dose-response curve by non-linear regression generated using GraphPad Prism ${ }^{\circledR}$ (v. 7.0; San Diego, CA, USA) software. For comparative purposes, pentamidine at a fixed concentration of $1 \mu \mathrm{M}$ was employed as a drug standard.

\subsection{Growth and Maintenance of HeLa Cells}

HeLa cells were grown and maintained in a culture medium comprised of Dulbecco's Modified Eagle's Medium (DMEM) with $5 \mathrm{mM}$ L-glutamine (Lonza, Basel, Switzerland), supplemented with $10 \%(v / v)$ heat inactivated foetal bovine serum and antibiotics (penicillin/streptomycin/fungizone-PSF) in a humidified chamber at $37^{\circ} \mathrm{C}$ with an atmosphere of $5 \% \mathrm{CO}_{2}$. To carry out passaging of cells, cultures were treated with $1 \%$ trypsin $(w / v)$ to lift cells, which were then washed in $1 \times$ phosphate buffered saline (PBS) before being re-seeded into culture flasks.

\subsection{Assessment of the Cytotoxicity of the Small Molecules on a Mammalian Cell Line}

For assessment of the cytotoxic effects, the small molecules were added to HeLa cells at a fixed concentration of $20 \mu \mathrm{M}$. After an incubation period of $24 \mathrm{~h}$, the number of cells surviving drug exposure 
were determined using a resazurin-based cytotoxicity assay. The resazurin-based cytotoxicity assay was conducted as previously mentioned. Results were expressed as \% cell-the resorufin fluorescence in small molecule-treated wells relative to untreated controls. Assessment of each small molecule was conducted in duplicate, with error bars representing standard deviation (SD). For comparative purposes, emetine at a fixed concentration of $10 \mu \mathrm{M}$ was employed as a drug standard.

\subsection{MDH Aggregation Suppression Assay}

The described assay was adapted as a tool for screening the modulatory effects of the selected compounds on the chaperone function of the T. brucei Hsp70s. As an initial screen of the modulatory effects of the compounds on the chaperone function of the Hsp70s, compounds were used at a concentration of $300 \mu \mathrm{M}$. For compounds identified to have a modulatory effect on the chaperone function of Hsp70, a concentration-dependency experiment was conducted where the screening expanded the concentration range $(0,50,150$, and $300 \mu \mathrm{M})$ of the compound. These experiments were conducted on three independently purified batches of proteins, but due to limited availability of the selected compounds, each assay was conducted in duplicate on each batch of protein. Several controls were incorporated into the study. To evaluate the effect of DMSO on the chaperone activity of the Hsp70s, the solvent was added to a final concentration of $1 \%(v / v)$ in the assay with MDH and the T. brucei Hsp70. The selected compounds were also assayed (at the maximum concentration: $300 \mu \mathrm{M}$ ) together with MDH (no chaperone) to rule out that the compounds were causing an increase or decrease in $\mathrm{MDH}$ aggregation; and together with chaperones (no $\mathrm{MDH}$ ) to ensure that the modulatory of the chaperone activity was not due to aggregation of the Hsp70 in the presence of compounds. The assays were performed in duplicate on three independently purified batches of proteins.

\subsection{ATPase Activity Assay}

The determination of the ATPase activity of the Hsp70 proteins was performed using the high throughput colorimetric ATPase assay kit (Innova Biosciences, Cambridge, UK). This method enables the quantification of the inorganic phosphate $(\mathrm{Pi})$ released from ATP hydrolysis by an enzyme. Briefly, the molecular chaperones were prepared in ATPase assay buffer (100 mM Tris- $\mathrm{HCl}, 7.5,2 \mathrm{mM} \mathrm{MgCl}$, $50 \mathrm{mM} \mathrm{KCl}, 0.5 \mathrm{mM}$ DTT) and incubated with ATP $(0-2 \mathrm{mM})$ for $1 \mathrm{~h}$ at $37^{\circ} \mathrm{C}$. A negative control did not contain the enzyme. The samples containing Pi hydrolysed from ATP were incubated with the PiColorLock ${ }^{\mathrm{TM}}$ solution, which is a malachite green dye solution that in the presence of Pi changes absorbance due to generation of molybdate-phosphate complexes. The absorbance was measured at $595 \mathrm{~nm}$ using a Powerwave 96-well plate reader (BioTek Instruments, Inc., Winooski, VT, USA), and absorbance values were converted to phosphate concentrations using a standard curve of absorbance vs. phosphate concentration based on a set of Pi standards provided by the supplier assayed along with the samples. All samples were corrected for spontaneous breakdown of ATP observed in a control experiment in the absence of protein. The trypanosomal and human Hsp70s were used at $0.8 \mu \mathrm{M}$, and the J-proteins were used at $0.4 \mu \mathrm{M}$. An initial screen of the modulatory effects of the compounds on the ATPase activity of the Hsp70s was conducted using $300 \mu \mathrm{M}$ of the compounds. Compounds identified to have a modulatory effect on the basal and J-protein-stimulated ATPase activity of Hsp70 were used at varying concentrations. The modulatory effect of the selected compounds on the basal and J-protein stimulated ATPase activity of the T. brucei Hsp70s was represented as fold change with the basal and J-protein stimulated ATPase activity of the Hsp70s taken as 1 respectively. These experiments were conducted on three independently purified batches of proteins, but due to limited availability of the selected compounds, each assay was conducted in duplicate on each batch of protein. In control reactions to evaluate the effect of DMSO on basal and J-protein stimulated ATPase activity of the Hsp70s, the solvent was added to a final concentration of $1 \%(v / v)$ in the assay. The assays were performed in duplicate on three independently purified batches of proteins. 


\section{Conclusions}

In conclusion, a large number of malonganenone and nuttingin analogues have been synthesized and assessed for SAR relating to the anti-trypanosomal activity. Some relevant observations include a general increase in anti-parasitic activity with increasing lipophilicity (side-chain length) and certain head-groups are responsible for heightened activity over others. Of particular note is that the greatest anti-parasitic activity was achieved with compounds 47 and 48 , which share the same head-group but vary in the position of the side chain, indicating flexibility within the SAR to allow for variation around both geometry and position of the lipophilic portion of the drug. In addition, cytotoxicity studies have shown that the compounds tested are generally inactive against mammalian cells, while biochemical studies have shown that these compounds potentially modulate the Hsp70 basal chaperone activity, but not the co-chaperone-stimulated chaperone activity. Overall, our study has therefore opened a new series of drug leads and could support the rational design of more active chemotherapeutic agents in the future. Such work is ongoing in our laboratories.

Supplementary Materials: The following are available online at http://www.mdpi.com/1660-3397/18/2/81/s1, Figure S1: Assessment of the anti-trypanosomal activity of the compounds, Table S1: $\mathrm{IC}_{50}$ values and structures of 48 select compounds, Figure S2: Evaluation of the cytotoxicity on mammalian cells of the compounds, Figure S3: The solubility of Human HSPA8 after heat exposure, Figure S4: Investigation of the modulatory effect of the small molecules on the thermally induced aggregation of $\mathrm{MDH}$, Figure S5: Purification of the recombinant trypanosomal and human heat shock proteins, Figure S6: Preliminary screening of the effects of the compounds on the basal ATPase activities of the TbHsp70s and HsHSPA8, Figure S7: Preliminary screening of the effects of the compounds on the J-stimulated ATPase activities of the TbHsp70s and HsHSPA8, Figures S8-S156: ${ }^{1} \mathrm{H}$ and ${ }^{13} \mathrm{C}$ NMR spectra of synthesized compounds.

Author Contributions: Conceptualization, A.B. and R.A.K.; methodology, G.L.B., A.B. and R.A.K.; formal analysis, S.J.B., S.K.A., A.B. and R.A.K.; investigation, S.J.B. and S.K.A.; resources, A.B. and R.A.K.; writing-Original draft preparation, S.J.B., A.B., and S.K.A.; writing-Review and editing, S.J.B., S.K.A., A.B., G.L.B. and R.A.K.; supervision, A.B. and R.A.K.; project administration, A.B. and R.A.K. All authors have read and agreed to the published version of the manuscript.

Funding: This work was funded by a grant from the National Research Foundation (NRF), grant number 87663. S.J.B. was a recipient of an NRF Doctoral Innovation Scholarship.

Acknowledgments: The assistance of J. Vorster with NMR and MS analyses, and J. Harvey for synthetic discussions, is gratefully acknowledged, as is the Curtis Gordon Research Scholarship for personal funding (S.K.A.). The pET28a-Tbj2 and pQE2-TbHsp70.4 expression vectors were kindly provided by Michael Ludewig (Rhodes University, South Africa). The pPROEXHTa-HsHSPA8 expression vector was kindly provided by Jason Young (McGill University, Canada). Michelle Isaacs (Rhodes University) for T. $b$. brucei culturing, and the screening of the cytotoxicity of the compounds on T. b. brucei parasites and HeLa cells at the parasite facility, which is supported by the South African Medical Research Council (MRC).

Conflicts of Interest: The authors declare no conflict of interest.

\section{References}

1. Aksoy, S. Control of tsetse flies and trypanosomes using molecular genetics. Vet. Parasitol. 2003, 115, 125-145. [CrossRef]

2. Baral, T.N. Immunobiology of African trypanosomes: Need of alternative interventions. J. Biomed. Biotechnol. 2010, 2010, 389153. [CrossRef] [PubMed]

3. Barrett, M.P.; Croft, S.L. Management of trypanosomiasis and leishmaniasis. Br. Med. Bull. 2012, 104, $175-196$. [CrossRef] [PubMed]

4. Shonhai, A.; Maier, A.G.; Przyborski, J.M.; Blatch, G.L. Intracellular protozoan parasites of humans: The role of molecular chaperones in development and pathogenesis. Protein Pept. Lett. 2011, 18, 143-157. [CrossRef]

5. Requena, J.M.; Montalvo, A.M.; Fraga, J. Molecular chaperones of leishmania: Central players in many stress-related and -unrelated physiological processes. Biomed Res. Int. 2015, 2015, 301326. [CrossRef]

6. Bukau, B.; Horwich, A.L. The Hsp70 and Hsp60 chaperone machines. Cell 1998, 92, 351-366. [CrossRef]

7. Mayer, M.P.; Bukau, B. Hsp70 chaperones: Cellular functions and molecular mechanism. Cell. Mol. Life Sci. 2005, 62, 670-684. [CrossRef] 
8. Zhu, X.; Zhao, X.; Burkholder, W.F.; Gragerov, A.; Ogata, C.M.; Gottesman, M.E.; Hendrickson, W.A. Structural analysis of substrate binding by the molecular chaperone DnaK. Science 1996, 272, 1606-1614. [CrossRef]

9. Wang, T.F.; Chang, J.H.; Wang, C. Identification of the peptide binding domain of hsc70. 18-Kilodalton fragment located immediately after ATPase domain is sufficient for high affinity binding. J. Biol. Chem. 1993, 268, 26049-26051.

10. Cheetham, M.E.; Caplan, A.J. Structure, function and evolution of DnaJ: Conservation and adaptation of chaperone function. Cell Stress Chaperon. 1998, 3, 28-36. [CrossRef]

11. Stirling, P.C.; Lundin, V.F.; Leroux, M.R. Getting a grip on non-native proteins. Embo Rep. 2003, 4, 565-570. [CrossRef] [PubMed]

12. Bentley, S.J.; Jamabo, M.; Boshoff, A. The Hsp70/J-protein machinery of the African trypanosome, Trypanosoma brucei. Cell Stress Chaperon. 2019, 24, 125-148. [CrossRef] [PubMed]

13. Alsford, S.; Turner, D.J.; Obado, S.O.; Sanchez-Flores, A.; Glover, L.; Berriman, M.; Hertz-Fowler, C.; Horn, D. High-throughput phenotyping using parallel sequencing of RNA interference targets in the African trypanosome. Genome Res. 2011, 21, 915-924. [CrossRef] [PubMed]

14. Ludewig, M.H.; Boshoff, A.; Horn, D.; Blatch, G.L. Trypanosoma brucei J protein 2 is a stress inducible and essential Hsp40. Int. J. Biochem. Cell Biol. 2015, 60, 93-98. [CrossRef]

15. Burger, A.; Ludewig, M.H.; Boshoff, A. Investigating the chaperone properties of a novel heat shock protein, Hsp70.c, from Trypanosoma brucei. J. Parasitol. Res. 2014, 2014, 172582. [CrossRef]

16. Botha, M.; Chiang, A.N.; Needham, P.G.; Stephens, L.L.; Hoppe, H.C.; Kulzer, S.; Przyborski, J.M.; Lingelbach, K.; Wipf, P.; Brodsky, J.L.; et al. Plasmodium falciparum encodes a single cytosolic type I Hsp40 that functionally interacts with Hsp70 and is upregulated by heat shock. Cell Stress Chaperon. 2011, 16, 389-401. [CrossRef]

17. Cockburn, I.L.; Pesce, E.-R.; Pryzborski, J.M.; Davies-Coleman, M.T.; Clark, P.G.K.; Keyzers, R.A.; Stephens, L.L.; Blatch, G.L. Screening for small molecule modulators of Hsp70 chaperone activity using protein aggregation suppression assays: Inhibition of the plasmodial chaperone PfHsp70-1. Biol. Chem. 2011, 392, 431-438. [CrossRef]

18. Cockburn, I.L.; Boshoff, A.; Pesce, E.-R.; Blatch, G.L. Selective modulation of plasmodial Hsp70s by small molecules with antimalarial activity. Biol. Chem. 2014, 395, 1353-1362. [CrossRef]

19. Zininga, T.; Ramatsui, L.; Makhado, P.B.; Makumire, S.; Achilinou, I.; Hoppe, H.; Dirr, H.; Shonhai, A. (-)-Epigallocatechin-3-gallate inhibits the vhaperone sctivity of Plasmodium falciparum Hsp70 chaperones and abrogates their association with functional partners. Molecules 2017, 22, 2139. [CrossRef]

20. Zininga, T.; Pooe, O.J.; Makhado, P.B.; Ramatsui, L.; Prinsloo, E.; Achilonu, I.; Dirr, H.; Shonhai, A. Polymyxin B inhibits the chaperone activity of Plasmodium falciparum Hsp70. Cell Stress Chaperon. 2017, 22, 707-715. [CrossRef]

21. Keyzers, R.A.; Gray, C.A.; Schleyer, M.H.; Whibley, C.E.; Hendricks, D.T.; Davies-Coleman, M.T. Malonganenones A-C, novel tetraprenylated alkaloids from the Mozambique Gorgonian Leptogorgia gilchristi. Tetrahedron 2006, 62, 2200-2206. [CrossRef]

22. Sorek, H.; Rudi, A.; Benayahu, Y.; Ben-Califa, N.; Neumann, D.; Kashman, Y. Nuttingins A-F and malonganenones D-H, tetraprenylated slkaloids from the Tanzanian gorgonian Euplexaura nuttingi. J. Nat. Prod. 2007, 70, 1104-1109. [CrossRef] [PubMed]

23. Zhang, J.-R.; Li, P.-L.; Tang, X.-L.; Qi, X.; Li, G.-Q. Cytotoxic tetraprenylated alkaloids from the South China sea Gorgonian Euplexaura robusta. Chemi. Biodivers. 2012, 9, 2218-2224. [CrossRef] [PubMed]

24. Sun, Z.-H.; Cai, Y.-H.; Fan, C.-Q.; Tang, G.-H.; Luo, H.-B.; Yin, S. Six new tetraprenylated alkaloids from the South China sea Gorgonian Echinogorgia pseudossapo. Mar. Drugs 2014, 12, 672-681. [CrossRef]

25. Chamgordani, E.J.; Paulsen, J.; Gundersen, L.-L. Selective N-7 alkylation of 3-methylhypoxanthine; the first synthesis of malonganenone. J. Tetrahedron Lett. 2016, 57, 4926-4929. [CrossRef]

26. Lindquist, S.; Craig, E.A. The heat-shock proteins. Annu. Rev. Genet. 1988, 22, 631-677. [CrossRef]

27. Bukau, B.; Weissman, J.; Horwich, A. Molecular chaperones and protein quality control. Cell 2006, 125, 443-451. [CrossRef]

28. Florin, L.; Becker, K.A.; Sapp, C.; Lambert, C.; Sirma, H.; Muller, M.; Streeck, R.E.; Sapp, M. Nuclear translocation of papillomavirus minor capsid protein L2 requires Hsc70. J. Virol. 2004, 78, 5546-5553. [CrossRef] 
29. Rohde, M.; Daugaard, M.; Jensen, M.H.; Helin, K.; Nylandsted, J.; Jaattela, M. Members of the heat-shock protein 70 family promote cancer cell growth by distinct mechanisms. Genes Dev. 2005, 19, 570-582. [CrossRef]

30. Cheetham, M.E.; Brion, J.P.; Anderton, B.H. Human homologues of the bacterial heat-shock protein DnaJ are preferentially expressed in neurons. Biochem. J. 1992, 284, 469-476. [CrossRef]

31. Westhoff, B.; Chapple, J.P.; van der Spuy, J.; Hohfeld, J.; Cheetham, M.E. HSJ1 is a neuronal shuttling factor for the sorting of chaperone clients to the proteasome. Curr. Biol. 2005, 15, 1058-1064. [CrossRef] [PubMed]

32. Cheetham, M.E.; Jackson, A.P.; Anderton, B.H. Regulation of 70-kDa heat-shock-protein ATPase activity and substrate binding by human DnaJ-like proteins, HSJ1a and HSJ1b. Eur. J. Biochem. 1994, 226, 99-107. [CrossRef] [PubMed]

33. Gao, X.C.; Zhou, C.J.; Zhou, Z.R.; Wu, M.; Cao, C.Y.; Hu, H.Y. The C-terminal helices of heat shock protein 70 are essential for J-domain binding and ATPase activation. J. Biol. Chem. 2012, 287, 6044-6052. [CrossRef] [PubMed]

34. García-Rubiño, M.E.; Núñez-Carretero, M.C.; Choquesillo-Lazarte, D.; García-Ruiz, J.M.; Madrid, Y.; Campos, J.M. Stereospecific alkylation of substituted adenines by the Mitsunobu coupling reaction under microwave-assisted conditions. RSC Adv. 2014, 4, 22425-22433. [CrossRef]

35. Meth-Cohn, O.; Stanforth, S.P. The Vilsmeier-Haack reaction. In Comprehensive Organic Synthesis, 1st ed.; Trost, B.M., Fleming, I., Eds.; Pergamon: Oxford, UK, 1991; Volume 2, pp. 777-794.

36. Suchý, M.; Elmehriki, A.A.H.; Hudson, R.H.E. A remarkably simple protocol for the N-formylation of amino acid esters and primary amines. Org. Lett. 2011, 13, 3952-3955. [CrossRef]

37. Clark, P.G.K.; Lein, M.; Keyzers, R.A. Studies of the H-D exchange mechanism of malonganenone B. Org. Biomol. Chem. 2012, 10, 1725-1729. [CrossRef]

38. Huffman, C.W. Formylation of amines. J. Org. Chem. 1958, 23, 727-729. [CrossRef]

39. Reed, M.A.; Weaver, D.; Sun, S.; McLellan, A.; Lu, E. Terpenoid Analogues and uses Thereof for Treating Neurological Condtions. U.S. Patent US2013/0267571A1, 10 October 2013.

40. Matsumoto, S.; Doteuchi, M.; Mizui, T.; Hirai, K. Isoprenoidamine Derivatives, Compositions Containing Them, Their Preparation, and Their Use. EP0194901A2, 17 September 1986.

41. Coppola, G.M.; Prashad, M. A convenient preparation of farnesylamine. Synth. Commun. 1993, $23,535-541$. [CrossRef]

42. Johnstone, R.A.W.; Rose, M.E. A rapid, simple, and mild procedure for alkylation of phenols, alcohols, amides and acids. Tetrahedron 1979, 35, 2169-2173. [CrossRef]

43. Li, W.; Wu, X.-F. A Practical and general base-catalyzed carbonylation of amines for the synthesis of N-formamides. Chem. Eur. J. 2015, 21, 14943-14948. [CrossRef]

44. Moller, M.; Herzer, K.; Wenger, T.; Herr, I.; Wink, M. The alkaloid emetine as a promising agent for the induction and enhancement of drug-induced apoptosis in leukemia cells. Oncol. Rep. 2007, 18, 737-744. [CrossRef] [PubMed]

45. Babokhov, P.; Sanyaolu, A.O.; Oyibo, W.A.; Fagbenro-Beyioku, A.F.; Iriemenam, N.C. A current analysis of chemotherapy strategies for the treatment of human African trypanosomiasis. Pathog. Glob. Health 2013, 107, 242-252. [CrossRef] [PubMed]

46. Kennedy, P.G. Clinical features, diagnosis, and treatment of human African trypanosomiasis (sleeping sickness). Lancet Neurol. 2013, 12, 186-194. [CrossRef]

47. Nagle, A.S.; Khare, S.; Kumar, A.B.; Supek, F.; Buchynskyy, A.; Mathison, C.J.; Chennamaneni, N.K.; Pendem, N.; Buckner, F.S.; Gelb, M.H.; et al. Recent developments in drug discovery for leishmaniasis and human African trypanosomiasis. Chem. Rev. 2014, 114, 11305-11347. [CrossRef] [PubMed]

48. Barrett, M.P.; Vincent, I.M.; Burchmore, R.J.; Kazibwe, A.J.; Matovu, E. Drug resistance in human African trypanosomiasis. Future Microbiol. 2011, 6, 1037-1047. [CrossRef] [PubMed]

49. Rudiger, S.; Germeroth, L.; Schneider-Mergener, J.; Bukau, B. Substrate specificity of the DnaK chaperone determined by screening cellulose-bound peptide libraries. EMBO J. 1997, 16, 1501-1507. [CrossRef] [PubMed]

50. Wright, A.E.; Roth, G.P.; Hoffman, J.K.; Divlianska, D.B.; Pechter, D.; Sennett, S.H.; Guzmán, E.A.; Linley, P.; McCarthy, P.J.; Pitts, T.P.; et al. Isolation, synthesis, and biological activity of aphrocallistin, an adenine-substituted bromotyramine metabolite from the Hexactinellida sponge Aphrocallistes beatrix. J. Nat. Prod. 2009, 72, 1178-1183. [CrossRef] 
51. Roe, S.J.; Oldfield, M.F.; Geach, N.; Baxter, A. A convergent stereocontrolled synthesis of [3-14 C]solanesol. J. Label.Comd. Radiopharm. 2013, 56, 485-491. [CrossRef]

52. Grinco, M.; Kulciţki, V.; Ungur, N.; Jankowski, W.; Chojnacki, T.; Vlad, P.F. Superacid-catalyzed cyclization of methyl (6Z)-geranylfarnesoates. Helv. Chim. 2007, 90, 1223-1229. [CrossRef]

53. Bakkestuen, A.K.; Gundersen, L.-L.; Petersen, D.; Utenova, B.T.; Vik, A. Synthesis and antimycobacterial activity of agelasine E and analogs. Org. Biomol. Chem. 2005, 3, 1025-1033. [CrossRef]

54. Valles, E.; García, P.A.; Miguel del Corral, J.M.; Pérez, M.; Ferreira, I.C.F.R.; Calhelha, R.C.; San Feliciano, A.; Castro, M.Á. Synthesis and cytotoxic evaluation of new terpenylpurines. RSC Adv. 2016, 6, 105412-105420. [CrossRef]

55. Vik, A.; Hedner, E.; Charnock, C.; Tangen, L.W.; Samuelsen, Ø.; Larsson, R.; Bohlin, L.; Gundersen, L.-L. Antimicrobial and cytotoxic activity of agelasine and agelasimine analogs. Bioorg. Med. Chem. 2007, 15, 4016-4037. [CrossRef] [PubMed]

56. Sharma, M.L.; Singh, J. First total synthesis of a guanidine alkaloid nitensidine D using immobilized ionic liquid, microwaves and formamidinesulfinic acid. J. Chem. Sci. 2014, 126, 1869-1874. [CrossRef]

57. Sen, S.E.; Roach, S.L. A convenient two-step procedure for the synthesis of substituted allylic amines from allylic alcohols. Synthesis 1995, 1995, 756-758. [CrossRef]

58. Minutolo, F.; Bertini, S.; Betti, L.; Danesi, R.; Gervasi, G.; Giannaccini, G.; Papi, C.; Placanica, G.; Barontini, S.; Rapposelli, S.; et al. Stable analogues of geranylgeranyl diphosphate possessing improved geranylgeranyl versus farnesyl protein transferase inhibitory selectivity. Bioorg. Med. Chem. Lett. 2003, 13, 4405-4408. [CrossRef]

59. Baggaley, K.H.; Hindley, R.M.; Tee, J.L.; Brooks, S.G. Biologically Active Imidazoles. GB1365312A, 21 August 1974.

60. Wada, K. Inhibition of gibberellin biosynthesis by geraniol derivatives and 17-nor-16-azakauranes. Agric. Biol. Chem. 1978, 42, 787-791. [CrossRef]

61. Neochoritis, C.G.; Stotani, S.; Mishra, B.; Dömling, A. Efficient isocyanide-less isocyanide-based multicomponent reactions. Org. Lett. 2015, 17, 2002-2005. [CrossRef]

62. Li, Z.-Y.; Yu, Z.-G.; Guo, Y.-W. New N-containing sesquiterpenes from Hainan marine sponge Axinyssa sp. Helv. Chim. 2008, 91, 1553-1558. [CrossRef]

63. Simpson, J.S.; Brust, A.; Garson, M.J. Biosynthetic pathways to dichloroimines; precursor incorporation studies on terpene metabolites in the tropical marine sponge Stylotella aurantium. Org. Biomol. Chem. 2004, 2, 949-956. [CrossRef]

64. Bentley, S.J.; Boshoff, A. Trypanosoma brucei J-Protein 2 functionally co-operates with the cytosolic Hsp70 and Hsp70.4 proteins. Int. J. Mol. Sci. 2019, 20, 5843. [CrossRef]

65. Bowling, T.; Mercer, L.; Don, R.; Jacobs, R.; Nare, B. Application of a resazurin-based high-throughput screening assay for the identification and progression of new treatments for human African trypanosomiasis. Int. J. Parasitol. Drugs Drug Resist. 2012, 2, 262-270. [CrossRef] [PubMed]

(C) 2020 by the authors. Licensee MDPI, Basel, Switzerland. This article is an open access article distributed under the terms and conditions of the Creative Commons Attribution (CC BY) license (http://creativecommons.org/licenses/by/4.0/). 